\title{
COMO AS ECONOMIAS dE SÃO PAULO E DE MINAS GERAIS SE COMPARAM À DO RESTO DO BRASIL: UMA ANÁLISE DAS SUAS ESTRUTURAS PRODUTIVAS
}

\author{
CARLOS EDUARDO LOBO E SILVA \\ Economista
}

Orientador: Prof. Dr. JOAQUIM JOSÉ MARTINS GUILHOTO

\begin{abstract}
Dissertação apresentada à Escola Superior de Agricultura "Luiz de Queiroz", Universidade de São Paulo, para obtenção do título de Mestre em Ciências, Área de Concentração: Economia Aplicada.
\end{abstract}

P I R A C I C A B A

Estado de São Paulo - Brasil

Maio - 2001 


\section{Dados Internacionais de Catalogação na Publicação (CIP) DIVISÃO DE BIBLIOTECA E DOCUMENTAÇÃO - Campus "Luiz de Queiroz"/USP}

\section{Silva, Carlos Eduardo Lobo e}

Como as economias de Sảo Paulo e de Minas Gerais se comparam à do resto do Brasil: uma análise das suas estruturas produtivas / Carlos Eduardo Lobo e Silva. - - Piracicaba, 2001.

$108 \mathrm{p}$.

Dissertação (mestrado) - Escola Superior de Agricultura Luiz de Queiroz, 2001.

Bibliografia.

1. Economia aplicada 2. Economia regional 3. Insumo-produto 4. Minas Gerais 5. São Paulo I. Título

CDD 330.9 


\section{DEDICO}

Dedico este trabalho à minha família, de quem sempre recebi amor e apoio incondicionais, e a todos aqueles que fazem da alegria um instrumento para melhorar o mundo. 


\section{AGRADECIMENTO}

Iniciei meu curso de graduação na FEA-USP e recebi o título de bacharel em ciências econômicas pela FEARP-USP. Em seguida, ingressei no programa de mestrado em economia aplicada da ESALQ-USP. Portanto, toda minha curta história acadêmica foi vivida dentro da Universidade de São Paulo. Por isso, meu primeiro agradecimento vai ao Estado de São Paulo que mantém a maior e melhor universidade da América Latina. $\mathrm{O}$ orgulho que sinto pela USP só não é maior que a dívida que tenho com este Estado. Espero, um dia, poder retribuir com meu trabalho para que, no futuro, todos os filhos e netos daqueles que sustentaram meus estudos possam estudar em uma escola com a qualidade da Universidade de São Paulo.

Ainda no campo institucional, agradeço à Capes pelo auxílio financeiro.

Aprendi, durante os últimos anos, alguma coisa sobre matriz insumo-produto, mas aprendi muito mais com o exemplo de profissional entusiasmado, amigo e dedicado dado pelo meu orientador, Professor (na essência da palavra) Guilhoto. O apoio em todas as situações foi uma força determinante para que os desafios fossem superados e novos desafios estejam hoje à minha frente. A ele, agradeço muito e carrego comigo este período de tanto aprendizado.

Vários outros professores foram importantes para a realização deste trabalho e a eles vão meus agradecimentos.

Ao Prof Bento, com quem tive conversas ótimas e esclarecedoras no começo do trabalho e que colaborou muito na definição dos rumos da pesquisa, através de comentários objetivos tanto no seminário quanto na qualificação. Ao Prof. Shirota que também participou de todas as fases e ajudou a clarear alguns pontos importantes. A Profa Márcia Azanha, pela leitura cuidadosa do texto e que deixou o trabalho bem mais acabado e consistente do que estava até sua colaboração.

A outros professores que, se não acompanharam tão de perto o desenvolvimento da pesquisa, me fizeram gostar ainda mais de economia: Prof Adriano e Prof Geraldo. 
Finalmente, mas não menos importante, ao Prof Bacha que, além de ter me ensinado macroeconomia, me deu enorme apoio enquanto estive nos EUA.

Ao Prof Hewings que dirige o REAL e que me deu a rara oportunidade de conviver com ele e seus estudantes, em um ambiente extremamente fértil e agradável. Um pesquisador de inquestionável importância na academia mundial, que conduz seu grupo com leveza e liderança e que me fez, em tão pouco tempo, seu admirador.

A todos os funcionários da Esalq, especialmente à Maielli que se dedica com prazer ao seu trabalho e torna muito mais fácil a vida dos estudantes de pós-graduação.

Quanto aos colegas, a lista não é pequena. Para não me estender demasiadamente, me concentrarei nos companheiros de churrasco. Companheiros que não só dividiram a carne e a cerveja, mas também - e principalmente - formaram um grupo solidário para superar os desafios das listas de exercício, dos capítulos mais complicados das disciplinas, etc. Sempre com muita determinação, sem esquecer o divertimento. Ao Glauco, dono da churrascaria e grande especialista em café; ao Goncílio, companheiro de república, amigo antigo e parceiro de ótimas conversas; ao Magri, pai de todos, que nos ensinou a ser mais jovens; à Paula que pensa sobre os problemas da economia de uma maneira própria, eficiente e enriquecedora a quem divide com ela algumas questões relativas ao tema e a Valeriana, para quem meus agradecimentos extrapolam os churrascos e o ótimo convívio em Piracicaba. A ela, pela sua intensidade, típica de quem ama a vida, e pelo apoio imenso nos momentos decisivos desse trabalho. Levo comigo todos os momentos.

Um agradecimento especial vai ao Alexandre, gerente do Albergue do Conchas, que sempre me recebeu com a simpatia que lhe é peculiar.

Não poderia deixar de citar alguns amigos que, por motivos variados, fazem parte dessa lista: Dílson, Casemiro, Marcos, Fábio, Dani, Paulo, Cris e todos que ajudaram a fazer desses anos, um período de ótimo convívio.

Ao prof Rudinei da FEARP-USP, que foi um apoio decisivo em momentos profissionais difíceis.

Agora, quero abrir os agradecimentos "extra-universidade", dizendo um muito obrigado a minha mãe. Exemplo de alegria que contagia as pessoas que convivem com ela, um 
exemplo de luta e dedicação. Definição, para os filhos, de amor incondicional. Muito obrigado pelo apoio e entusiasmo, fontes permanentes e fundamentais de energia. Sou eternamente grato pela dedicação e formação que recebi.

Ao meu pai, responsável por criar em mim a curiosidade intelectual. Um exemplo profissional que norteia minha vida. Obrigado pela formação, pelos valores e pelo entusiasmo que sempre dividiu com os filhos.

Aos meus dois irmãos, artistas de quem sou fã. Ter dois irmãos com alma de artista é um presente da vida. A torcida recíproca me faz muito bem e mostra que a enorme admiração talvez seja a menor parte de tudo que nos une.

À Hanna e ao Du que alegram a nossa família e fazem parte dela.

À Xan, namorada de longos e ótimos anos, de espírito iluminado, decisiva na minha formação e com quem aprendi muito. Por tudo o que vivemos, um agradecimento fica muito aquém da nossa história.

Aos amigos de vida, Marcelo e Renato, parceiros nas primeiras aventuras e amigos para todos os momentos. Da quadra de esporte à mesa do bar, sempre foi um enorme prazer estarmos juntos.

Ao Flávio, primo irmão. Conversas intermináveis sobre tudo. Outra referência na minha vida.

E, finalmente, à Nádia que, em tão pouco tempo, tem me mostrado que a luta e a superação não enrigessem a alma.

Para a minha vida, o valor das pessoas acima é muito maior que o deste trabalho, mas vale a oportunidade de agradecer.

A todos e por tudo, muito obrigado. 


\section{SUMÁRIO}

LISTAS DE GRÁFICOS

LISTAS DE QUADROS ...................................................................... viii

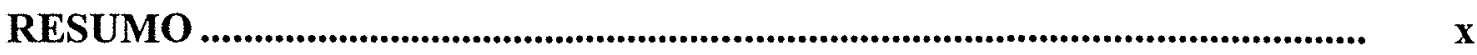

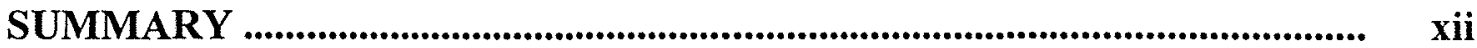

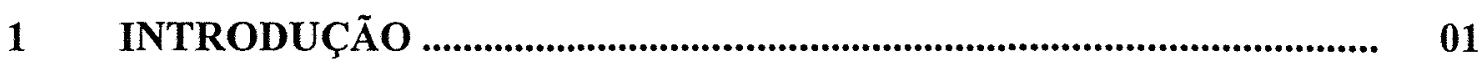

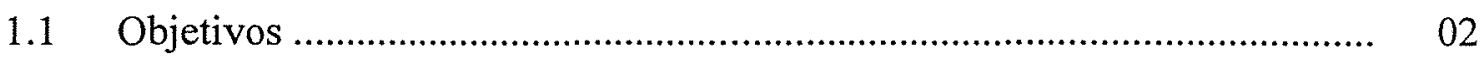

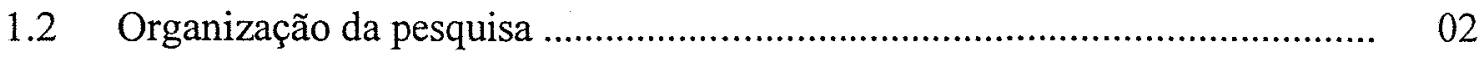

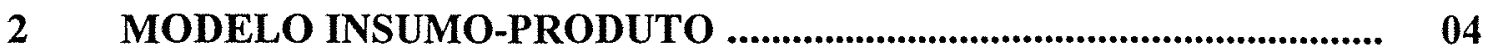

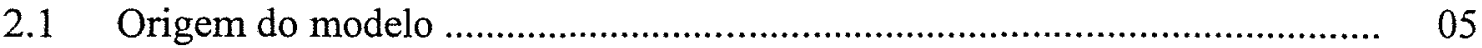

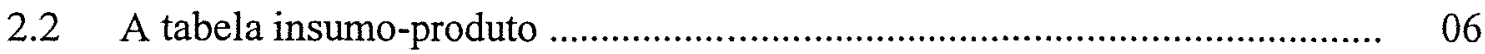

2.3 Representação algébrica e matricial do modelo ..................................... 10

2.4 Matriz insumo produto regional e inter-regional ................................... 14

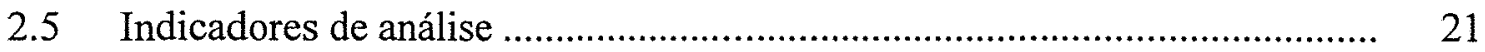

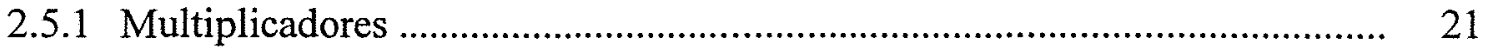

2.5.2 Índice de ligação Hirschmam-Rasmussem .......................................... 24

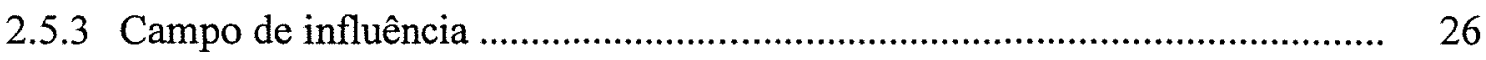

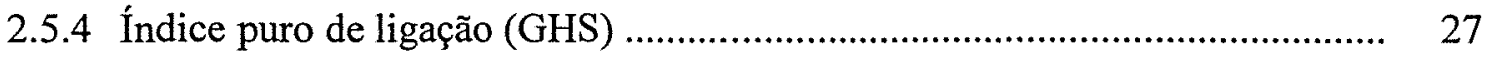

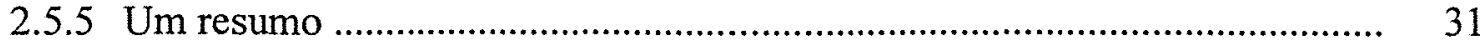


Página

2.6 Dados censitários e estimação ............................................................... 32

3 CONSTRUÇÃO DO MODELO ........................................................ 36

4 ANÁLISE DOS RESULTADOS ....................................................... 43

4.1 Índice de ligação Hirschmam-Rasmussem ................................................ 43

4.2 Índice puro de ligação .......................................................................... 49

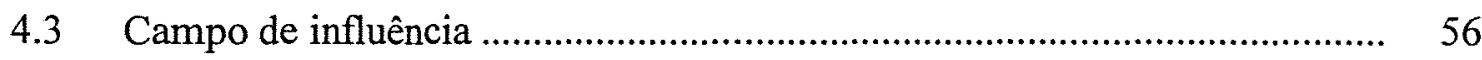

4.4 Multiplicadores ............................................................................. 60

5 APLICAÇÃO PARA A GUERRA FISCAL ....................................... 80

5.1 Considerações iniciais e aspectos legais ............................................. 80

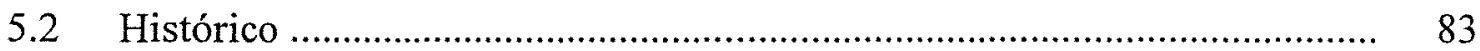

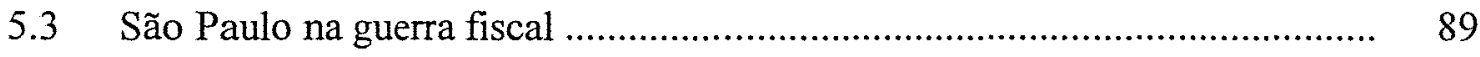

5.3.1 O conceito de estado hegemônico .......................................................... 89

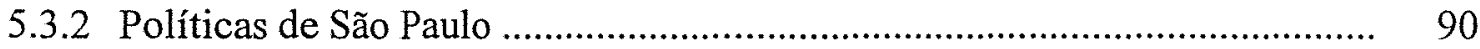

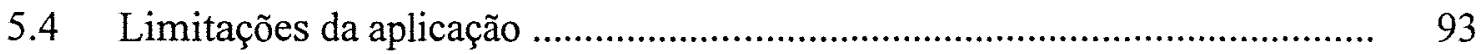

5.5 Resultados da aplicação e análise ......................................................... 95

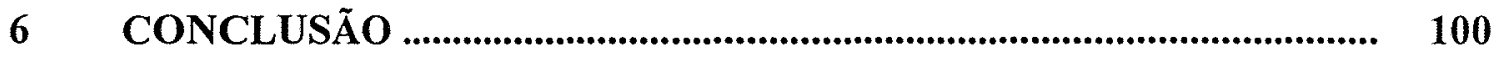

REFERÊNCIAS BIBLIOGRÁFICAS ....................................... 103 


\section{LISTA DE GRÁFICOS}

\section{Página}

1. Índice Puro de Ligação: importância das regiões para a economia brasileira 56

2. Campo de influência para Minas Gerais 57

3. Campo de influência para São Paulo 58

4. Campo de influência para o Resto do Brasil 59 


\section{LISTA DE QUADROS}

Página

1. Relação esquemática entre setores, componentes da demanda

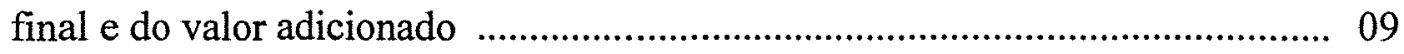

2. Índice de ligação de Hirschman-Rasmussen para as três regiões...................... 45

3. Índice de ligação Hirschman- Rasmussen em ordem decrescente para as três regiões, antecedidos do número dos setores

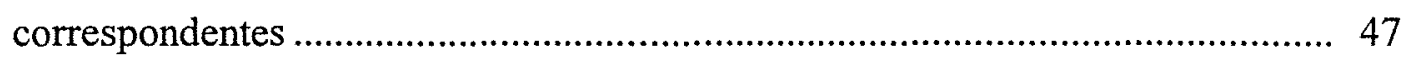

4. Coeficiente de correlação entre as posições dos setores no índice

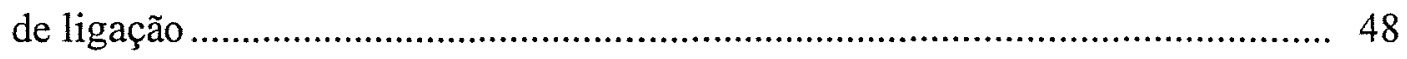

5. Índice puro total normalizado para Brasil integrado .................................. 50

6. Índices puros totais, normalizados e regionais por setor ........................... 52

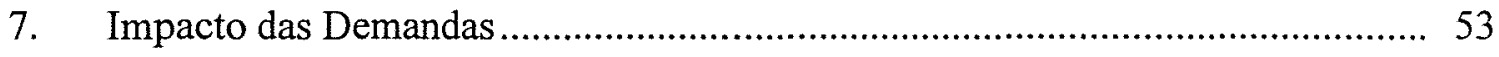

8. Influência das demandas regionais .................................................. 54

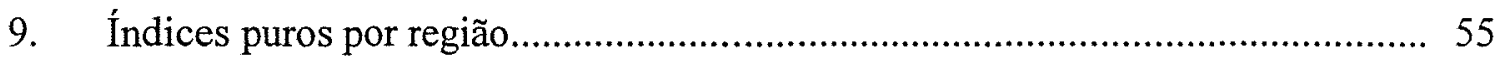

10. Setores de destaque para o campo de influência por região .......................... 60

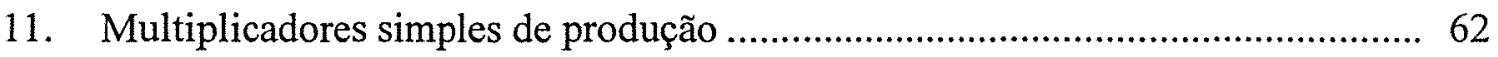

12. Distribuição do multiplicador simples entre as regiões .................................. 64

13. Multiplicador total de produção e renda para São Paulo em

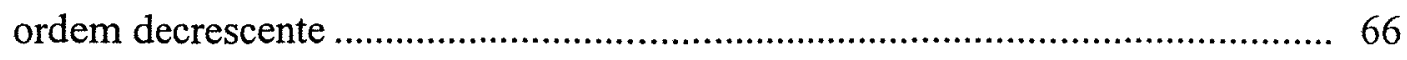


14. Multiplicador total de produção e renda para Minas em ordem decrescente.

15. Multiplicador total de produção e renda para o Resto do Brasil em ordem decrescente

16. Distribuição regional dos multiplicadores de produção para os setores de São Paulo

17. Distribuição regional dos multiplicadores de produção para os setores de Minas Gerais

18. Distribuição regional dos multiplicadores de produção para os setores do Resto do Brasil.

19. Multiplicador total de emprego para os setores de São Paulo. 74

20. Multiplicador total de empregos para os setores de Minas Gerais 75

21. Multiplicador total de empregos dos setores do Resto do Brasil 76

22. Multiplicador de renda para uma variação inicial de um real na renda dos setores 78

23. Perdas em reais por transferência de um real da demanda 96 


\title{
COMO AS ECONOMIAS DE SÃO PAULO E DE MINAS GERAIS SE COMPARAM À DO RESTO DO BRASIL: UMA ANÁLISE DAS SUAS ESTRUTURAS PRODUTIVAS
}

\author{
Autor: CARLOS EDUARDO LOBO E SILVA \\ Orientador: Prof. JOAQUIM JOSÉ MARTINS GUILHOTO
}

\section{RESUMO}

Este trabalho tem como objetivo principal comparar as estruturas econômicas e as relações inter-regionais de três regiões brasileiras: São Paulo, Minas Gerais e o Resto do Brasil.

Para tanto, um modelo inter-regional de insumo-produto foi construído para o ano de 1996 e, a partir dos indicadores desta metodologia, procura-se identificar os setores mais importantes das economias em questão, seus encadeamentos e a propagação de impactos entre as regiões. Além disso, o trabalho faz ainda uma aplicação do modelo para analisar alguns efeitos relativos à guerra fiscal entre os Estados da Federação ocorrida no Brasil durante a década de 90.

Pelos resultados obtidos, pode-se concluir que há uma similaridade entre as estruturas de Minas Gerais e resto do Brasil do ponto de vista setorial. A agropecuária e as indústrias ligadas a ela (exceção feita à Fabricação de açúcar), além do setor de 
siderurgia, têm destaque maior no caso de Minas e Resto do Brasil do que o verificado para a economia paulista.

São Paulo tem nos serviços - Comércio e Serviços prestados às famílias Construção civil e Automóveis, caminhões e ônibus os setores de maior relevância, quando se leva em conta, além das ligações setoriais, o volume de produção.

As ligações inter-setoriais também demonstram a importância para São Paulo de setores como Indústria têxtil e Celulose, papel e gráfica, que não estão entre os líderes nos casos de Minas e Resto do Brasil. Além deles, Fabricação de açúcar é o setor que apresenta maior índice de ligação na economia paulista.

Outro ponto que chama a atenção é a importância da economia do Estado de São Paulo em relação à brasileira, superando inclusive a influência do Resto do Brasil, segundo indicadores utilizados, apesar desta última região apresentar valores absolutos de produção maiores.

Finalmente, a aplicação do modelo contribui para a questão da guerra fiscal na medida em que estima os impactos inter-regionais para cada setor das três regiões. Os resultados são distintos, dependendo das regiões e dos setores analisados. 


\title{
HOW THE ECONOMIES OF SÃO PAULO AND MINAS GERAIS COMPARE TO THE REST OF BRAZIL: AN ANALYSIS OF THEIR PRODUCTIVE STRUCTURES
}

\author{
Author: CARLOS EDUARDO LOBO E SILVA \\ Adviser: Prof. JOAQUIM JOSÉ MARTINS GUILHOTO
}

\section{SUMMARY}

This work has as main objective to compare the economical structures and the inter-regional relationships of three Brazilian areas: São Paulo, Minas Gerais and the Rest of Brazil.

For so much, an inter-regional model of input-output is built for the year of 1996 and, starting from the indicators of this methodology, this work tries to identify the most important sections of the economies above mentioned, their linkages and the propagation of impacts among them. Besides, this study makes an application of the model to analyze some relative effects to the fiscal competition among the Brazilian States that took place during the 90 's.

According to the obtained results, it can be concluded that there is a similarity between the structures of Minas Gerais and the Rest of Brazil as far as the sectorial point of view is concerned. The Farming and the related industries to it (except for the Sugar Production), besides the steel metallurgy sector, are more important to the economy of Minas and the Rest of Brazil than to the State of São Paulo. 
For São Paulo the following sectors of services, Civil construction, Automobiles, trucks and buses production, are the most important when it is taken into account, besides the sectorial linkages, the total production. The inter-sectorial linkages also show the importance of sectors like textile Industry and Paper ,Graphic and Cellulose, that are not among the leaders in the cases of Minas and Rest of Brazil. Besides them, Sugar Production is the section that presents the biggest linkages index in the economy of São Paulo.

Another point that gets the attention is the importance of the economy from São Paulo in relation to the Brazilian's, overcoming the influence of the Rest of Brazil, according to the used indicators, in spite of the fact that the Rest of Brazil shows a larger total production.

Finally, the application of the model contributes to the issue of the fiscal competition because it estimates the inter-regional impacts for each sector of the three regions. The results are different, depending on the areas and of the analyzed sectors. The sectors of Minas and of the Rest of Brazil that most concentrate the impacts in the own area from an increase of its production are exactly the sectors of São Paulo, which least concentrate the impacts in the own area. 


\section{INTRODUÇÃO}

Quando se analisam os números da economia brasileira, não é difícil perceber que há um forte desequilíbrio entre as suas regiões. Quase um terço do total produzido no Brasil está concentrado no Estado de São Paulo. Em 1996, sua participação ultrapassava os $32 \%$, enquanto a população do estado correspondia a $21,7 \%$ da nacional (FIBGE,1998). Portanto, não só em termos absolutos, mas também relativos, São Paulo desempenha um papel de liderança dentro do cenário econômico brasileiro. Ampliando o foco de análise, constata-se que a região sudeste, ainda em 96, era responsável por aproximadamente $57 \%$ do PIB nacional (FIBGE, 1999).

Os valores apresentados acima não deixam dúvida quanto à concentração produtiva existente no Brasil. Mas não respondem a uma questão mais complexa que diz respeito à estrutura econômica das diversas regiões brasileiras. São essas economias regionais semelhantes do ponto de vista estrutural? Os setores que as compõem estão distribuídos homogeneamente entre elas? Qual a importância, para cada região, dos seus diversos setores? A inter-relação econômica entre elas é marcada por diferenças substanciais oriundas de estruturas díspares?

Todas essas perguntas não são de respostas imediatas. Há algumas alternativas metodológicas para se estudar estas questões e, no presente trabalho, optouse pelo modelo de insumo-produto desenvolvido por Leontief durante a segunda metade da década de 30 . 
Portanto, o desafio principal desta pesquisa é justamente identificar e comparar as estruturas econômicas de três regiões brasileiras: São Paulo, Minas Gerais e o Resto do Brasil.

A escolha de São Paulo baseia-se na importância evidente para a economia nacional. O interesse especial pelo Estado de Minas Gerais se justifica em razão dos números apresentados pelo estado: seu PIB é expressivo e gira em torno de $10 \%$ do total brasileiro e, apesar de fazer parte da região mais desenvolvida do país, apresenta uma renda per capita abaixo da média nacional (Ferreira, 1998).

A partir da construção do modelo e dos resultados por ele obtidos, será feita uma aplicação deste instrumental para analisar algumas questões relativas à guerra fiscal, fenômeno que marcou a economia brasileira durante a década de 90 e que colocou as unidades da Federação em campos opostos na disputa por novos investimentos. Procura-se aqui estimar os impactos causados por transferências regionais das unidades produtivas para todos os setores da economia brasileira.

\subsection{Objetivos}

- Comparar as estruturas econômicas das três regiões brasileiras, procurando identificar, para cada uma delas, os setores importantes e a estrutura de encadeamento existentes entre eles, além de analisar as relações inter-regionais.

- Aplicar o modelo desenvolvido para estimar os impactos, nas três regiões, decorrentes da transferência de unidades produtivas entre as regiões.

\subsection{Organização da pesquisa}

Este trabalho prossegue apresentando a metodologia no capítulo 2. Neste capítulo, será desenvolvido o modelo de insumo-produto do ponto de vista algébrico e matricial, dedicando especial importância às matrizes regionais e inter-regionais. 
No capítulo 3, os procedimentos adotados na construção do presente modelo são apresentados. Em seguida, o capítulo 4 traz os resultados obtidos pelo modelo interregional e suas análises.

A aplicação da guerra fiscal está contida no capítulo seguinte, onde os resultados são precedidos de um breve levantamento sobre o histórico da competição fiscal e alguns aspectos relativos ao tema, além das limitações intrínsecas aos objetivos propostos pela aplicação.

Finalmente, o capítulo 6 é reservado para a conclusão do trabalho. Além das considerações finais, neste capítulo, são feitas algumas sugestões para possiveis aperfeiçoamentos do modelo desenvolvido. 


\section{MODELO INSUMO-PRODUTO}

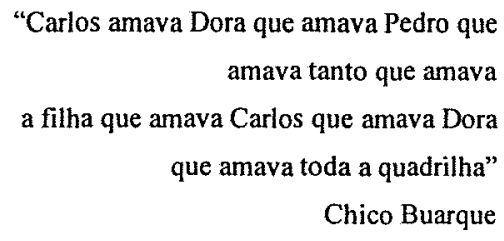

Quando um morador da cidade de São Paulo toma um café na Avenida Paulista, ele pode ter estimulado a indústria automobilística do $\mathrm{ABC}$ e a têxtil de Americana. O caminhão que transportou a mercadoria para a capital demandou tecido e muitos outros insumos no seu processo de produção. Todos estes insumos foram imprescindíveis para que o paulistano pudesse tomar seu café na Paulista. Para se chegar até o caminhão, pode-se perguntar onde o dono do bar comprou o produto. No caso do café, esta sucessão de fornecedores/clientes pode não ter fim e a cada insumo que é introduzido a este processo, uma nova sucessão de compra e venda de outros insumos se inicia. Qual o efeito do cafezinho da Avenida Paulista para a economia do Estado de São Paulo?

De um cafezinho talvez seja desprezível, mas o simples exemplo mostra a complexidade de uma economia desenvolvida como a do estado de São Paulo e a dificuldade de se visualizar os encadeamentos existentes entre todos os setores. Ampliando este exemplo e imaginando as consequêencias setoriais de um aumento substancial da demanda final por café (aumento das exportações, por exemplo), a análise certamente se perderá no caminho se não contar com um instrumental apropriado para analisar esta questão. 
Os modelos inter-regionais de insumo-produto possibilitam a separação entre as relações inter e intra regionais e, assim, identificam, setor a setor, a forma como cada um deles se relaciona com a própria e com as demais regiões.

Além disso, esta ferramenta é apropriada para estudos que procuram detectar os encadeamentos comerciais entre os setores e, a partir deles, simular cenários e estimar o resultado de algumas variáveis agregadas, como renda e emprego, para cada simulação.

Portanto, os objetivos deste estudo se encaixam às vocações do modelo: diagnóstico estrutural da economia, análise das repercussões em uma região devido à instalação de uma atividade em outra (ou na própria) e identificação dos setores regionais mais significativos e com maior poder de impacto dentro da economia regional estudada.

\subsection{Origem do Modelo}

$\mathrm{Na}$ segunda metade da década de 30, o professor Wassily Leontief economista russo radicado nos Estados Unidos em 1931 - ambicionou construir, dentro de uma visão holística, um modelo em que toda a economia fosse ali retratada. Se, à primeira vista, a intenção parece exageradamente audaciosa, para Leontief, a tentativa the valeu o Prêmio Nobel de Economia no ano de 1973.

O modelo desenvolvido por ele procura identificar as relações dos diversos setores da economia. Para tanto, Leontief criou um instrumental algébrico e matricial capaz de estimar as respostas dos setores em função de mudanças de determinadas variáveis. Este arcabouço teórico, portanto, permite que se faça simulações do comportamento da economia em decorrência das variações escolhidas.

Naturalmente, o modelo de insumo-produto criado por Leontief simplifica alguns aspectos econômicos - coeficientes fixos de insumos e função de produção linear - mas, por fazer uma análise da economia como um todo a partir da interação dos 
setores, se constitui numa ferramenta extremamente útil em questões relacionadas ao planejamento macroeconômico e/ou ao diagnóstico regional e setorial.

Importantes avanços teóricos e operacionais ocorreram durante os últimos sessenta anos. Os teóricos permitem que se trabalhe com mais fidelidade o comportamento dos agentes econômicos e os operacionais (hardware, software) admitem modelos matematicamente mais complexos, oferecendo respostas rápidas a simulações cada vez mais precisas.

\title{
2.2 A Tabela Insumo-Produto
}

Seguindo as idéias de François Quesnay (1758), que propunha um tratamento contábil às variáveis econômicas, através de um quadro no qual "a economia é descrita em termos de circulação, isto é, como um sistema integrado de fluxos e transferências de insumos e produtos de um setor a outro" (Montoya, 1998, p.40), Leontief elabora um matriz de insumo-produto para retratar as interações entre os diversos setores de uma economia, apoiando-se também em alguns conceitos desenvolvidos por Walras sobre o equilíbrio geral quase cem anos antes.

Crocomo (1998, p.19) recupera a definição do próprio Leontief (1986) para definir o que é uma análise de insumo-produto:

\begin{abstract}
"(...)é uma extensão prática da teoria clássica de interdependência geral, que vê a economia inteira de uma região, de um país ou inclusive do mundo como um só sistema e se propõe a interpretar todas as suas funções em termos das propriedades específicas mensuráveis de sua estrutura."
\end{abstract}

Para se chegar a uma matriz insumo-produto, deve-se, inicialmente, dividir a economia em n setores, segundo suas atividades. Esta tarefa muitas vezes não é trivial, em razão de algumas indústrias produzirem mais de um bem. Miller e Blair (1985, 
p.159) discutem essa questão e sugerem que a indústria deve ser enquadrada no setor do seu principal produto.

No caso do IBGE, "as atividades são formadas agregando-se os estabelecimentos com estruturas relativamente homogêneas de consumo e produção. É levado em conta que as unidades produtivas podem produzir produtos típicos de outras atividades; os estabelecimentos são classificados pela produção principal, resultando assim uma produção secundária de produtos não representativos de sua atividade" (FIBGE, 1997).

Superada esta fase, deve-se construir uma tabela com $n+k$ linhas e $n+m$ colunas, utilizando-se para isso duas matrizes elaboradas pelos órgãos governamentais: a matriz de uso e a matriz de produção. As primeiras $n$ linhas e colunas representam os $n$ setores de atividade da economia. As últimas $k$ linhas correspondem ao que a bibliografia trata como valor adicionado, que vem a ser a remuneração dos fatores trabalho, terra e capital - além dos impostos e das importações. Quanto às últimas $m$ colunas, elas representam a demanda final para os produtos da economia estudada. Os itens que compõem a demanda final são: consumo das famílias, formação bruta de capital, variação de estoques, gasto do governo e exportações.

Os valores da tabela correspondem, na prática, aos fluxos monetários da economia. Se por um lado, o fluxo monetário homogeneiza a unidade de conta, por outro, traz o problema da variação dos preços relativos. Uma variação dos preços relativos alteraria os valores da tabela, que, como será visto a frente, deverão manter-se constantes durante a análise do modelo. Segundo Guilhoto (1995, p.6), "o que usualmente é feito, em termos analíticos, para resolver este problema, é assumir que os preços são constantes".

Portanto, se o elemento $a_{i, j}$ (i-ésima linha e j-ésima coluna) for igual a 100 , isto significa que, para dado intervalo de tempo, 100 unidades monetárias passaram do setor $j$ para o setor $i$. E será sempre assim: o valor monetário é transferido do setor da coluna para o setor da linha. As vendas de um setor são as compras de outro. Dessa 
forma, "suas linhas representam a distribuição da produção e suas colunas os insumos absorvidos pelos setores na produção" (Crocomo,1998 p.19). "Para cada indústria catalogada na tabela, ocorre a igualdade entre a receita obtida com as vendas e o gasto total" (Simões, 1998, p.87) com bens e serviços adquiridos de outras indústrias e pagamento de fatores.

Especial atenção deve ser dedicada aos setores "comércio" e "transporte". Os fluxos monetários entre as indústrias são contabilizados diretamente na linha do vendedor e na coluna do comprador, sem a intermediação comercial. Divide-se o montante do pagamento relativo à compra de um insumo em duas partes: uma que vai diretamente ao setor que o vendeu e outra que vai para o setor comércio e/ou transporte. $\mathrm{Ou}$ seja, o setor que vende, vende seu produto diretamente ao setor que compra. O setor de comércio recebe, do comprador, apenas as margens de comercialização. Tratamento análogo é dado ao setor de transporte.

A Tabela de Insumo-Produto, segundo Leontief (1960, p.4), “...mostra o fluxo real de mercadorias e serviços que saem de uma indústria para outras, das indústrias para as famílias e das famílias para as indústrias".

Criando uma coluna $n+m+1$ em que conste em cada elemento o somatório dos valores da respectiva linha e uma nova linha $n+k+1$ em que conste em cada elemento o somatório dos valores da respectiva coluna, chega-se à seguinte tabela: 


\begin{tabular}{|l|l|l|l|l|l|l|l|l|}
\hline & $\begin{array}{c}\text { Setor } \\
1\end{array}$ & $\begin{array}{c}\text { Setor } \\
2\end{array}$ & Consumo & Governo & $\begin{array}{c}\text { Invest. em } \\
\text { capit }\end{array}$ & $\begin{array}{l}\text { Var. de } \\
\text { estoque }\end{array}$ & Export. & Total \\
\hline Setor 1 & $Z_{11}$ & $Z_{12}$ & $C_{l}$ & $G_{I}$ & $I_{I}$ & $V_{I}$ & $E_{l}$ & $X_{I}$ \\
\hline Setor 2 & $Z_{2 l}$ & $Z_{22}$ & $C_{2}$ & $G_{2}$ & $I_{2}$ & $V_{2}$ & $E_{2}$ & $X_{2}$ \\
\hline Salário & $L_{l}$ & $L_{2}$ & & & & & & $L$ \\
\hline Remun. Do Capital & $N_{l}$ & $N_{2}$ & & & & & & $N$ \\
\hline Impostos (governo) & $T_{1}$ & $T_{2}$ & $T_{c}$ & $T_{g}$ & $T_{l}$ & $T_{y}$ & $T_{e}$ & $T$ \\
\hline Importação & $M_{l}$ & $M_{2}$ & $M_{c}$ & $M_{g}$ & $M_{i}$ & $M_{v}$ & & $M$ \\
\hline Total & $X_{1}$ & $X_{2}$ & $C$ & $G$ & $I$ & $V$ & $E$ & \\
\hline
\end{tabular}

Quadro 1. Relação esquemática entre setores, componentes da demanda final e do valor adicionado.

Sendo:

$Z_{i j}$ o fluxo monetário entre os setores i e j;

$C_{i}$ o total consumido do setor $\mathrm{i}$;

$G_{i}$ o gasto do governo junto ao setor i;

$I_{i}$ a demanda por investimento;

$V_{i}$ a variação de estoques do setor $\mathrm{i}$;

$E_{i}$ o total exportado do setor $\mathrm{i}$;

$X_{i}$ o total de produção do setor $\mathrm{i}$;

$L_{i}$ o salário pago pelo setor $\mathrm{i}$;

$N_{i}$ a remuneração do capital pago pelo setor i;

$T_{i}$ o total de tributos pagos por $\mathrm{i}$;

$M_{i}$ a importação de i. 
A tabela acima permite estabelecer a igualdade:

$$
X_{1}+X_{2}+C+G+I+V+E=X_{1}+X_{2}+L+N+T+M
$$

Eliminando $X_{1}$ e $X_{2}$ de ambos os lados:

$$
C+G+I+V+E=L+N+T+M
$$

Rearranjando:

$$
C+(G-T)+(I+V)+(E-M)=L+N
$$

Portanto, a Tabela de Insumo-Produto, além de trazer a relação entre os setores da economia, ainda preserva as identidades macroeconômicas.

\subsection{Representação Algébrica e Matricial do Modelo}

A Tabela Insumo-Produto mostra um retrato da economia e a interação entre os setores, mas não fornece grande poder de análise. Para isso, é necessário que essa tabela seja transformada em uma matriz para a construção do modelo de insumoproduto.

Segundo Ferreira Filho (1995), a estrutura matemática de um modelo de insumo-produto consiste em um conjunto de $\mathrm{n}$ equações lineares com $\mathrm{n}$ incógnitas e pode, portanto, ser resolvido através da inversão de matrizes, para todos os sistemas linearmente independentes.

Inicia-se a construção do modelo por um setor i qualquer da economia. Este setor vende seu produto para os demais setores e para a demanda final. Portanto, pode-se escrever:

$$
X_{i}=X_{i, 1}+X_{i, 2}+\ldots+X_{i, n}+Y_{i}
$$

Sendo: 
$X_{i}$ o valor total da produção do setor i;

$X_{i, j}$ o fluxo monetário correspondente às compras do setor $\mathrm{j}$ junto ao setor $\mathrm{i}$;

$Y_{i}$ a demanda final do setor $\mathrm{i}$.

Fazendo o mesmo procedimento para todos os setores da economia teremos:

$$
\begin{aligned}
& X_{1}=X_{1,1}+X_{1,2}+\ldots+X_{1, n}+Y_{1} \\
& X_{2}=X_{2,1}+X_{2,2}+\ldots+X_{2, n}+Y_{2} \\
& X_{3}=X_{3,1}+X_{3,2}+\ldots+X_{3, n}+Y_{3} \\
& \vdots \\
& \quad \vdots \quad \vdots \\
& X n=X n, 1+X n, 2+\ldots+X n, n+Y n
\end{aligned}
$$

Pode-se, agora, escolher o elemento $X_{1,2}$ e analisá-lo separadamente. $X_{1,2}$ corresponde ao fluxo monetário transferido do setor 2 ao setor 1 . Dividindo este valor pela produção total do setor 2 , chega-se ao valor de $\mathrm{a}_{1,2}$, como descrito abaixo:

$$
X_{1,2} / X_{2}=a_{1,2}
$$

Dessa forma, a fração $\mathrm{a}_{1,2}$ diz quanto é comprado de insumo do setor 1 para cada unidade monetária de produção do setor 2. Por exemplo, se o setor 2 compra 50 $\left(\mathrm{X}_{1,2}\right)$ unidades monetárias do setor 1 e tem uma produção total igual a $500\left(\mathrm{X}_{2}\right)$ unidades monetárias, então, de cada unidade monetária produzida, 0,1 será comprado de insumo do setor 1. A esta fração dá-se o nome de coeficiente técnico (Miller e Blair, 1985).

Como, para uma mesma tabela, os coeficientes não se alteram, independentemente da quantidade produzida, o modelo de insumo-produto assume retornos constantes de escala para todos os setores (Simões, 1998). 
Novamente, pode-se generalizar este cálculo para todo $X_{i, j}$, o que daria:

$$
\begin{aligned}
& X_{1}=a_{1,1} X_{1}+a_{1,2} X_{2}+\ldots+a_{1, n} X_{n}+Y_{1} \\
& X_{2}=a_{2,1} X_{1}+a_{2,2} X_{2}+\ldots+a_{2, n} X_{n}+Y_{2} \\
& \vdots \quad \vdots \quad \vdots \quad \vdots \\
& X_{n}=a_{n, 1} X_{1}+a_{n, 2} X_{2}+\ldots+a_{n, n} X_{n}+Y_{n}
\end{aligned}
$$

Isolando os $Y s$ :

$$
\begin{gathered}
\left(1-a_{1,1}\right) X_{1}-a_{1,2} X_{2}-\ldots-a_{1, n} X_{n}=Y_{1} \\
-a_{2,1} X_{1}+\left(1-a_{2,2}\right) X_{2}-\ldots-a_{2, n} X_{n}=Y_{2} \\
-a_{3,1} X_{1}-a_{3,2} X_{2}-\ldots-a_{3, n} X_{n}=Y_{3} \\
\vdots \quad \vdots \quad \vdots \\
-a_{n, 1} X_{1}-a_{n, 2} X_{2}-\ldots+\left(1-a_{n, n}\right) X_{n}=Y_{n}
\end{gathered}
$$

Sendo $A$ a matriz nxn dos coeficientes técnicos; $X$ o vetor dos $n X s$ e $Y$ o vetor $\operatorname{dos} \mathrm{n} Y s$, tem-se a seguinte relação matricial:

$$
(I-A) X=Y
$$

Calculando inversa de $(I-A)$, chega-se a:

$$
X=(I-A)^{-1} Y
$$

Esta equação permite estimar o efeito de uma variação da demanda final $(Y)$ sobre a produção de todos os setores da economia $(X)$.

Vale ressaltar que este instrumental também possibilita transformar itens da demanda final em variáveis endógenas, como por exemplo, o consumo, visto que, em 
geral, é o item mais significativo da demanda final (Miller e Blair, 1985). Para tanto, basta desagregar a coluna "consumo das famílias" da coluna "demanda final". Com a desagregação, pode-se considerar a rubrica "consumo das famílias" como mais um "setor" da economia e, desta forma, os coeficientes técnicos relativos ao consumo passam a integrar a matriz $\mathrm{A}$, assim como sua linha correspondente. Portanto, uma variação da demanda final (que não mais inclui o consumo), apresenta como solução não só as variações ocorridas nos setores de atividade da economia, como também a ocorrida no consumo total e a solução passa a ser o resultado da interação entre os setores que compunham previamente a matriz A e deles com o consumo, que passa a fazer parte da solução do sistema e também a influenciar o resultado final.

Quando endogeniza-se o consumo das famílias, assume-se que o aumento da produção de determinado produto, aumentará o montante pago na remuneração dos fatores e isso terá um efeito positivo sobre o consumo que, por sua vez, estimula um novo aumento de produção para os produtos demandados pelas famílias. Portanto, neste caso, o consumo não é autônomo e participa da interação dos setores que se influenciam mutuamente. Se o setor "governo" for endogenizado, será admitido que o gasto do governo não é autônomo e, um aumento da tributação implicará um aumento dos gastos do governo, mantendo-se a proporção original de seus gastos em cada setor.

Do ponto de vista da álgebra matricial, não é difícil perceber a correção do método, mas pode-se entender mais de perto o significado econômico da matriz inversa de Leonteif.

Pós-multiplicando a matriz $(I-A)$ por $\left(I+A+A^{2}+A^{3}+A^{4}+A^{5}+A^{6}+\right.$ $\left.\ldots+A^{n}\right)$, chega-se a:

$$
\left(I-A^{n+1}\right)
$$

Como todos os coeficientes técnicos da matriz A estão entre 0 e 1 , fazendo $n$ tender ao infinito, os valores do último termo se aproximam de zero e, dessa forma, pode-se considerar como resultado da multiplicação apenas o termo $I$ (matriz 
identidade). Sendo assim, conclui-se que $\left(I+A+A^{2}+A^{3}+A^{4}+A^{5}+A^{6}+\ldots+A^{n}\right)$ se aproxima da matriz inversa de $(I-A)$ quando n assume valores altos.

Se houver um aumento da demanda por determinado setor $\left(X_{i}\right)$, o impacto inicial será o aumento da produção deste setor no valor exato do ocorrido na demanda. Esta variação está refletida no primeiro termo (I) do somatório $\left(I+A+A^{2}+A^{3}+A^{4}+\right.$ $\left.A^{5}+A^{6}+\ldots+A^{n}\right)$. Mas para aumentar a produção, o setor $X_{i}$ demanda insumos dos demais setores, segundo a proporção estabelecida pela coluna n. Pré-multiplicando o vetor da variação da demanda pela matriz $(I+A)$, chega-se ao seguinte resultado: $X_{i}$ terá um aumento de produção correspondente à variação da demanda mais o valor necessário de insumo demandado pelo próprio setor em função do aumento da demanda final. Todos os demais setores que fornecem insumo ao setor $\mathrm{n}$ também terão suas produções alteradas. $\mathrm{O}$ acréscimo será correspondente à variação da demanda vezes o coeficiente técnico $a_{s, n}$. Portanto o termo $A$ representa a necessidade de insumo do setor originalmente demandado e mede os efeitos da "primeira rodada". Mas a produção desses insumos demandará, por sua vez, outros insumos e o valor desta demanda será calculada através do termo $A^{2}$. Este encadeamento não tem fim e cada "rodada" é contemplada pela inclusão de mais um termo no somatório. Como os valores de A estão entre 0 e 1 , os termos do somatório se aproximam rapidamente do zero.

\subsection{Matriz Insumo-Produto Regional e Inter-regional ${ }^{1}$}

Há uma tendência de quanto menor for a região representada em uma matriz, maior será sua dependência em relação às demais. Se esta peculiaridade já é bastante intuitiva e de fácil entendimento teórico, não é difícil comprova-la na prática, basta que se analise os dados. Mas aqui se chega à segunda diferença entre um modelo regional e um nacional e, nesse caso, essa diferença trará repercussões importantes na metodologia da construção da matriz: a obtenção dos dados.

${ }^{1}$ O desenvolvimento algébrico e matricial deste item está baseado integralmente em Miller e Blair (1985). 
Para se construir uma matriz regional a partir da matriz nacional, deve-se perguntar, inicialmente, qual a parcela dos insumos utilizados para a produção de determinado produto que vem da própria região e quanto da produção regional atende às demandas intermediária e final internas. Deve-se, assim, estimar a origem dos insumos e o destino e o valor da produção regional.

Outra questão que se coloca é quanto à tecnologia de produção nacional ser ou não idêntica à tecnologia da produção regional para os setores correspondentes. Como a matriz é construída a partir de algumas agregações, muitas vezes, em um mesmo setor, atividades semelhantes são agrupadas, mesmo que demandem insumos diversos. Com vocações regionais diferentes, o setor regional pode apresentar coeficientes técnicos significativamente diferentes dos coeficientes para a indústria nacional. Se houver, por exemplo, o setor "agropecuária", a região produtora de leite terá uma estrutura tecnológica muito diferente da média nacional, que leva em conta todas as atividades do setor.

Apesar dessas especificidades, uma matriz regional apresenta a mesma estrutura de uma matriz nacional. A única diferença em sua apresentação é que, em geral, descrimina-se o que é exportação (importação) para as outras regiões do país e o que é exportação (importação) para outros países.

Segundo Miller e Blair (1985), os primeiros estudos que trabalharam com modelos regionais de insumo-produto utilizaram um percentual de oferta regional estimado para a obtenção dos dados da região $\left(p_{j}^{r}\right)$. Este estimador consiste na seguinte relação:

$$
p_{j}^{r}=\left(X_{j}^{r}-E_{j}^{r}\right) /\left(X_{j}^{r}-E_{j}^{r}+M_{j}^{r}\right) \text { onde, }
$$

$X_{j}^{r}=$ produção total de $j$ da região $r$;

$E_{j}^{r}=$ total exportado de $j$ da região $r$;

$M_{j}^{r}=$ total importado de $j$ pela região $r$. 
Portanto, este valor, que estará sempre entre zero e um $\left(p_{j}^{r}\right)$, determina quanto da demanda total (final + intermediária) do produto $\mathrm{j}$ é atendida pela produção interna.

Fazendo $\hat{P}$ o vetor $P$ diagonalizado, podemos construir um modelo de insumo-produto regional.

$$
\begin{aligned}
& A^{r}=\hat{P} A \\
& X^{r}=(I-\hat{P} A)^{-1} Y^{r}
\end{aligned}
$$

Como o valor $p_{i j}$, que dá origem a matriz $\hat{P}$, indica o percentual da demanda total do produto $j$ atendido pela produção interna, quando se faz $A^{r}=\hat{P} A$, todos os setores da região $r$ que demandarem $j$ obedecerão à proporção estabelecida pela percentagem de oferta. Ou seja, todos os setores que demandam, por exemplo, alumínio, compram $\left(p_{i j} * 100\right) \%$ da própria região e o restante importam das demais. Miller e Blair (1985) salientam que esta modificação uniforme dos elementos em uma linha da matriz A é uma hipótese extremamente forte.

Além desta hipótese, outra também importante é assumida quando se trabalha com o percentual de oferta regional $(P)$. A técnica de produção regional é considera idêntica à técnica nacional, pois a matriz $\mathrm{A}$ é mantida com os valores originais.

No caso do percentual de oferta regional, tanto as especificidades técnicas de cada região como a discriminação por cada setor da parcela dos insumos comprada de outra região não são consideradas. Através de uma tabela de insumo-produto censitária, pode-se resolver as duas questões.

Inicialmente, determina-se o coeficiente de insumo regional que vem a ser:

$$
a_{i j}^{L L}=z_{i j}^{L L} / X_{j}^{L}
$$


Sendo:

$z_{i j}^{L L}$ o valor monetário da venda do bem do setor $i$ localizado na região $L$ para o setor $j$, também situado na região $L \mathrm{e}$

$X_{j}^{L}$ o total da produção do setor $i$ da região $L$.

A partir da matriz $A^{L L}$, composta pelos elementos $a_{i j}{ }^{L L}$, pode-se calcular os impactos de uma variação da demanda final da região $L$, fazendo procedimento análogo e já desenvolvido anteriormente:

$$
X^{L}=\left(I-A^{L L}\right)^{-I} Y^{L}
$$

Deve-se notar que a relação acima guarda grandes semelhanças com o método do percentual de oferta regional já exposto: $X^{r}=(I-\hat{P} A)^{-I} Y^{r}$.

Mas, apesar de necessitar de dados mais precisos, por ser o coeficiente de insumo regional específico para cada relação de compra e venda de cada um dos setores, ele permite que seja feita não só distinção entre as técnicas regional e nacional de produção, como também a determinação da parcela de insumos importadas de cada um deles. Portanto, constitui-se em um método mais preciso e, por outro lado, demanda um volume maior de dados.

Similarmente, pode-se calcular o coeficiente de comércio:

$$
a_{i j}^{M L}=z_{i j}^{M L} / X_{j}^{L}
$$

Sendo:

$z_{i j}^{M L}$ o valor monetário da venda do bem do setor $i$ localizado na região $M$ para o setor $j$ situado na região $L \mathrm{e}$

$X_{j}^{L}$ o total da produção do setor $i$ da região $L$.

Fazendo: 


$$
a_{i j}^{L}=a_{i j}^{M L}+a_{i j}^{L L}
$$

define-se o coeficiente técnico regional.

Seguindo a estrutura dos demais modelos, pode-se fazer:

$$
X=\left(I-\hat{P} A^{L}\right)^{-1} Y^{L}
$$

Quando se usa o coeficiente técnico regional não há uma distinção quanto à origem do insumo. Portanto, uma variável como $\hat{P}$ se faz necessária e o termo $\hat{P} A^{L}$ passa a ser um estimador de $A^{L L}$.

Segundo Moretto (2000, p.42), "o objetivo (...) é quantificar os impactos que uma variação na demanda final por bens produzidos na região de interesse teria sobre os setores nela localizados".

Antes de se prosseguir no desenvolvimento dos tratamentos dos modelos regionais, deve-se atentar para um efeito não captado pelos modelos descritos acima.

A variação da demanda regional estimula a produção em $L . O$ aumento da produção dos setores de $L$ pode provocar um aumento da demanda por insumo da região $M$. A produção de insumo em $M$, por sua vez, pode demandar outros insumos da região $L$, o que propicia um novo aumento na produção em $L$. Nos modelos vistos até aqui, este último efeito (feedback inter-regional) não é captado, pois uma variação da demanda de $M$ por insumos oriundos de $L$ não tem repercussão, em função das relações interregionais não fazerem parte do modelo.

Resolve-se esta questão, através da utilização de modelos inter-regionais. Estes modelos trabalham com os coeficientes de insumos regionais e levam em conta não apenas $\mathrm{a}_{\mathrm{ij}}^{\mathrm{LL}}$, mas inclui em sua matriz os elementos: $a_{i j}{ }^{M L}, a_{i j}{ }^{L M} e a_{i j}^{M M}$ (no caso de duas regiões). 


$$
\begin{aligned}
& A=\left[\begin{array}{ll}
\mathrm{A}^{\mathrm{LL}} & \mathrm{A}^{\mathrm{LM}} \\
\mathrm{A}^{\mathrm{ML}} & \mathrm{A}^{\mathrm{MM}}
\end{array}\right] \\
& Y=\left[\begin{array}{l}
\mathrm{Y}^{\mathrm{L}} \\
\mathrm{Y}^{\mathrm{M}}
\end{array}\right] \\
& I=\left[\begin{array}{ll}
I & 0 \\
0 & I
\end{array}\right]
\end{aligned}
$$

E fazer:

$$
(I-A) X=Y
$$

O que resulta em:

$$
\begin{aligned}
& \left(I-A^{L L}\right) X^{L}-A^{L M} X^{M}=Y^{L} \\
& -A^{M L} X^{L}+\left(I-A^{M M}\right) X^{M}=Y^{M}
\end{aligned}
$$

Miller e Blair (1985) assumem uma variação da demanda da região $L\left(Y^{L}\right)$, enquanto $Y^{M}$ permanece constante, para identificar o feedback inter-regional. Os autores passam a trabalhar em termos de variação da produção total e da demanda. Portanto, fazem $Y^{M}=0$.

Dessa forma, isolam $X^{M}$ na equação (41) e substituem em (40):

$$
\begin{aligned}
& X^{M}=\left(I-A^{M M}\right)^{-1} A^{M L} X^{L} \\
& \left(I-A^{L L}\right) X^{L}-A^{L M}\left(I-A^{M M}\right)^{-1} A^{M L} X^{L}=Y^{L}
\end{aligned}
$$

No modelo para uma única região, tinha-se:

$$
\left(I-A^{L L}\right) X^{L}=Y^{L}
$$


Portanto, o termo $\left\{A^{L M}\left(I-A^{M M}\right)^{-1} A^{M L} X^{L}\right\}$ corresponde ao feedback captado no modelo inter-regional. O aumento na produção da região $L\left(X^{L}\right)$ provoca um aumento na produção de insumos em $M\left(A^{M L} X^{L}\right)$. Este efeito corresponde a um aumento da demanda externa pelos produtos de $M$. Assim, as relações internas da região geram um aumento calculado por $\left\{\left(I-A^{M M}\right)^{-1} A^{M L} X^{L}\right\}$. Este termo representa o aumento da produção em $M$ causado pelo aumento da produção em $L$. Esta variação, por sua vez, demandará insumos de $L$ e, assim, finalmente, quando se pré-multiplica a variação ocorrida em $M$ por $A^{L M}$, tem-se a variação em $L$ para fornecer insumos necessários ao aumento em $M$.

\subsection{Indicadores de Análise}

\subsubsection{Multiplicadores}

Como já foi dito, o modelo insumo-produto permite que se estime o impacto total na produção da economia estudada, dada uma variação na demanda final de um produto desta economia. E esta é justamente a idéia do multiplicador: estimar o poder de multiplicação que o acréscimo de uma unidade na demanda final exerce sobre a produção total da economia em questão. O multiplicador permite, dessa forma, uma comparação entre os diversos setores e os respectivos potenciais de multiplicação que cada um apresenta.

O efeito direto de um acréscimo de um real na demanda pelo bem i é o aumento em um real na produção do bem. Mas a matriz inversa de Leontief $(I-A)^{-1}$ leva em conta todas as interações comerciais entre os setores - efeitos direto e indireto constituindo-se, por essa razão, no principal instrumento para a obtenção dos multiplicadores.

Utilizando-se a relação matricial do modelo insumo-produto, não é difícil

perceber que o somatório dos valores da coluna $\mathrm{j}$ da matriz $(I-A)^{-1}$ determina o aumento total da produção da economia, causada pela variação da demanda do setor $j$, como está demonstrada abaixo: 


$$
\begin{aligned}
& X=(I-A)^{-1} Y \\
& \Delta X=(I-A)^{-1} \Delta Y \\
& \Delta X=\left[\begin{array}{ll}
\alpha_{11} & \alpha_{12} \\
\alpha_{21} & \alpha_{22}
\end{array}\right]\left[\begin{array}{l}
1 \\
0
\end{array}\right]=\left[\begin{array}{l}
\alpha_{11} \\
\alpha_{21}
\end{array}\right]
\end{aligned}
$$

Portanto, fazendo $\left(\alpha_{11}+\alpha_{21}\right)$, chega-se ao aumento da produção total devido à variação de uma unidade da demanda pelo bem 1 .

Este multiplicador contabiliza o efeito direto e o indireto, mas como as famílias não fazem parte da matriz inversa de Leontief, o efeito de um aumento da renda das famílias em função do aumento da produção total não repercute em um novo aumento de produção e por isso é chamado de multiplicador simples. Se o modelo endogenizar o setor "famílias", passará a levar em conta este efeito, denominado efeito induzido. A forma de cálculo do multiplicador total segue o mesmo método, sendo que, para uma economia com dois setores, deve-se fazer :

$$
O_{1}=\left(\alpha_{11}+\alpha_{21}+\alpha_{31}\right)
$$

É importante notar que $\alpha_{3 l}$ não corresponde ao aumento da produção e sim ao aumento dos pagamentos de fatores efetuados pelo setor 1. Este último termo pode, então, ser retirado do cálculo para que o resultado apresente apenas a mudança da produção. Mesmo assim, o multiplicador resultante é sempre maior que o multiplicador simples, pois é composto pelo efeito direto e indireto e mais o efeito induzido.

Se o modelo permite uma análise sobre multiplicador de produção, possibilita também a determinação do multiplicador de renda. A idéia é a mesma nos dois casos. Quando se obtêm os valores $\alpha_{11}$ e $\alpha_{2 l}$, basta multiplicá-los pelos coeficientes técnicos $a_{31}$ e $a_{32}$ e somar os produtos como segue:

$$
H_{1}=\alpha_{11} a_{31}+\alpha_{21} a_{32}
$$


O termo $\left(\alpha_{11} a_{31}\right)$ corresponde ao aumento da produção do setor 1 vezes a renda necessária em forma de pagamentos de fatores para a produção de uma unidade monetária do setor 1 . Analogamente, o termo $\left(\alpha_{21} a_{32}\right)$ faz a mesma conta para o setor 2 .

Novamente, pode-se considerar o multiplicador simples ou o total, dependendo do tratamento que se dá às famílias.

Outra possibilidade de cálculo é a determinação do número de empregos que uma alteração pode provocar. Para essa estimativa, é necessário determinar quantos empregos são gerados por cada unidade monetária a mais de produção de um setor, ou seja:

$$
w_{n+1, j}=e_{j} / X_{j}
$$

onde $X_{j}$ é o total da produção do setor $j$ e $e_{j}$ é o total de empregos do mesmo setor.

$$
E_{j}=\sum_{i=1}^{n}\left(w_{n+1, i}, \alpha_{i j}\right)
$$

Logo:

será o número de empregos criados em todos os setores por certo período de tempo em função do aumento de um real na demanda final do produto do setor $j$.

Os multiplicadores regionais seguem a metodologia utilizada para o cálculo dos multiplicadores vistos até aqui. Apenas, deve-se fazer adaptações que incorporem as especificidades dos modelos regionais já mencionados no item 5.4.

Se o método é o mesmo, a interpretação merece alguns cuidados. Vale lembrar que, como no caso do aumento de produção, o multiplicador do modelo de apenas uma região não consegue captar o feedback e a simplificação da fórmula que 
homogeneiza a participação de determinado insumo importado para todos os setores que fazem uso dele tornam os resultados menos precisos.

No modelo inter-regional, a matriz dos coeficientes técnicos será:

$$
A=\left[\begin{array}{ll}
\mathrm{A}^{\mathrm{LL}} & \mathrm{A}^{\mathrm{LM}} \\
\mathrm{A}^{\mathrm{ML}} & \mathrm{A}^{\mathrm{MM}}
\end{array}\right]
$$

E a inversa de Leontief:

$$
(I-A)^{-1}=\left[\begin{array}{ll}
\alpha^{\mathrm{LL}} & \alpha^{\mathrm{LM}} \\
\alpha^{\mathrm{ML}} & \alpha^{\mathrm{MM}}
\end{array}\right]
$$

Sendo $\alpha_{\mathrm{ij}}$ o elemento da i-ésima linha e j-ésima coluna da matriz inversa, pode-se somar os valores de uma coluna, levando-se em conta apenas a matriz $\alpha^{L L}$, para determinar o efeito intra-regional do multiplicador. De maneira análoga, somando os elementos de uma coluna da matriz $\alpha^{M L}$, chega-se ao efeito inter-regional. Finalmente, para determinar o efeito multiplicador total para as duas regióes devido ao aumento da demanda do setor $j$ da região $L$, faz-se a soma dos valores da coluna $j$ encontrados na determinação do efeito intra e inter-regional. Para uma variação na demanda final da região $M$, o procedimento não difere do exposto acima.

\subsection{2 Índices de Ligação Hirschman - Rasmussen}

Os multiplicadores fornecem aos analistas o potencial de cada setor de impactar o valor da produção, a renda ou o emprego da economia. Já os índices de ligação se preocupam com os encadeamentos existentes entre as atividades produtoras, procurando identificar os setores com maior encadeamento tanto para frente - na venda de seus produtos - como para trás - na compra de insumos para a produção. Portanto, focalizam a estrutura de produção da economia.

Os índices de Hirschman - Rasmussen partem da matriz inversa de Leontief $B$ e definem $B^{*}$ como sendo a média de todos os elementos de $B$. Em seguida, somam-se 
os elementos das colunas, $B_{j}$, e das linhas, $B_{i}$. Finalmente, obtêm os índices de ligação para frente e para trás, respectivamente:

$$
\begin{aligned}
& U_{i}=\left[B_{i} / n\right] / B^{*} \\
& U_{j}=\left[B_{j} / n\right] / B^{*}
\end{aligned}
$$

sendo $n$ o número de setores da economia.

Dessa forma, o fato do setor apresentar índice acima de 1 é sinal que seu nível de encadeamento é superior à média da economia, pois $\left[B_{j} / n\right]$ corresponde à média dos valores da coluna e, estando ele acima da média de toda a matriz $B$, ou seja, $B^{*}$, seu valor será maior que 1 . O mesmo vale para o índice de ligação para frente.

Conceitualmente, o índice de ligação para trás guarda forte relação com o multiplicador. $B_{j}$ (somatório da coluna $j$ da matriz inversa de Leontief) nada mais é que o multiplicador do setor $j$. Para se chegar ao índice de ligação para trás, deve-se, inicialmente, dividir $B_{j}$ pelo número de setores $(n)$, o que fornece um "multiplicador médio por interação do setor $j$ ". Esta média, então, é comparada com a média de todos os elementos da inversa de Leontief.

O resultado indica se o "multiplicador médio por interação do setor $j$ " é maior, igual ou menor que o "multiplicador médio por interação" de toda a economia. Já o resultado do índice de ligação para frente refere-se ao grau de encadeamento que há entre um determinado setor e seus demandantes de insumo.

Rodrigues (2000) aponta duas limitações relativas aos índices de ligação de Hirschman - Rasmussen. Segundo o autor, o tamanho dessas ligações não informa sobre a proporção dos impulsos transmitidos e ainda a presença de uma ligação não informa a direção do possivel impulso.

Um exame teórico e mais detalhado entre os diferentes aspectos do índice para frente e para trás de Hirschman - Rasmussen é feito por Cella (1984). 


\subsubsection{Campo de Influência}

Os índices de ligação de Hirschman - Rasmussen medem o grau de encadeamento que cada setor tem com o resto da economia. Seguindo esta linha, Sonis e Hewings (1989 e 1995) criaram o conceito de campo de influência que procura identificar "quais seriam os coeficientes que, se alterados, teriam um maior impacto no sistema como um todo" (Guilhoto, Sonis, Hewings e Martins, 1994, p.296)

Toma-se um valor arbitrariamente pequeno $k$ e uma matriz $E$ de zeros $n x n$, cujos elementos são representados por $e_{i j}$. Soma-se $k$ ao elemento da linha $i$ e coluna $j$ e tem-se a matriz $E_{i j}$, que tem todos os valores iguais a zero com exceção de $e_{i j}$.

A partir de $E_{i j}$, obtêm-se $K_{i j}$. Fazendo:

$$
K_{i j}=A+E_{i j}
$$

Chega-se a:

$$
\begin{aligned}
& B=(I-A)^{-I} \\
& B_{i j}=\left(I-K_{i j}\right)^{-1}
\end{aligned}
$$

$B$ é a matriz inversa de Leontief original. $B_{i j}$ é a matriz inversa, sendo que um dos coeficientes da matriz original foi modificado pelo valor de $k$.

Encontra-se então a matriz $n x n$ do campo de influência do coeficiente $k_{i j}$ :

$$
F_{i j}=\left[B_{i j}-B\right] / k_{i j}
$$

Até aqui, haverá $n x n$ matrizes, cada uma correspondendo a um coeficiente $i j$.

Para se chegar a um valor único que represente o campo de influência de cada coeficiente, faz-se o somatório do quadrado de todos os elementos da matriz $F_{i j}$ : 


$$
S_{i j}=\sum_{p=1}^{n} \sum_{q=1}^{n}\left[f_{i j p q}\right]^{2}
$$

Quanto maior $S_{i j}$, maior será o campo de influência do coeficiente em questão.

Há um aprimoramento importante em relação ao índice de ligação de Rasmussen - Hirschman. Rasmussen e Hirschman levam em conta apenas as relações diretas de cada setor. No caso de campo de influência, a análise concentra-se no efeito de uma mudança tecnológica de determinado setor e os impactos que essa mudança traria à estrutura econômica e aos multiplicadores. Se o setor $A$ compra pouco em relação a sua produção do setor $B$, mas o setor $B$ tem um forte encadeamento com os demais setores, uma mudança no coeficiente que determina a parcela que $A$ compra de $B$ pode ter um grande impacto na economia.

\subsection{4 Índice Puro de Ligação (GHS)}

Nos três métodos descritos acima - multiplicador, índices de ligação e campo de influência - não se leva em conta o valor da produção, apenas a estrutura da economia e seu poder de encadeamento. Os valores têm origem nos coeficientes técnicos que são medidas relativas ao total produzido.

Com o objetivo de incorporar o valor absoluto da produção dos setores à

análise da importância de determinado setor para a economia, Guilhoto, Sonis e Hewings (1996) propõem um aperfeiçoamento da metodologia apresentada por Cella (1984). Essa técnica procura "identificar os graus dos impactos de demanda final em determinadas regiões e sobre todas as outras"(Crocomo,1998, p.75e76), através do cálculo de índices puros de ligação.

Operacionalmente, o cálculo do índice procura isolar o setor (ou região) j do resto da economia, de maneira que se possa mensurar os efeitos das inter-relações. Para tanto, decompõe-se a matriz dos coeficientes técnicos em: 


$$
A=\left(\begin{array}{l}
A_{j J} A_{j r} \\
A_{r j} A_{r r}
\end{array}\right)=\left(\begin{array}{l}
A_{j j} A_{j r} \\
A_{r j} 0
\end{array}\right)+\left(\begin{array}{cc}
0 & 0 \\
0 & A_{r r}
\end{array}\right)=A_{j}+A_{r}
$$

Onde $A_{r}$ representa o resto da economia isolado.

Para se obter a inversa de Leontief:

$$
B=(I-A)^{-1}=\left(\begin{array}{cc}
B_{i j} & B_{j r} \\
B_{r j} & B_{r r}
\end{array}\right)=\left(\begin{array}{cc}
\Delta_{i j} & 0 \\
0 & \Delta_{r r}
\end{array}\right)\left(\begin{array}{cc}
\Delta_{j} & 0 \\
0 & \Delta_{r}
\end{array}\right)\left(\begin{array}{cc}
I & A_{j r} \Delta_{r} \\
A_{r j} \Delta_{j} & I
\end{array}\right)
$$

Onde os elementos da equação acima são definidos como:

$$
\begin{aligned}
& \Delta_{j}=\left(I-A_{j j}\right)^{-I} \\
& \Delta_{r}=\left(I-A_{r r}\right)^{-I} \\
& \Delta_{j j}=\left(I-\Delta_{j} A_{j r} \Delta_{r} A_{r j}\right)^{-I} \\
& \Delta_{r r}=\left(I-\Delta_{r} A_{r j} \Delta_{j} A_{j r}\right)^{-I}
\end{aligned}
$$

$\Delta_{j}$ representa os efeitos para a economia de $j$, dado um aumento da demanda final de $j$.

$\Delta_{r}$ representa os efeitos para o resto da economia, dado um aumento na demanda final do resto da economia.

Nos dois casos $\left(\Delta_{r}\right.$ e $\left.\Delta_{j}\right)$, leva-se em conta apenas os efeitos dentro do resto da economia ou do setor $j$, separadamente. Não há efeito feedback e não é levada em conta nenhuma relação entre o setor $j$ e o resto da economia.

$\Delta_{j j}$ corresponde ao efeito final na produção do setor $j$ causado pela demanda do setor $j$ por insumos do resto da economia. 
$\Delta_{r r}$ corresponde ao efeito final na produção do resto da economia causado pela demanda do resto da economia por insumos do setor $j$.

As duas últimas variáveis definidas captam as conseqüências da interação entre o setor $j$ e o resto da economia. Quando $r$ demanda insumo de $j\left(A_{j r}\right), j$ tem sua produção aumentada em $\Delta_{j}$, o que, por sua vez, demanda insumos de $r\left(A_{r j}\right)$ e, esta demanda resultará em um aumento de produção para a região $r\left(\Delta_{r}\right)$. A inversa de $\left(I-\Delta_{r}\right.$ $A_{r j} \Delta_{j} A_{j r}$ ) fornece os efeitos diretos e indiretos dessas relações.

Recuperando a expressão $X=(I-A)^{-1} Y$ e aplicando à decomposição feita acima:

$$
\left[\begin{array}{l}
X_{j} \\
X_{r}
\end{array}\right]=\left[\begin{array}{cc}
\Delta_{i j} & 0 \\
0 & \Delta_{r r}
\end{array}\right] *\left[\begin{array}{cc}
\Delta_{j} & 0 \\
0 & \Delta_{r}
\end{array}\right] *\left[\begin{array}{cc}
I & A_{j r} \Delta_{r} \\
A_{r j} \Delta_{j} & I
\end{array}\right] *\left[\begin{array}{c}
F_{j} \\
F_{r}
\end{array}\right]
$$

Multiplicando os últimos termos do lado direito:

$$
\left[\begin{array}{c}
X_{j} \\
X_{r}
\end{array}\right]=\left[\begin{array}{cc}
\Delta_{i j} & 0 \\
0 & \Delta_{r r}
\end{array}\right] *\left[\begin{array}{l}
\Delta_{j} F_{j}+\Delta_{j} A_{j r} \Delta_{r} F_{r} \\
\Delta_{r} A_{r j} \Delta_{j} F_{j}+\Delta_{r} F_{r}
\end{array}\right]
$$

onde: $A_{j r} \Delta_{r} F_{r}$ é o impacto direto da demanda final do resto da economia sobre o setor $j$, isto é, determina o valor da importação vinda do setor $j$ necessário para a produção do resto da economia, dada a demanda $F_{r}$. Analogamente, $A_{r j} \Delta_{j} F_{j}$ é a importação do resto da economia para que $j$ possa atender sua demanda final. (Ghilhoto, Hewings e Sonis, 1997).

O índice puro de ligação para trás é dado por:

$$
P B L=\Delta_{r} A_{r j} \Delta_{j} F_{j}
$$


Esse índice representa o impacto puro da produção do setor $j$ na produção do setor $r$, não levando em consideração a demanda do setor $j$ por insumos do próprio setor e também do retorno da demanda do resto da economia por insumos de $j$. Portanto, em poucas palavras, o $P B L$ mede o impacto direto, em valor, da demanda de $j$ na produção do resto da economia.

O índice para frente segue a mesma idéia:

$$
P F L=\Delta_{j} A_{j r} \Delta_{r} F_{r}
$$

PFL é o impacto direto da demanda final do resto da economia sobre a produção do setor $j$.

Como esses índices são expressos em valores correntes, pode-se calcular o índice puro total das ligações $(P T L)$ :

$$
P T L=P B L+P F L
$$

A partir da equação 83 , pode-se chegar a seguinte decomposição:

$$
\begin{aligned}
& {\left[\begin{array}{c}
X_{j} \\
x_{r}
\end{array}\right]=\left[\begin{array}{l}
\Delta_{i j} \Delta_{j} F_{j}+\Delta_{i j} \Delta_{j} A_{j r} \Delta_{r} F_{r} \\
\Delta_{r r} \Delta_{r} A_{r j} \Delta_{j} F_{j}+\Delta_{r r} \Delta_{r} F_{r}
\end{array}\right]=\left[\begin{array}{c}
X_{j}^{j}+X_{j}^{r} \\
X_{j}^{r}+X_{r}^{r}
\end{array}\right]} \\
& X_{j}^{j}=\Delta_{i j} \Delta_{j} F_{j} \\
& X_{j}^{r}=\Delta_{i j} \Delta_{j} A_{j r} \Delta_{r} F_{r}
\end{aligned}
$$

Analogamente:

$$
\begin{aligned}
& X_{r}^{r}=\Delta_{r r} \Delta_{r} F_{r} \\
& X_{r}^{j}=\Delta_{r r} \Delta_{r} A_{r j} \Delta_{j} F_{j}
\end{aligned}
$$


Onde $X_{j}^{r}$ indica a produção da região $j$ decorrente da demanda final da região $r$.

Os resultados do índice puro de ligação apresentam valores expressivos, justamente por estarem expressos em unidades monetárias. Para se obter valores próximos a 1, basta que se normalize os valores em torno da média dos índices inicialmente obtidos, encontrando, dessa forma, o índice puro normalizado.

\subsubsection{Um Resumo}

Os diversos indicadores econômicos utilizados nos modelos insumo-produto têm, cada qual, um enfoque, um objetivo e, por isso, seus resultados nem sempre são coincidentes. Sobre este ponto, Guilhoto et al. (1995, p.23) comentam que a apresentação de visões alternativas sobre a estrutura e as trocas estruturais em uma economia contribuirão para uma análise mais equilibrada sobre o processo de transformação econômica, apesar da literatura procurar eleger a melhor técnica para se identificar os setores-chave.

O índice de ligação de Hirschman e Rasmussen preocupa-se com a relação entre cada setor com os demais setores da economia. Determina, quando se trabalha com o índice de ligação para trás, o grau de encadeamento do setor $j$ relativamente ao grau de encadeamento da economia como um todo. Este resultado sinalizará se tal produção está concentrada em insumos ou, ao contrário, faz-se principalmente através do aumento do valor adicionado da economia. Quando se analisa o índice de ligação para frente, percebe-se a importância deste setor como fornecedor de insumo.

Os multiplicadores incorporam os efeitos diretos e indiretos para medir os impactos na economia causados por um choque de demanda. Constitui-se num instrumento de estimação dos efeitos causados por uma mudança das variáveis. Não há dúvida, como já foi visto, que altos índices de ligação (para trás) indicam altos multiplicadores. Mas os valores têm significados diferentes. 
Se para os multiplicadores a pergunta é qual o impacto para economia de uma mudança na demanda, para o campo de influência será: quais os coeficientes técnicos (estrutura de produção) que, se alterados, mais transformam a matriz inversa e, portanto, mais modificam os encadeamentos sucessivos causados por uma variação da demanda.

A importância dos índices puros de ligação se justifica pelo fato de levar em conta o valor de produção dos setores. Pelas abordagem matemática já descrita, pode-se perceber que tanto as interações inter e intra setoriais são levadas em conta como também a relevância do setor do ponto de vista do volume absoluto. Os setores indicados por este método como os mais importantes dentro da economia são, em geral, aqueles que unem grande interação e expressiva produção. Medem-se os efeitos não mais de uma alteração dos demais coeficientes ou da repercussão causada por uma pequena e constante variação da demanda dos diversos setores, o índice puro determina a perda de produção absoluta caso o setor $j$ seja hipoteticamente retirado da economia em questão.

\subsection{Dados censitários e estimação}

Os dados podem ser primários, obtidos através de métodos censitários, ou secundários que demandam alguma técnica de estimação.

Quando há disponibilidade para se trabalhar com dados primários, Montoya (1998) destaca dois métodos alternativos denominados modelo de Isard e o modelo de Metzler.

O modelo de Isard é, segundo o autor, considerado ideal na literatura de insumo-produto. Isto porque o modelo assume que há uma função de produção do tipo Leontief específica para cada setor de cada região e, ainda, "os coeficientes técnicos dependerão não somente da tecnologia utilizada e da estrutura de preços relativos, mas, também, da organização atual dos fluxos regionais de abastecimento em cada setor"(Montoya, 1998, p.55 e 56). 
Como os setores são considerados específicos, as relações inter-regionais são detalhadas e, dessa forma, os fluxos inter-regionais podem mensurar os efeitos de transbordamento entre as regiões causados pela variação da demanda final de uma delas.

Naturalmente, esta técnica exige um enorme volume de dados, o que dificulta a operacionalização do modelo proposto.

O modelo de Metzler também procura avaliar os impactos dos efeitos de transbordamento inter-regional decorrentes de uma variação autônoma da demanda final em uma das regiões.

Mas, ainda segundo o autor, o modelo é limitado na análise dos problemas regionais pelo fato de não discriminar "os efeitos inter-regionais por setor produtivo de cada região onde ocorrem as despesas. Trata-se, portanto, de um modelo inter-regional do tipo agregado, pelo qual não é possível visualizar os efeitos econômicos nos setores produtivos de cada região"(Montoya, 1998, p.54 e 55).

Quanto às estimações realizadas com dados secundários, há duas perguntas a serem respondidas quando se procura ajustar coeficientes regionais.

As estruturas de produção dos setores regionais se assemelham com a estrutura de produção nacional? Ou seja, há diferenciação tecnológica entre a região e o país para dado setor? A segunda pergunta é que parcela dos insumos utilizados por dado setor regional vem da própria região?

No que diz à primeira questão, uma das alternativas seria determinar a estrutura de cada setor regional, identificando diferenças estruturais entre os mesmos setores de regiões diferentes ${ }^{2}$. Para solucionar a segunda, Miller e Blair (1985) propõem

\footnotetext{
${ }^{2}$ Este trabalho assume mesma tecnologia para as três regiões, como está exposto no item "Construção do modelo".
} 
alguns métodos para a estimação dos valores. Uma das técnicas descritas pelos autores refere-se ao quociente locacional. São apresentadas três abordagens distintas para esta técnica. Todos as três procuram avaliar a tendência importadora dos setores.

O quociente locacional simples é definido pela relação:

$$
L Q_{i}^{R}=\left[\frac{X_{i}^{R} / X^{R}}{X_{i}^{N} / X^{N}}\right]
$$

onde $X_{i}^{R}$ é a produção total do setor $i$ da região $R$;

$X^{R}$ é a produção total da região $R$;

$X_{i}^{N}$ é a produção nacional total do setor $i \mathrm{e}$

$X^{N}$ é a produção nacional total.

Esta relação mede a participação relativa do setor $i$ na economia da região $R$ em relação a participação do mesmo setor na economia nacional. Assim, procura estimar o potencial importador da região em relação aos produtos do setor $i$. Se $L Q_{i}$ for menor que 1 , significa que, em decorrência da região $R$ ter uma produção proporcionalmente menor de produtos do setor $i$, há uma tendência a se importar este produto. Dessa forma, faz-se:

$$
a_{i j}^{R R}=a_{i j}^{N}\left(L Q_{i}^{R}\right)
$$

Se $L Q_{i}$ for igual ou maior que 1 , os setores que demandam os produtos correspondentes ao setor $i$ não terão necessidade de importá-los, portanto:

$$
a_{i j}^{R R}=a_{i j}^{N}
$$

Seguindo o mesmo raciocínio, os autores apresentam o quociente locacional de demanda (purchases-only location quotients). Neste caso, a relação é: 


$$
P L Q_{i}^{R}=\left[\frac{X_{i}^{R} / X^{* R}}{X_{i}^{N} / X^{* N}}\right]
$$

onde $X^{* R}$ e $X^{* N}$ são, respectivamente, o total da produção regional e nacional dos setores que demandam produtos do setor $i$. A idéia neste método é desconsiderar o tamanho dos setores que não demandam os produtos do setor $i$. O tratamento dado aos coeficientes regionais segue o utilizado no quociente locacional simples.

A terceira variação do quociente locacional é o quociente interindustrial (cross-industry quotients):

$$
C I Q_{i j}^{R}=\left[\frac{X_{i}^{R} / X_{i}^{N}}{X_{j}^{R} / X_{j}^{N}}\right]
$$

Neste caso, estima-se um quociente para cada célula da matriz regional. Mede-se a participação do setor regional ofertante no total de produção nacional deste setor em comparação com a participação do setor regional demandante em relação ao mesmo setor em termos nacionais. Novamente, o tratamento dado aos coeficientes regionais segue a metodologia do quociente simples.

Todos os métodos do quociente locacional visam estimar que parcela dos insumos vem da própria região e que parcela é importada do resto do país. A composição de insumos não se modifica, o quociente locacional determina apenas a origem regional desses insumos. 


\section{CONSTRUÇÃO DO MODELO}

O modelo inter-regional de insumo-produto para o ano de 1996 desenvolvido neste trabalho foi criado a partir da estimação das matrizes de produção e uso para os estados de São Paulo e Minas Gerais. As matrizes relativas ao resto do Brasil foram elaboradas a partir da diferença entre as matrizes regionais estimadas e a do Brasil para o ano em questão (FIBGE, 1997a).

No caso da matriz de produção de Minas Gerais, o trabalho se resumiu na atualização e desagregação da matriz construída em Silveira (2000) para o Estado de Minas. Neste trabalho, a economia mineira é dividida em 31 setores e os valores são estimados para o ano de 1995.

A desagregação seguiu a tabela elaborada pela autora que relaciona os setores do IBGE com os 31 setores escolhidos. Na maior parte dos casos, seguiu-se um critério de proporcionalidade para a desagregação. Como exemplo ilustrativo do procedimento seguido, tem-se o caso dos setores do IBGE "Material Elétrico" e "Equipamentos Eletrônicos" que são contemplados no trabalho de Silveira (2000) em um único setor denominado "Material Elétrico/Eletrônico". Calculou-se, então, qual a proporção entre os totais desses dois setores na matriz do IBGE e esta proporção nacional foi assumida para o caso de Minas.

Para outros casos, dada a importância dos setores ou a característica da economia mineira, buscou-se dados adicionais em bibliografia complementar para executar esta tarefa. No trabalho citado, "Metalurgia" agrega "Siderurgia", "Metalurgia não ferrosos" e "Outros Metalúrgicos". Para se fazer a desagregação, utilizou-se 
informações do Governo do Estado de Minas Gerais (2001), no intuito de aproximar os resultados da realidade da economia mineira.

Método semelhante foi utilizado na distribuição dos totais de cada setor pelos produtos existentes na matriz do IBGE. Os setores de Minas relacionados diretamente com os setores do IBGE tiveram sua distribuição entre os produtos mantida como estimada na matriz de Minas. Nos demais casos, os totais foram distribuídos de maneira proporcional à matriz brasileira. A única exceção que não se encaixa em nenhum dos dois procedimentos citados é o setor "Agropecuária". Neste caso, os valores por produto foram estimados a partir de informações encontradas no Censo Agropecuário 1995-1996 (FIBGE, 1997).

Quanto à atualização, os totais foram ajustados seguindo a diferença percentual verificada entre as matrizes do Brasil para os anos de 1995 e 1996.

Para se estimar a matriz de produção do Estado de São Paulo, o método empregado se concentrou em três referências básicas: Censo Agropecuário 1995-1996 (FIBGE, 1997), Pesquisa da Atividade Econômica Paulista (PAEP) (SEADE, 1999) e Contas Regionais 1996 (FIBGE, 1999).

Como primeiro passo, foi feita uma compatibilização entre os setores da matriz do IBGE e os setores presentes nas divulgações citadas. Nesta tarefa, utilizou-se as definições encontradas na CNAE (Classificação Nacional de Atividades Econômicas) publicadas pelo IBGE.

Resumidamente, o Censo Agropecuário 1995-1996 (FIBGE, 1997) forneceu os dados necessários para a construção do setor "Agropecuária" e a Pesquisa de Atividade Econômica Paulista (PAEP) foi utilizada basicamente para a elaboração dos setores industrias, enquanto os setores de serviço tiveram seus dados retirados da publicação Contas Regionais 1996 (FIBGE, 1999). 
Vale a observação que a etapa de estimação dos totais de cada setor teve sempre como referência os valores da matriz do Brasil 1996 (FIBGE, 1997a). Buscouse, nessas publicações, sempre a proporção entre a produção paulista e a brasileira. A partir desta relação, estimou-se o total de São Paulo como proporção do total nacional. Esta preocupação visa eliminar distorções eventuais causadas por diferenças metodológicas existentes entre as publicações consultadas.

No caso dos setores industrias, antes de se trabalhar com os dados da PAEP, foi calculada a proporção entre os totais de "Indústrias de Transformação" do Estado São Paulo e do Brasil, contidos nas Contas Regionais. Tendo a proporção entre São Paulo e Brasil e o total da matriz Brasil, pôde-se ajustar o total PAEP para que este valor obedecesse a proporção verificada em Contas Regionais. Portanto, todas as estimativas da PAEP foram ajustadas por este único fator encontrado na relação da produção total da indústria de transformação de São Paulo e do Brasil.

Ainda no caso dos setores industriais, a distribuição dos totais de cada setor entre os oitenta produtos presentes na matriz IBGE foi realizada, na maior parte das vezes, através da compatibilização da descrição dos produtos com a classificação de subsetores da Paep. Para alguns setores, as informações da PAEP não descriminavam subsetores, seguindo, por isso, a proporção brasileira, mas esta aproximação não prejudica essencialmente os resultados, tendo em vista que muitos desses setores têm sua produção fortemente concentrada em um único produto na matriz Brasil.

O nível de detalhamento para a estimativa de cada setor variou tanto no caso dos industriais como no dos serviços. O cálculo foi feito caso a caso, aproveitando a maior quantidade possível de informação. Portanto, as linhas gerais estão traçadas acima, mas as contas específicas realizadas para a estimativa dos setores não contaram com uma receita única e padronizada.

No tocante à construção das matrizes de uso, este trabalho assume a hipótese de mesma tecnologia de produção para os mesmos setores de regiões diferentes, ou seja, para um mesmo setor, as composições de insumos e de componentes do valor agregado, 
assim como a proporção entre esses dois totais, mantiveram a mesma relação verificada na matriz de uso do Brasil para o ano de 1996.

Para justificar esta hipótese simplificadora, tendo como um dos objetivos do trabalho a análise estrutural das economias em questão, vale lembrar que o objetivo aqui é identificar como os setores se relacionam dentro da economia e não uma comparação entre as estruturas dos mesmos setores de regiões diferentes. Evidentemente, a definição dos insumos utilizados por cada setor interfere na relação que ele vai ter com os demais, mas três aspectos sugerem a adoção da hipótese de mesma tecnologia.

Em primeiro lugar, a dificuldade da obtenção de dados que não são produzidos pelos órgãos do governo. A segunda questão diz respeito à precisão da estimativa. Qualquer critério utilizado para se estimar os insumos de determinado setor ou produto vai assumir algum nível de agregação e simplificação, como é feito no caso da hipótese de mesma tecnologia. Finalmente, parte-se do pressuposto que os mesmos setores de diferentes regiões não tem uma estrutura de produção, principalmente em relação aos insumos, tão distinta uma da outra que prejudique decisivamente os resultados.

O total de cada setor encontrado para a construção da matriz de produção das três regiões foi utilizado na elaboração da matriz de uso das respectivas regiões. Este processo não discrimina a origem regional dos insumos, determina apenas quanto de cada insumo será usado no processo produtivo dos diversos setores das regiões. Portanto, o passo seguinte é justamente integrar as três regiões numa única matriz e, para tanto, utilizou-se o Quociente Locacional Simples (QLS) por produto, cuja metodologia já foi detalhada no item anterior.

Como o Quociente Locacional (QL) estima o potencial exportador ou importador de determinada economia, para o caso dos modelos com mais de duas regiões, surge um problema adicional na definição da origem dos insumos. Quando há mais de uma região exportadora, não se sabe, analisando apenas os resultados obtidos 
através do emprego do QL, de qual região vem os insumos comprados pela região importadora.

Há várias técnicas sugeridas na literatura para solucionar esta questão ${ }^{3}$. Montoya (1998) cita os modelos de coeficiente linha e os de coeficiente coluna. Os primeiros admitem que a proporção do produto vendida pelas diversas regiões é a mesma. Para os modelos de coeficiente coluna "cada região importa uma proporção fixa de suas necessidades de um dado produto, de uma região específica" e "cada setor segue o mesmo padrão da região como um todo" (Montoya, 1998, p.52).

No modelo aqui desenvolvido, compara-se, inicialmente, para cada produto, o valor de produção da região exportadora com o valor hipotético de produção que levaria a um QL igual a um. Esta diferença pode ser vista como um "excesso" de produção, um montante que supera o volume necessário para que a região seja autosuficiente em relação ao produto em questão. A seguir, calcula-se o total do "excesso" de produto das regiões exportadoras. Assim, os percentuais de participação de cada região neste total da economia determinará a proporção da origem dos insumos. Se a região A produz 70\% do "excedente" do produto p e a região B produz 30\%; as regiões importadoras comprarão, do total importado, $70 \%$ da primeira e $30 \%$ da segunda.

A técnica do QL pode subestimar os valores transacionados entre as regiões, como foi verificado em Domingues e Haddad (2000), onde os autores comparam o total do valor obtido através da utilização do QL e o total registrado na Balança Comercial Interestadual para 1997. A possibilidade de subestimação das transações inter-regionais deve ser levada em conta quando se analisam os resultados de estudos que utilizam o QL, como é o caso do presente trabalho.

Tendo determinado as trocas inter-setoriais, inter-regionais e o valor adicionado, estimar a demanda final para as três regiões passou a ser a última tarefa para o fechamento do modelo.

\footnotetext{
${ }^{3}$ Ver em Hulu e Hewings (1993) e Round (1983).
} 
Além dos cinco componentes da demanda final - consumo das famílias, formação bruta de capital, exportação, variação de estoque e despesa da administração pública - descriminados nas matrizes de uso construídas pelo IBGE, este modelo inclui também a Dummy financeira como o sexto componente da demanda final.

Segundo definição de Domingues e Haddad (2000, p.19 e 20), "a Dummy Financeira é uma atividade fictícia que aparece em todas as matrizes de consumo intermediário nacional e sua inclusão é justificada metodologicamente como forma de captar os custos de serviços financeiros de cada atividade, a fim de não superestimar o valor adicionado por atividade (...) assim, seu valor de produção é nulo".

A decisão de incluí-la na demanda final segue procedimento utilizado em outros trabalhos, como de Crocomo (1998) e Domingues e Haddad (2000).

Para o cálculo do consumo das famílias, inicialmente, levou-se em conta o PIB de cada região e, em seguida, aplicou-se o Quociente Locacional para determinar a origem dos bens consumidos.

As exportações foram estimadas a partir da distribuição proporcional das exportações segundo a produção de cada região para cada produto. Os valores encontrados foram ajustados com os números relativos à exportação estadual encontrados no Ministério do Desenvolvimento, Indústria e Comércio Exterior (2001) que foi realizado através de um fator de conversão para todos os produtos, de tal forma que a participação relativa de cada estado obedecesse à apresentada pelo Ministério. Quando se ajusta todos os produtos por um único fator, os totais por produto não batem mais com os totais da matriz Brasil. Esta diferença nunca foi maior que $4 \%$ do total exportado e um novo ajuste foi feito, distribuindo a diferença proporcionalmente entre as regiões. Como resultado final, chegou-se a valores intermediários para cada região entre o determinado por uma simples distribuição proporcional e os números do Ministério do Desenvolvimento, Indústria e Comércio Exterior. 
Os investimentos para o Estado de São Paulo seguiram a média histórica de participação no investimento nacional, conforme dados oficiais do Governo do Estado de São Paulo (2001). Para Minas, utilizou-se a participação do PIB estadual no PIB brasileiro.

Os valores relativos aos gastos da administração pública tiveram como fonte o Ministério do Planejamento, Orçamento e Gestão (2001). Dados adicionais necessários e não encontrados foram obtidos, novamente, segundo as participações estaduais no PIB nacional.

Finalmente, o item "Variação de Estoque" foi determinado setorialmente pela diferença entre, de um lado, a soma do total do consumo intermediário e dos cinco outros componentes da demanda final e, de outro, o total produzido. Portanto, este item desempenhou uma função de fechamento do modelo inter-regional. Os resultados mostram em alguns setores uma variação negativa muito expressiva em relação a produção regional total. Dessa forma, um aperfeiçoamento das estimativas dos componentes da demanda final seria uma boa sugestão para aprimorar o modelo construido neste trabalho.

Vale lembrar, de qualquer forma, que os valores estimados para a demanda final, com exceção do item "consumo das famílias", não fazem parte dos itens incluídos nos cálculos dos resultados do modelo. Para os resultados finais, foram usados, segundo metodologia de cada índice, apenas as trocas inter-setoriais e o consumo das famílias. 


\section{ANÁLISE DOS RESULTADOS}

Os indices escolhidos para retratar a estrutura econômica das regiões estudadas e identificar os setores de maior ou menor impacto na propagação intra e inter-regional da expansão de suas produções são: índice de ligação de HirschmanRasmussen, índice puro de ligação, campo de influência e multiplicadores de produção, renda e emprego. $\mathrm{O}$ conceito de todos esses indicadores foi tratado no capítulo 2.

\section{1 Índice de Ligação de Hirschamn-Rasmussen}

Quando se trabalha com modelos inter-regionais, os índices de ligação de Hirschman-Rasmussen podem ser obtidos através de dois procedimentos distintos, chegando-se ao índice independente e ao dependente.

No primeiro caso, as economias regionais são vistas de maneira isolada, sem se levar em consideração os efeitos inter-regionais. Já para o cálculo do índice dependente, os valores trazem com eles os efeitos das interações regionais.

Do ponto de vista algébrico, o índice independente se origina a partir do cálculo de uma matriz inversa de Leontief para cada região. O dependente, por sua vez, requer que se inverta a matriz (I-A) para todo o modelo e, após a inversão, chega-se, então, aos valores.

Apesar do tratamento diferenciado, os resultados são muito próximos e a diferença não se mostra significativa para o caso dos índices de ligação. Por esta razão, este trabalho se limita a apresentar o índice dependente. A inclusão do índice independente não modificaria a análise dos resultados, conforme os critérios adotados - 
setor-chave e posição dos setores no ranking dos índices de ligação - que estão expostos a seguir. Assim, procura-se, sem prejuízo da análise, uma apresentação objetiva, evitando a redundância nas interpretações.

$\mathrm{Na}$ Quadro 2 são apresentados os valores encontrados para o índice de ligação para todos os setores das três regiões do modelo. Partindo-se dos setores-chave da economia que recebem esta dominação por apresentarem índices de ligação maiores que 1 tanto para trás como para frente (McGilvray ${ }^{4}$ citado por Silveira, 2000), pode-se destacar, pela Quadro 2, três setores que se enquadram nesta definição nas três regiões do modelo. São eles: Metalúrgicos não ferrosos (6), Outros metalúrgicos (7) e Químicos diversos (18).

\footnotetext{
${ }^{4}$ McGilvray, J. Linkages, key sectors and development strategy. In: Leontief, W. (Ed.) Structure, system and economic policy. Cambridge: University Press, 1977. P.49-56.
} 


\begin{tabular}{|c|c|c|c|c|c|c|c|}
\hline \multirow[t]{2}{*}{ Hirschman- Rasmussen } & & \multicolumn{2}{|c|}{ SP } & \multicolumn{2}{|c|}{$\overline{M G}$} & \multicolumn{2}{|c|}{$\overline{\mathrm{RB}}$} \\
\hline & & $\mathrm{P} /$ trás & $\mathrm{P} /$ frente & $\mathrm{P} /$ trás & $\mathrm{P} /$ frente & $\mathrm{P} /$ trás & $\mathrm{P} /$ frente \\
\hline AGROPECUÁRIA & 1 & 0,84 & 2,19 & 0,89 & 3,79 & 0,90 & 3,26 \\
\hline EXTRAT. MINERAL & 2 & 1,02 & 0,61 & 1,05 & 0,89 & 1,06 & 0,87 \\
\hline PETRÓLEO E GÁS & 3 & 0,91 & 0,61 & 0,84 & 0,85 & 0,85 & 0,96 \\
\hline MINERAL Ñ METÁLICO & 4 & 1,07 & 1,05 & 1,09 & 0,97 & 1,09 & 0,98 \\
\hline SIDERURGIA & 5 & 0,97 & 1,05 & 1,39 & 1,99 & 1,33 & 1,51 \\
\hline METALURG. Ñ FERROSOS & 6 & 1,21 & 1,18 & 1,18 & 1,10 & 1,16 & 1,08 \\
\hline OUTROS METALÚRGICOS & 7 & 1,07 & 1,39 & 1,25 & 1,31 & 1,14 & 1,24 \\
\hline MÁQUINAS E EQUIP. & 8 & 0,97 & 1,36 & 0,95 & 1,18 & 0,90 & 0,89 \\
\hline MATERIAL ELÉTRICO & 9 & 1,23 & 0,85 & 1,10 & 0,64 & 1,06 & 0,62 \\
\hline EQUIP. ELETRÔNICOS & 10 & 0,94 & 0,67 & 0,82 & 0,59 & 0,84 & 0,63 \\
\hline AUTOM./CAM/ONIBUS & 11 & 1,19 & 0,65 & 1,12 & 0,61 & 0,99 & 0,59 \\
\hline PEÇAS E OUT. VEÍCULOS & 12 & 1,25 & 1,08 & 1,23 & 1,04 & 1,08 & 0,81 \\
\hline MADEIRA E MOBILIÁRIO & 13 & 0,99 & 0,73 & 1,04 & 0,72 & 1,10 & 0,78 \\
\hline CELULOSE, PAPEL E GRÁF. & 14 & 1,23 & 1,54 & 0,99 & 0,87 & 0,95 & 0,67 \\
\hline IND. DA BORRACHA & 15 & 1,13 & 1,05 & 0,89 & 0,64 & 1,10 & 0,87 \\
\hline ELEMENTOS QUIMICOS & 16 & 1,09 & 1,07 & 1,08 & 0,84 & 0,96 & 0,74 \\
\hline REFINO DO PETRÓLEO & 17 & 0,79 & 1,19 & 0,97 & 1,90 & 1,03 & 2,56 \\
\hline QUÍMICOS DIVERSOS & 18 & 1,03 & 1,35 & 1,02 & 1,14 & 1,06 & 1,27 \\
\hline FARMAC. E VETERINÁRIA & 19 & 0,95 & 0,65 & 0,94 & 0,59 & 0,95 & 0,59 \\
\hline ARTIGOS PLÁSTICOS & 20 & 1,02 & 1,00 & 0,91 & 0,64 & 0,97 & 0,77 \\
\hline IND. TÊXTIL & 21 & 1,15 & 1,44 & 0,99 & 1,03 & 1,18 & 1,43 \\
\hline ARTIGOS DO VESTUÁRIO & 22 & 1,23 & 0,62 & 0,93 & 0,57 & 1,15 & 0,59 \\
\hline FABRICAÇÃO CALÇADOS & 23 & 1,16 & 0,74 & 0,93 & 0,61 & 1,12 & 0,70 \\
\hline INDÚSTRIA DO CAFÉ & 24 & 0,99 & 0,64 & 1,35 & 0,75 & 1,14 & 0,78 \\
\hline BENEF. PROD. VEGETAIS & 25 & 0,92 & 0,66 & 1,20 & 0,74 & 1,21 & 0,76 \\
\hline ABATE DE ANIMAIS & 26 & 1,05 & 0,66 & 1,27 & 0,71 & 1,30 & 0,74 \\
\hline INDÚSTRIA DE LATICÍNIOS & 27 & 1,18 & 0,79 & 1,31 & 0,73 & 1,09 & 0,61 \\
\hline FABRICAÇÃO DE AÇÚCAR & 28 & 1,40 & 0,84 & 1,33 & 0,78 & 1,07 & 0,67 \\
\hline FAB. ÓLEOS VEGETAIS & 29 & 0,96 & 0,72 & 1,40 & 0,93 & 1,43 & 0,95 \\
\hline OUTROS PROD. ALIMENT. & 30 & 1,05 & 0,82 & 1,24 & 0,81 & 1,22 & 0,74 \\
\hline INDÚSTRIAS DIVERSAS & 31 & 1,03 & 0,71 & 0,95 & 0,67 & 0,99 & 0,73 \\
\hline 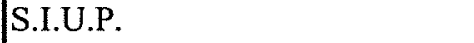 & 32 & 0,92 & 1,58 & 0,85 & 1,58 & 0,82 & 1,35 \\
\hline CONSTRUÇÃO CIVIL & 33 & 0,89 & 0,72 & 0,84 & 0,66 & 0,86 & 0,73 \\
\hline COMÉRCIO & 34 & 0,86 & 1,79 & 0,84 & 1,68 & 0,89 & 1,68 \\
\hline TRANSPORTES & 35 & 0,90 & 1,33 & 0,89 & 1,47 & 0,94 & 1,48 \\
\hline COMUNICAÇÕES & 36 & 0,75 & 0,87 & 0,68 & 0,82 & 0,70 & 0,85 \\
\hline $\begin{array}{l}\text { INSTITUIÇÕES } \\
\text { FINANCEIRAS }\end{array}$ & 37 & 0,83 & 1,18 & 0,74 & 0,87 & 0,78 & 1,04 \\
\hline SERV. PREST. À FAMÍLIA & 38 & 0,88 & 0,91 & 0,85 & 0,84 & 0,85 & 0,89 \\
\hline SERV. PREST. À EMPRESA & 39 & 0,83 & 1,49 & 0,72 & 1,29 & 0,73 & 1,33 \\
\hline ALUGUEL DE IMÓVEIS & 40 & 0,64 & 0,86 & 0,59 & 0,77 & 0,61 & 0,79 \\
\hline ADMINISTRAÇÃO PÚBLICA & 41 & 0,82 & 0,76 & 0,76 & 0,81 & 0,77 & 0,92 \\
\hline SERV. PRIV. Ñ MERCANTIS & 42 & 0,66 & 0,61 & 0,63 & 0,57 & 0,64 & 0,58 \\
\hline
\end{tabular}

Quadro 2. Indice de ligação de Hirschman-Rasmussen para as três regiões.

Fonte: resultados da pesquisa. 
Siderurgia (5), Indústria Têxtil (21) e Peças e outros veículos (12) são setores-chave em duas das três regiões, não podendo se caracterizar como tal para as três em função, respectivamente, de São Paulo, Minas Gerais e Resto do Brasil.

Ainda aparecem na tabela acima alguns setores com relevância regional nos critérios adotados pelo índice de ligação. Para o Estado de São Paulo, Minerais não metálicos (4), Celulose, papel e gráfica (14), Indústria da borracha (15), Elementos químicos (16) e Artigos plásticos (20) são considerados setores-chave. Refino do petróleo (17) é o destaque regional para o Resto do Brasil. Minas Gerais não possui nenhum setor de relevância exclusiva na região.

Vale chamar a atenção para o setor Agropecuária que, apesar de não ser setor-chave em nenhuma das três regiões, apresenta, por larga margem, o maior índice de ligação para frente em São Paulo, Minas Gerais e Resto do Brasil.

Quando o foco da interpretação dos índices de ligação se volta aos setoreschave, perde-se de vista a estrutura da economia como um todo, pois a preocupação deste conceito é identificar apenas os setores de maior destaque. Com o intuito de conseguir um panorama mais completo da estrutura econômica, no Quadro 3, os índices são apresentados na ordem decrescente, antecedidos de seus respectivos setores. 


\begin{tabular}{|c|c|c|c|c|c|c|c|c|c|c|c|}
\hline \multicolumn{2}{|l|}{ SP } & \multicolumn{2}{|c|}{$\mathrm{SP}$} & \multicolumn{2}{|c|}{$\overline{\mathrm{MG}}$} & \multicolumn{2}{|c|}{$\overline{M G}$} & \multicolumn{2}{|c|}{$\overline{R B}$} & \multicolumn{2}{|r|}{$\overline{\mathrm{RB}}$} \\
\hline Setor & $\mathrm{P} /$ trás & Setor & $\mathrm{P} /$ frente & Setor & $\mathrm{P} /$ trás & Setor & $\mathrm{P} /$ frente & Setor & $\mathrm{P} /$ trás & Setor & $P /$ frente \\
\hline 28 & $\overline{1,40}$ & 1 & 2,19 & 29 & 1,40 & I & 3,79 & 29 & 1,43 & 1 & 3,26 \\
\hline 12 & 1,25 & 34 & 1,79 & 5 & 1,39 & 5 & 1,99 & 5 & 1,33 & 17 & 2,56 \\
\hline 14 & 1,23 & 32 & 1,58 & 24 & 1,35 & 17 & 1,90 & 26 & 1,30 & 34 & 1,68 \\
\hline 9 & 1,23 & 14 & 1,54 & 28 & 1,33 & 34 & 1,68 & 30 & 1,22 & 5 & 1,51 \\
\hline 22 & 1,23 & 39 & 1,49 & 27 & 1,31 & 32 & 1,58 & 25 & 1,21 & 35 & 1,48 \\
\hline 6 & 1,21 & 21 & 1,44 & 26 & 1,27 & 35 & 1,47 & 21 & 1,18 & 21 & 1,43 \\
\hline 11 & 1,19 & 7 & 1,39 & 7 & 1,25 & 7 & 1,31 & 6 & 1,16 & 32 & 1,35 \\
\hline 27 & 1,18 & 8 & 1,36 & 30 & 1,24 & 39 & 1,29 & 22 & 1,15 & 39 & 1,33 \\
\hline 23 & 1,16 & 18 & 1,35 & 12 & 1,23 & 8 & 1,18 & 7 & 1,14 & 18 & 1,27 \\
\hline 21 & 1,15 & 35 & 1,33 & 25 & 1,20 & 18 & 1,14 & 24 & 1,14 & 7 & 1,24 \\
\hline 15 & 1,13 & 17 & 1,19 & 6 & 1,18 & 6 & 1,10 & 23 & 1,12 & 6 & 1,08 \\
\hline 16 & 1,09 & 6 & 1,18 & 11 & 1,12 & 12 & 1,04 & 13 & 1,10 & 37 & 1,04 \\
\hline 7 & 1,07 & 37 & 1,18 & 9 & 1,10 & 21 & 1,03 & 15 & 1,10 & 4 & 0,98 \\
\hline 4 & 1,07 & 12 & 1,08 & 4 & 1,09 & 4 & 0,97 & 4 & 1,09 & 3 & 0,96 \\
\hline 26 & 1,05 & 16 & 1,07 & 16 & 1,08 & 29 & 0,93 & 27 & 1,09 & 29 & 0,95 \\
\hline 30 & 1,05 & 4 & 1,05 & 2 & 1,05 & 2 & 0,89 & 12 & 1,08 & 41 & 0,92 \\
\hline 31 & 1,03 & 15 & 1,05 & 13 & 1,04 & 14 & 0,87 & 28 & 1,07 & 8 & 0,89 \\
\hline 18 & 1,03 & 5 & 1,05 & 18 & 1,02 & 37 & 0,87 & 2 & 1,06 & 38 & 0,89 \\
\hline 20 & 1,02 & 20 & 1,00 & 14 & 0,99 & 3 & 0,85 & 9 & 1,06 & 15 & 0,87 \\
\hline 2 & 1,02 & 38 & 0,91 & 21 & 0,99 & 16 & 0,84 & 18 & 1,06 & 2 & 0,87 \\
\hline 24 & 0,99 & 36 & 0,87 & 17 & 0,97 & 38 & 0,84 & 17 & 1,03 & 36 & 0,85 \\
\hline 13 & 0,99 & 40 & 0,86 & 31 & 0,95 & 36 & 0,82 & 11 & 0,99 & 12 & 0,81 \\
\hline 5 & 0,97 & 9 & 0,85 & 8 & 0,95 & 41 & 0,81 & 31 & 0,99 & 40 & 0,79 \\
\hline 8 & 0,97 & 28 & 0,84 & 19 & 0,94 & 30 & 0,81 & 20 & 0,97 & 13 & 0,78 \\
\hline 29 & 0,96 & 30 & 0,82 & 23 & 0,93 & 28 & 0,78 & 16 & 0,96 & 24 & 0,78 \\
\hline 19 & 0,95 & 27 & 0,79 & 22 & 0,93 & 40 & 0,77 & 14 & 0,95 & 20 & 0,77 \\
\hline 10 & 0,94 & 41 & 0,76 & 20 & 0,91 & 24 & 0,75 & 19 & 0,95 & 25 & 0,76 \\
\hline 32 & 0,92 & 23 & 0,74 & 35 & 0,89 & 25 & 0,74 & 35 & 0,94 & 26 & 0,74 \\
\hline 25 & 0,92 & 13 & 0,73 & 1 & 0,89 & 27 & 0,73 & 8 & 0,90 & 16 & 0,74 \\
\hline 3 & 0,91 & 33 & 0,72 & 15 & 0,89 & 13 & 0,72 & 1 & 0,90 & 30 & 0,74 \\
\hline 35 & 0,90 & 29 & 0,72 & 32 & 0,85 & 26 & 0,71 & 34 & 0,89 & 31 & 0,73 \\
\hline 33 & 0,89 & 31 & 0,71 & 38 & 0,85 & 31 & 0,67 & 33 & 0,86 & 33 & 0,73 \\
\hline 38 & 0,88 & 10 & 0,67 & 3 & 0,84 & 33 & 0,66 & 38 & 0,85 & 23 & 0,70 \\
\hline 34 & 0,86 & 26 & 0,66 & 34 & 0,84 & 20 & 0,64 & 3 & 0,85 & 14 & 0,67 \\
\hline 1 & 0,84 & 25 & 0,66 & 33 & 0,84 & 9 & 0,64 & 10 & 0,84 & 28 & 0,67 \\
\hline 37 & 0,83 & 11 & 0,65 & 10 & 0,82 & 15 & 0,64 & 32 & 0,82 & 10 & 0,63 \\
\hline 39 & 0,83 & 19 & 0,65 & 41 & 0,76 & 23 & 0,61 & 37 & 0,78 & 9 & 0,62 \\
\hline 41 & 0,82 & 24 & 0,64 & 37 & 0,74 & 11 & 0,61 & 41 & 0,77 & 27 & 0,61 \\
\hline 17 & 0,79 & 22 & 0,62 & 39 & 0,72 & 10 & 0,59 & 39 & 0,73 & 19 & 0,59 \\
\hline 36 & 0,75 & 2 & 0,61 & 36 & 0,68 & 19 & 0,59 & 36 & 0,70 & 22 & 0,59 \\
\hline 42 & 0,66 & 3 & 0,61 & 42 & 0,63 & 22 & 0,57 & 42 & 0,64 & 11 & 0,59 \\
\hline 40 & 0,64 & 42 & 0,61 & 40 & 0,59 & 42 & 0,57 & 40 & 0,61 & 42 & 0,58 \\
\hline
\end{tabular}

Quadro 3. Indice de ligação Hirschman- Rasmussen em ordem decrescente para as três regiões, antecedidos do número dos setores correspondentes.

Fonte: resultados da pesquisa. 
Não é difícil perceber, através da comparação regional, que Minas Gerais e o Resto do Brasil possuem estruturas de ligação semelhantes. Os quatro setores de maiores ligações para frente, em ambas, são: Agropecuária (1), Siderurgia (5), Refino de petróleo (17) e Comércio (34).

São Paulo mantém Agropecuária (1) e Comércio (34), mas a lista dos quatro primeiros no índice de ligação para frente é completada pelos setores Celulose, papel e gráfica (14) e S.I.U.P (32).

Nas ligações para trás, a mesma tendência é verificada: Minas Gerais e o Resto do Brasil têm Fabricação de óleos vegetais (29) e Siderurgia (5) como setores com os valores mais expressivos, enquanto em São Paulo, Fabricação de açúcar (28) e Peças e outros veículos (12) lideram o ranking.

Uma coincidência maior acontece para os setores com os menores índices de ligação para trás. Minas e Resto do Brasil têm os mesmos seis setores com os menores valores. No caso de São Paulo, a estrutura é quase a mesma, apenas Refino do petróleo (17) está entre os mais baixos índices, ao contrário do que é verificado para as demais regiões.

Ainda no intuito de tornar mais objetiva a comparação das estruturas econômicas, será calculado o coeficiente de correlação entre as posições dos setores no ranking dos índices de ligação e os resultados, apresentados no Quadro 4, confirmam a análise:

\begin{tabular}{l|ccc|}
\hline & SP-MG & SP-RB & MG-RB \\
\hline Trás & 0,665 & 0,642 & 0,848 \\
Frente & 0,753 & 0,675 & 0,885 \\
Quadro 4. & Coeficiente de & correlação \\
& entre as posições dos setores \\
& no índice de ligação.
\end{tabular}

Fonte: resultados da pesquisa. 
Portanto, este procedimento torna ainda mais claro o fato das estruturas de ligação de Minas e do Resto do Brasil estarem mais próximas uma da outro do que quando a comparação envolve o Estado de São Paulo.

Vale lembrar que, neste caso, quanto maior o coeficiente de correlação, maior a similaridade entre as estruturas.

\section{2 Índice Puro de Ligação (GHS)}

O índice puro de ligação permite uma análise que vai além da elaborada a partir dos índices de Hischaman-Rasmussen. A economia não é vista apenas pelas suas ligações setoriais, o índice puro leva em conta o tamanho da produção e, portanto, procura identificar os setores que, dadas suas ligações e suas produções, são mais essenciais à economia estudada.

Como no caso de Hischaman-Rasmussen, obtêm-se índices para frente, para trás e totais para cada setor. Neste trabalho, serão apresentados apenas os totais. Portanto, na análise setorial, a intenção é avaliar a importância dos setores como um todo para as economias regionais ou nacional, sem detalhar em que direção está o efeito principal.

Os valores apresentados nas duas primeiras tabelas do índice puro estão normalizados.

Inicialmente, toma-se o modelo como uma única região, ou seja, os resultados encontrados no quadro 5 refletem a relevância dos setores para toda a economia. 


\begin{tabular}{|c|c|c|c|c|c|c|c|c|}
\hline Posição & Setor & Valor & Posição & Setor & Valor & Posição & Setor & Valor \\
\hline 1 & $1 \mathrm{RB}$ & 6,73 & 43 & $12 \mathrm{RB}$ & 0,90 & 85 & $23 \mathrm{SP}$ & 0,32 \\
\hline 2 & $41 R B$ & 5,89 & 44 & $27 \mathrm{SP}$ & 0,88 & 86 & $25 \mathrm{MG}$ & 0,30 \\
\hline 3 & $33 R B$ & 5,75 & 45 & $21 \mathrm{SP}$ & 0,87 & 87 & $29 S P$ & 0,30 \\
\hline 4 & $34 \mathrm{RB}$ & 4,95 & 46 & 40SP & 0,87 & 88 & $19 R B$ & 0,29 \\
\hline 5 & 17RB & 4,69 & 47 & $20 \mathrm{SP}$ & 0,86 & 89 & $14 R B$ & 0,27 \\
\hline 6 & $38 \mathrm{RB}$ & 4,38 & 48 & $36 \mathrm{RB}$ & 0,82 & 90 & $7 \mathrm{MG}$ & 0,26 \\
\hline 7 & $34 \mathrm{SP}$ & 3,60 & 49 & $34 \mathrm{MG}$ & 0,80 & 91 & $26 \mathrm{MG}$ & 0,26 \\
\hline 8 & $35 \mathrm{RB}$ & 2,75 & 50 & $22 \mathrm{RB}$ & 0,79 & 92 & $28 \mathrm{RB}$ & 0,26 \\
\hline 9 & $38 \mathrm{SP}$ & 2,67 & 51 & 22SP & 0,78 & 93 & $8 \mathrm{MG}$ & 0,25 \\
\hline 10 & 25RB & 2,61 & 52 & $8 \mathrm{RB}$ & 0,78 & 94 & $31 S P$ & 0,24 \\
\hline 11 & $11 \mathrm{SP}$ & 2,50 & 53 & $4 \mathrm{SP}$ & 0,75 & 95 & $37 \mathrm{MG}$ & 0,22 \\
\hline 12 & $33 \mathrm{SP}$ & 2,43 & 54 & $16 \mathrm{RB}$ & 0,71 & 96 & $9 \mathrm{RB}$ & 0,22 \\
\hline 13 & $39 \mathrm{RB}$ & 2,36 & 55 & $41 \mathrm{MG}$ & 0,70 & 97 & $27 \mathrm{RB}$ & 0,21 \\
\hline 14 & 14SP & 2,33 & 56 & $10 \mathrm{SP}$ & 0,70 & 98 & $4 \mathrm{MG}$ & 0,21 \\
\hline 15 & $30 \mathrm{SP}$ & 2,23 & 57 & $3 R B$ & 0,69 & 99 & $2 \mathrm{MG}$ & 0,20 \\
\hline 16 & 41SP & 2,20 & 58 & $24 \mathrm{RB}$ & 0,66 & 100 & $29 \mathrm{MG}$ & 0,18 \\
\hline 17 & $26 \mathrm{RB}$ & 2,19 & 59 & $31 \mathrm{RB}$ & 0,64 & 101 & $18 \mathrm{MG}$ & 0,17 \\
\hline 18 & 37SP & 1,95 & 60 & $2 \mathrm{RB}$ & 0,63 & 102 & $3 \mathrm{MG}$ & 0,16 \\
\hline 19 & $39 \mathrm{SP}$ & 1,90 & 61 & $10 \mathrm{RB}$ & 0,62 & 103 & $40 \mathrm{MG}$ & 0,15 \\
\hline 20 & 30RB & 1,85 & 62 & $38 \mathrm{MG}$ & 0,62 & 104 & $14 \mathrm{MG}$ & 0,13 \\
\hline 21 & $37 \mathrm{RB}$ & 1,83 & 63 & $6 \mathrm{RB}$ & 0,61 & 105 & $16 \mathrm{MG}$ & 0,12 \\
\hline 22 & 8SP & 1,78 & 64 & $17 \mathrm{SP}$ & 0,58 & 106 & $13 \mathrm{MG}$ & 0,12 \\
\hline 23 & $1 \mathrm{SP}$ & 1,77 & 65 & $35 \mathrm{MG}$ & 0,55 & 107 & $36 \mathrm{MG}$ & 0,12 \\
\hline 24 & 9SP & 1,60 & 66 & 28SP & 0,54 & 108 & $21 \mathrm{MG}$ & 0,12 \\
\hline 25 & $29 \mathrm{RB}$ & 1,49 & 67 & $33 \mathrm{MG}$ & 0,53 & 109 & $6 \mathrm{MG}$ & 0,11 \\
\hline 26 & $7 \mathrm{RB}$ & 1,49 & 68 & $5 \mathrm{SP}$ & 0,53 & 110 & $27 \mathrm{MG}$ & 0,10 \\
\hline 27 & $35 \mathrm{SP}$ & 1,48 & 69 & $15 \mathrm{SP}$ & 0,52 & 111 & $42 \mathrm{RB}$ & 0,10 \\
\hline 28 & $1 \mathrm{MG}$ & 1,44 & 70 & $36 \mathrm{SP}$ & 0,51 & 112 & $24 \mathrm{SP}$ & 0,10 \\
\hline 29 & $12 \mathrm{SP}$ & 1,41 & 71 & $32 \mathrm{MG}$ & 0,51 & 113 & $28 \mathrm{MG}$ & 0,08 \\
\hline 30 & $32 \mathrm{RB}$ & 1,34 & 72 & $6 \mathrm{SP}$ & 0,51 & 114 & $24 \mathrm{MG}$ & 0,07 \\
\hline 31 & $5 \mathrm{MG}$ & 1,27 & 73 & $11 \mathrm{MG}$ & 0,49 & 115 & $9 \mathrm{MG}$ & 0,07 \\
\hline 32 & $18 \mathrm{RB}$ & 1,22 & 74 & $26 \mathrm{SP}$ & 0,43 & 116 & $19 \mathrm{MG}$ & 0,06 \\
\hline 33 & $5 \mathrm{RB}$ & 1,22 & 75 & $30 \mathrm{MG}$ & 0,40 & 117 & $31 \mathrm{MG}$ & 0,06 \\
\hline 34 & $32 \mathrm{SP}$ & 1,19 & 76 & $20 \mathrm{RB}$ & 0,39 & 118 & $22 \mathrm{MG}$ & 0,06 \\
\hline 35 & $7 \mathrm{SP}$ & 1,15 & 77 & $13 \mathrm{SP}$ & 0,39 & 119 & $10 \mathrm{MG}$ & 0,05 \\
\hline 36 & $4 \mathrm{RB}$ & 1,14 & 78 & $17 \mathrm{MG}$ & 0,38 & 120 & $42 \mathrm{SP}$ & 0,03 \\
\hline 37 & $13 R B$ & 1,10 & 79 & $12 \mathrm{MG}$ & 0,38 & 121 & $23 \mathrm{MG}$ & 0,03 \\
\hline 38 & $21 R B$ & 1,10 & 80 & $25 \mathrm{SP}$ & 0,38 & 122 & $20 \mathrm{MG}$ & 0,03 \\
\hline 39 & 40RB & 0,98 & 81 & $23 R B$ & 0,37 & 123 & $15 \mathrm{MG}$ & 0,02 \\
\hline 40 & $19 S P$ & 0,97 & 82 & $15 \mathrm{RB}$ & 0,37 & 124 & $42 \mathrm{MG}$ & 0,01 \\
\hline 41 & $18 \mathrm{SP}$ & 0,96 & 83 & $39 \mathrm{MG}$ & 0,35 & 125 & $2 \mathrm{SP}$ & 0,01 \\
\hline 42 & $16 \mathrm{SP}$ & 0,92 & 84 & $11 \mathrm{RB}$ & 0,34 & 126 & $3 \mathrm{SP}$ & 0,00 \\
\hline
\end{tabular}

Quadro 5. Indice puro total normalizado para Brasil integrado .

Fonte: resultados da pesquisa.

Como era de esperar, tendo em vista o tamanho de cada região estudada, os setores do Resto do Brasil lideram a lista dos índices puros de ligação. 
A Agropecuária (1) é o destaque. Em seguida e na ordem decrescente, Administração pública (41), Construção civil (33) e Comércio (34). Portanto, todos esses setores do Resto do Brasil têm importância vital ao funcionamento da economia brasileira.

Na sétima posição, aparece o primeiro setor paulista: Comércio (34). O que é interessante perceber é que depois de Comércio, São Paulo tem como setores de relevância para a economia nacional os Serviços prestados às famílias (38) e Automóveis, caminhões e ônibus (11), ocupando, respectivamente, o nono e o décimo primeiro lugar na lista. Apesar dos setores paulistas de Administração pública (41), Construção civil (33) e Agropecuária (1) terem posições de destaque, eles têm menos importância para a economia brasileira do que Serviços prestados às famílias (38) e Automóveis, caminhões e ônibus (11).

Minas Gerais aparece pela primeira vez em vigésimo oitavo lugar com Agropecuária (1). Em trigésimo primeiro está o setor mineiro de Siderurgia (5), que não só apresentava significativos índices de ligação como também conta com um volume de produção expressivo.

Em uma comparação entre os resultados dos dois índices já discutidos, podese notar que Administração pública (RB), Construção civil (RB) e Serviços prestados às famílias (SP) não apresentam valores muito altos para o índice de HirschamanRasmussen, o que indica que o volume expressivo da produção é o responsável por colocar estes setores como destaques no índice puro.

Automóveis, caminhões e ônibus (SP) tem índice de ligação para trás relevante e Agropecuária e Comércio para as três regiões apresentam fortes índices para frente.

Alterando a pergunta e voltando a atenção às regiões separadamente, o quadro 6 abaixo mostra os setores importantes dentro de cada região. Os valores a seguir demonstram qual a relevância do setor dentro da sua própria região. 


\begin{tabular}{|cccc|}
\hline Setor & SP & MG & RB \\
1 & 1,55 & 4,01 & 4,06 \\
2 & 0,00 & 0,46 & 0,38 \\
3 & 0,00 & 0,51 & 0,30 \\
4 & 0,84 & 0,76 & 0,85 \\
5 & 0,50 & 1,06 & 0,80 \\
6 & 0,51 & 0,42 & 0,40 \\
7 & 1,12 & 1,00 & 1,00 \\
8 & 1,42 & 0,90 & 0,48 \\
9 & 1,30 & 0,26 & 0,13 \\
10 & 0,71 & 0,16 & 0,33 \\
11 & 2,62 & 2,05 & 0,16 \\
12 & 1,39 & 1,46 & 0,50 \\
13 & 0,33 & 0,50 & 0,68 \\
14 & 1,37 & 0,49 & 0,15 \\
15 & 0,43 & 0,07 & 0,25 \\
16 & 0,71 & 0,52 & 0,40 \\
17 & 0,40 & 1,58 & 2,12 \\
18 & 0,81 & 0,61 & 0,83 \\
19 & 0,81 & 0,24 & 0,18 \\
20 & 0,60 & 0,11 & 0,27 \\
21 & 0,85 & 0,39 & 0,69 \\
22 & 0,84 & 0,15 & 0,49 \\
23 & 0,29 & 0,08 & 0,21 \\
24 & 0,05 & 0,35 & 0,27 \\
25 & 0,26 & 1,40 & 1,64 \\
26 & 0,31 & 1,23 & 1,48 \\
27 & 0,61 & 0,49 & 0,10 \\
28 & 0,48 & 0,36 & 0,12 \\
29 & 0,20 & 0,79 & 0,88 \\
30 & 1,53 & 1,76 & 1,22 \\
31 & 0,25 & 0,21 & 0,39 \\
32 & 1,11 & 1,15 & 0,90 \\
33 & 2,45 & 2,14 & 3,37 \\
34 & 3,32 & 3,28 & 3,42 \\
35 & 1,44 & 1,84 & 1,79 \\
36 & 0,58 & 0,51 & 0,55 \\
37 & 1,91 & 0,84 & 1,22 \\
38 & 2,73 & 2,68 & 2,79 \\
39 & 2,08 & 1,61 & 1,77 \\
40 & 0,87 & 0,61 & 0,72 \\
41 & 2,37 & 2,89 & 3,66 \\
42 & 0,03 & 0,05 & 0,06 \\
\hline
\end{tabular}

Quadro 6. Índices puros totais, normalizados e regionais por setor.

Fonte: resultados da pesquisa. 
Para São Paulo e o Resto do Brasil, a ordem dos líderes pouco se altera em relação ao primeiro quadro. Em razão de serem economias com grande participação na economia brasileira, a importância nacional se reflete também na importância regional. No caso de Minas Gerais, isto já não é tão claro. O setor que chama mais a atenção de quem compara os dois índices - nacional e reginal - é a Siderurgia (5). Com grande participação na economia nacional, a Siderurgia (5) mineira não é tão relevante regionalmente. $O$ entendimento desse fato passa pela constatação de que este setor é um dos que mais interagem comercialmente com as demais regiões, principalmente como fornecedora de insumos para a indústria brasileira (ligações para frente).

As análises até aqui estiveram centradas nos setores das economias regionais. A seguir, os resultados serão advindos de uma nova perspectiva que avaliará as economias como um todo, identificando os efeitos e importâncias regionais e não mais setoriais.

Dessa forma, um novo conceito pode ser retirado a partir dos dados do próximo quadro (7). Eles indicam a importância das demandas internas (região A) e externas (regiões B e C) para a economia em questão. As linhas representam as economias das três regiões e as colunas separam a influência das demandas internas e externas.

\begin{tabular}{|l|rr|}
\hline & Própria & \multicolumn{2}{|c|}{ Outras } \\
\hline SP & 88,8 & 11,2 \\
MG & 81,5 & 18,5 \\
RB & 94,6 & 5,4 \\
\hline
\end{tabular}

Quadro 7. Impacto das Demandas.

Fonte: resultados da pesquisa.

O impacto não precisa ser direto, portanto, os valores acima não representam o quanto São Paulo vende para a demanda final de outras regiões e o quanto vende para a própria. Este resultado significa quanto a demanda das outras regiões acabam por repercutir na economia paulista, direta ou indiretamente. 
Sendo assim, é fácil notar que para São Paulo, 88,8\% da sua economia depende, em última instância, da demanda da própria região e $11,2 \%$ das demais.

Novamente, o volume de produção interfere fortemente nos resultados. Minas Gerais tem uma economia mais dependente da demanda das outras duas regiões e o Resto do Brasil é a região que, desse ponto de vista, tem a economia mais autônoma.

Pode-se fazer o raciocínio inverso: quanto a demanda de cada região influencia a economia das vizinhas. Isso é o que está mostrado no quadro 8 . Se o raciocínio é inverso, o resultado também. O Resto do Brasil e o Estado de São Paulo praticamente não recebem nenhum efeito da demanda de Minas. Já a demanda do Resto do Brasil, ao contrário do caso anterior, é responsável por quase $10 \%$ da produção da região "Minas - São Paulo". São Paulo ocupa uma posição intermediária e sua demanda é responsável por 5,6\% da produção das outras duas.

\begin{tabular}{|l|lr|}
\hline & $\begin{array}{l}\text { Demanda } \\
\text { Terceira } \\
\text { Região }\end{array}$ & $\begin{array}{l}\text { Demanda } \\
\text { própria }\end{array}$ \\
\hline MG e RB & 5,6 & 94,4 \\
SP e RB & 0,7 & 99,3 \\
SP e MG & 9,9 & 90,1 \\
\hline
\end{tabular}

Fonte: resultados da pesquisa.

As duas últimas tabelas deixam clara a dependência que o Estado de Minas tem com as demais regiões brasileiras e, além disso, o pouco que influencia a economia nacional.

No quadro 9, olha-se a importância de cada região para a economia nacional. Através dos índices puros de ligação, que são apresentados em valor monetário, tem-se uma estimativa da relevância de cada região para a economia brasileira. 


\begin{tabular}{|l|cc|cc|cc|}
\hline & Ordem & Trás & Ordem & Frente & Ordem & Total \\
SP & 2 & 47015156 & 1 & 52100173 & 1 & 99115329 \\
MG & 3 & 8462631 & 3 & 22218563 & 3 & 30681194 \\
RB & 1 & 57993569 & 2 & 39191491 & 2 & 97185060 \\
\hline
\end{tabular}

Quadro 9. Indices puros por região.

Fonte: resultados da pesquisa.

Neste caso, são apresentadas as três abordagens do índice puro, para frente, para trás e total (soma dos dois anteriores).

Esta tabela mostra que, do ponto de vista de ligações para trás, o Resto do Brasil é a região de maior relevância para a economia nacional. Porém, quando se leva em conta o resultado dos índices de ligação para frente, São Paulo tem o maior destaque.

Finalmente, somando os dois valores e encontrando o índice puro total, São Paulo se constitui na região de maior importância para a economia nacional.

O que isso quer dizer? Pode-se interpretar esse resultado da seguinte forma: a economia brasileira teria uma desestruturação maior no caso de São Paulo sair da economia do que se ocorresse o mesmo com Resto do Brasil ou Minas Gerais. Dadas as ligações intra e inter-regionais e setoriais, além do volume de produção e transação envolvidos nessas ligações, a economia paulista, apesar de ser, em termos absolutos, menor que a do Resto do Brasil, tem um papel preponderante na estrutura de encadeamento da produção nacional.

Este resultado não é decorrente da simples soma dos índices puros de ligação de todos os setores de uma região. Como se imagina a retirada de determinada região da economia, o grau de interação e a maneira com esta região se insere na economia nacional é determinante para o resultado final.

O Gráfico 1 apresenta os números do quadro 9. 


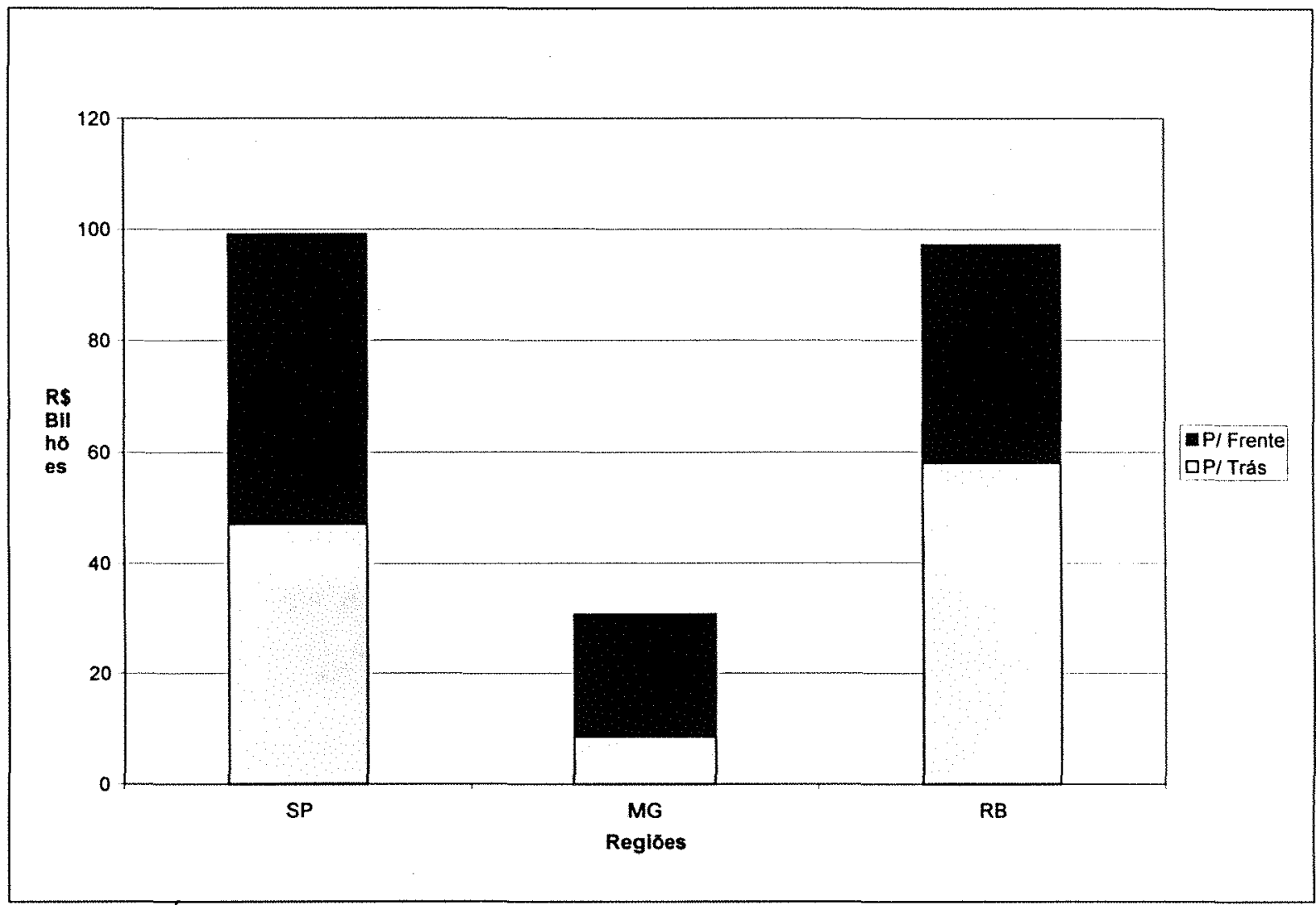

Gráfico 1. Índice Puro de Ligação: importância das regiões para a economia brasileira.

\subsection{Campo de Influência}

O campo de influência, pela definição do seu conceito, procura identificar os coeficientes das relações inter-setoriais que, quando alterados, mais modificam a estrutura de propagação dos efeitos oriundos de uma variação da demanda final.

Para a região de Minas Gerais (Gráfico 2), a Agropecuária (1) tem o maior destaque nas ligações de compra. Mas é o setor de Siderurgia (5) que aparece como um setor importante tanto nas ligações de compra quanto nas de venda. Em decorrência disso, pode-se dizer que alterações nos coeficientes de compra da siderurgia impactam fortemente a economia mineira. 


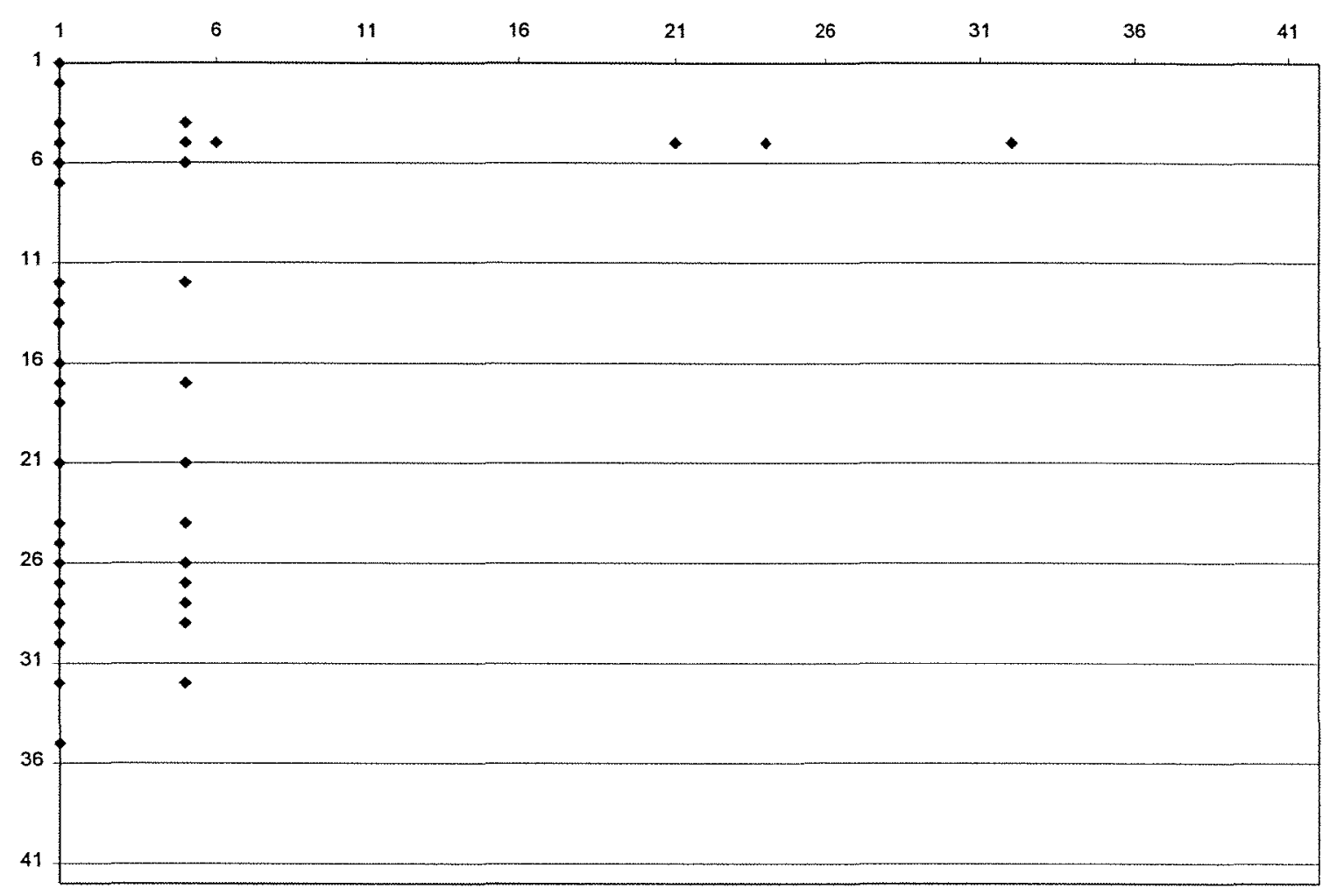

Gráfico 2. Campo de influência para Minas Gerais.

O resultado do campo de influência, apesar de não tratar exatamente do mesmo conceito, guarda estreita relação com os índices de ligação de HischamanRasmussen. Como a Agropecuária (1) tem alto índice de ligação para frente, este é um setor proporcionalmente muito demandado. Se houver alteração em seus coeficientes de compra, a alta demanda pelos produtos agropecuários passa a ser transmitida (aumento do coeficiente de compra) a outros setores da economia.

No caso da Siderurgia (5), os índices de ligação para frente e para trás são expressivos, o que se reflete no resultado do campo de influência, onde o setor se destaca nas ligações de compra e venda. 
No Gráfico 3, são apresentados os valores relativos ao campo de influência para região de São Paulo.

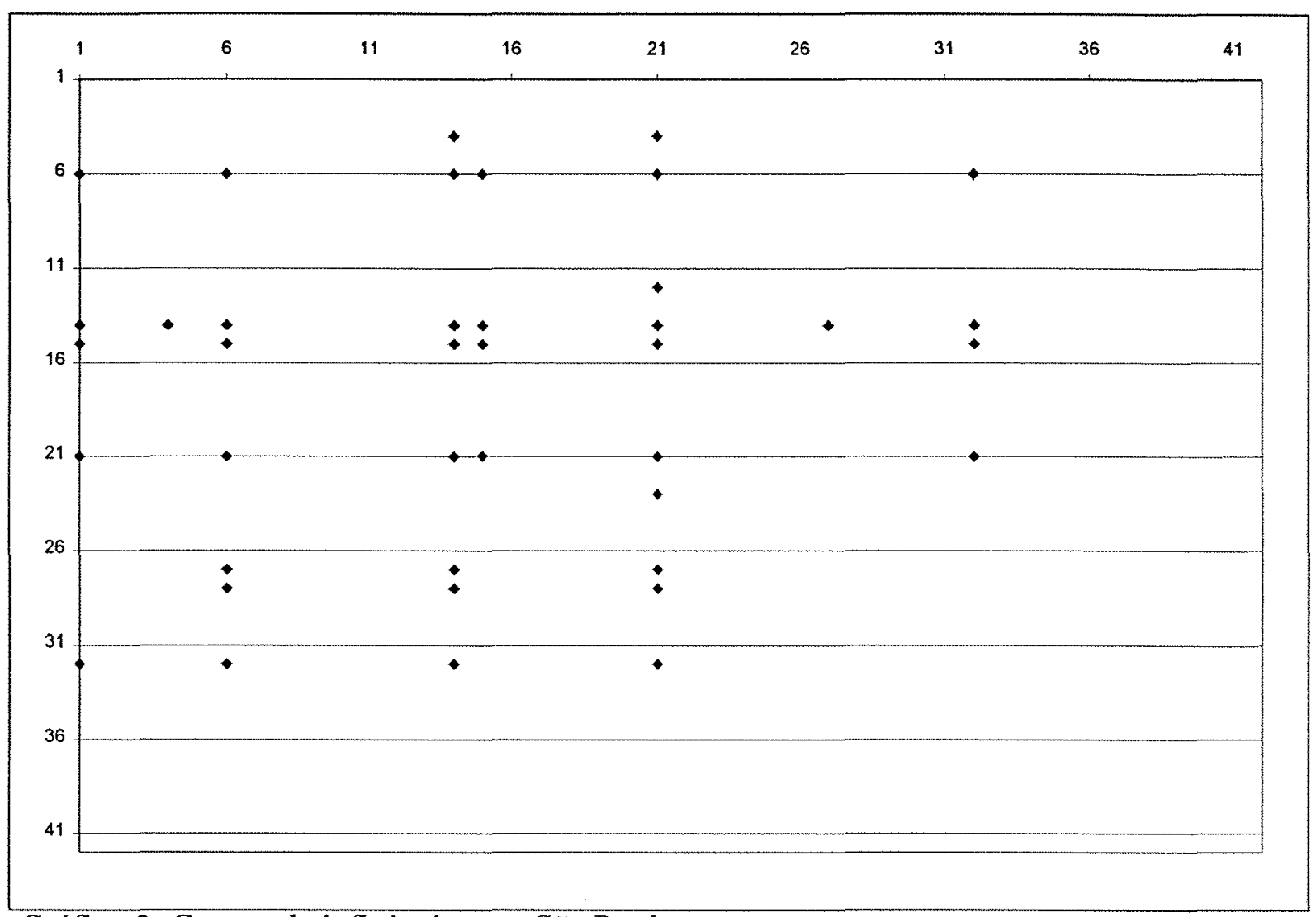

Gráfico 3. Campo de influência para São Paulo.

Através do gráfico, percebe-se que o setor Celulose, papel e gráfica (14) e Indústria Têxtil (21) têm destaque tanto nos coeficientes de compra como nos de venda. Estes são, do ponto de vista do campo de influência, os setores mais relevantes da região. Os dois setores citados se constituem em setores-chave da economia paulista, segundo resultados obtidos nos índices de ligação.

Além destes setores, Metalurgia dos não ferrosos (6), Indústria da borracha (15) e S.I.U.P. (Serviços Industriais de Utilidade Pública) (32) também são relevantes 
nos dois tipos de ligação, apesar de apresentarem relevância mais modesta que os dois primeiros.

Finalmente, o terceiro gráfico deste item (Gráfico 4) é relativo ao Resto do Brasil.

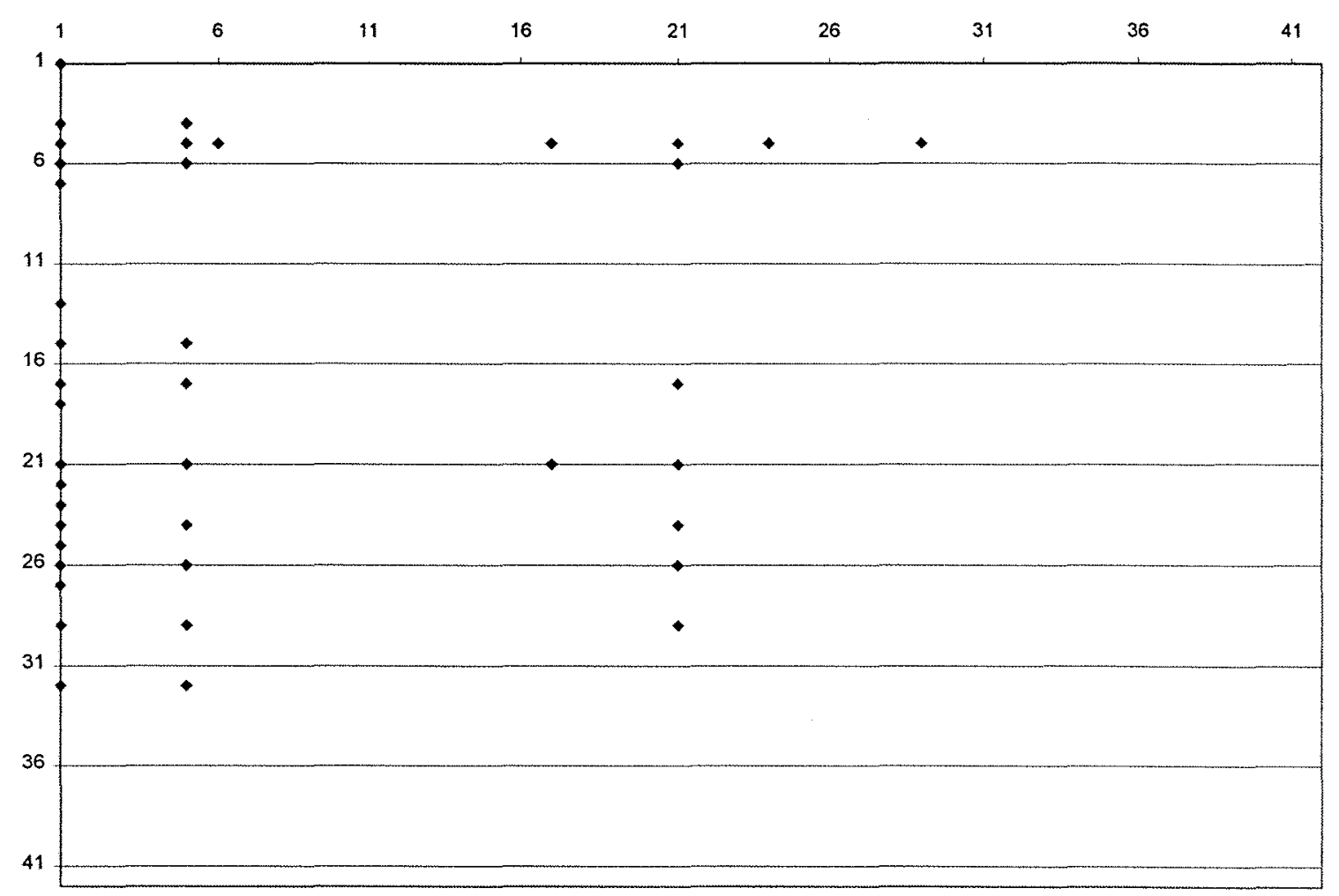

Gráfico 4. Campo de influência para o Resto do Brasil.

Pela forte presença da Agropecuária (1) nas ligações de compra e da Siderurgia (5) nas compras e vendas, pode-se perceber a semelhança existente entre estes resultados e os obtidos para o Estado de Minas Gerais.

A importância do setor Indústria têxtil (21), por outro lado, coincide com o setor de maior relevância para a economia de São Paulo. 
Portanto, os gráficos permitem relacionar as regiões e os setores de destaque da seguinte forma:

\begin{tabular}{|c|c|c|c|c|}
\hline & $\begin{array}{l}\text { Agropecuária } \\
\text { (compra) }\end{array}$ & $\begin{array}{l}\text { Siderurgia } \\
\text { (compra e venda) }\end{array}$ & $\begin{array}{l}\text { Indústria têxtil } \\
\text { (compra e venda) }\end{array}$ & $\begin{array}{l}\text { Celulose, papel e gráfica } \\
\text { (compra e venda) }\end{array}$ \\
\hline São Paulo & & & $\overline{X X X X X X X X X}$ & 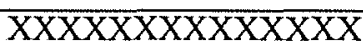 \\
\hline Minas Gerais & $\mathrm{XXXXXXX}$ & XXXXXXXX & & \\
\hline Resto do Brasil & XXXXXXX & $\mathrm{XXXXXXXX}$ & XXXXXXXXX & \\
\hline
\end{tabular}

Quadro 10. Setores de destaque para o campo de influência por região.

Fonte: resultados da pesquisa.

\subsection{Multiplicadores}

Para um exame mais detalhado do multiplicador, a apresentação abordará vários aspectos. Inicialmente, será apresentado o multiplicador simples de produção, que não inclui como variável endógena do modelo o setor família. Em seguida, os novos resultados já estarão com o setor família incorporado no modelo e, para este caso, outros enfoques serão dados, como, por exemplo, o multiplicador de renda e de emprego, além do multiplicador de produção.

A renda neste trabalho é obtida através da soma das remunerações com parte do excedente bruto de produção, de tal maneira que o total da renda iguale o total do consumo das famílias (bens nacionais e importados).

O emprego, seguindo a hipótese de mesma tecnologia de produção para as três regiões, foi distribuído proporcionalmente entre elas, conforme o total de produção.

A interpretação dos valores dos multiplicadores simples utilizará duas diferentes tabelas. O quadro 11, portanto, traz o multiplicador simples de produção. Este indicador sinaliza para o poder de propagação de um determinado setor quando há uma variação na sua demanda final. $O$ quadro 12 mede a distribuição percentual do multiplicador nas três regiões estudadas para cada um dos 126 setores (42 setores em 
três regiões) da economia. Como a interpretação dos dados levará em conta todos os aspectos presentes nas duas tabelas, elas são apresentadas a seguir, conjuntamente. 


\begin{tabular}{|c|c|c|c|c|c|c|c|c|c|c|c|c|}
\hline \multirow{3}{*}{ Setores } & \multicolumn{4}{|c|}{ Variação demanda de SP } & \multicolumn{4}{|c|}{ Variação demanda de MG } & \multicolumn{4}{|c|}{ Variação demanda do $\mathrm{RB}$} \\
\hline & \multicolumn{4}{|c|}{$\begin{array}{l}\text { Efeito na economia } \\
\text { de: }\end{array}$} & \multicolumn{4}{|c|}{$\begin{array}{l}\text { Efeito na economia } \\
\text { de: }\end{array}$} & \multicolumn{4}{|c|}{$\begin{array}{l}\text { Efeito na economia } \\
\text { de: }\end{array}$} \\
\hline & $\begin{array}{l}\text { São } \\
\text { Paulo }\end{array}$ & Çinas & $\begin{array}{l}\text { Resto } \\
3 r\end{array}$ & & $\begin{array}{l}\text { São } \\
\text { Paulo }\end{array}$ & Minas & Sesto & & $\begin{array}{l}\text { São } \\
\text { Paulo }\end{array}$ & Minas & esto & \\
\hline AGROPECUÁRIA & 1,39 & 0,04 & 0,24 & 1,67 & 0,08 & 1,56 & 0,03 & 1,67 & 0,09 & 0,02 & 1,56 & 1,67 \\
\hline EXTRAT. MINERAL & 1,68 & 0,11 & 0,26 & 2,04 & 0,13 & 1,85 & 0,06 & 2,04 & 0,17 & 0,04 & 1,83 & 2,04 \\
\hline PETRÓLEO E GÁS & 1,50 & 0,04 & 0,06 & 1,60 & 0,09 & 1,48 & 0,03 & 1,60 & 0,12 & 0,03 & 1,46 & 1,60 \\
\hline MINERAL Ñ METÁLICO & 1,77 & 0,09 & 0,22 & 2,08 & 0,11 & 1,91 & 0,06 & 2,08 & 0,16 & 0,04 & 1,88 & 2,08 \\
\hline SIDERURGIA & 1,60 & 0,82 & 0,18 & 2,60 & 0,11 & 2,44 & 0,05 & 2,60 & 0,16 & 0,16 & 2,28 & 2,60 \\
\hline $\begin{array}{l}\text { METALURG. Ñ } \\
\text { FERROSOS }\end{array}$ & 1,99 & 0,09 & 0,15 & 2,23 & 0,12 & 2,07 & 0,05 & 2,23 & 0,20 & 0,04 & 1,99 & 2,23 \\
\hline OUTROS METALÚRG. & 1,77 & 0,45 & 0,10 & 2,33 & 0,10 & 2,19 & 0,04 & 2,33 & 0,16 & 0,22 & 1,96 & 2,33 \\
\hline MÁQUINAS E EQUIP. & 1,60 & 0,14 & 0,07 & 1,80 & 0,11 & 1,66 & 0,03 & 1,81 & 0,16 & 0,08 & 1,56 & 1,80 \\
\hline MATERIA & 2,03 & 0,12 & 0,12 & 2,27 & 0,29 & 1,93 & 0,06 & 2,27 & 0,37 & 0,08 & 1,82 & 2,27 \\
\hline EQUIP. ELETRÔNICOS & 1,55 & 0,04 & 0,07 & 1,67 & 0,19 & 1,44 & 0,04 & 1,67 & 0,18 & 0,03 & 1,45 & 1,66 \\
\hline AUTOM./CAM/ONIBUS & 1,97 & 0,12 & 0,09 & 2,19 & 0,18 & 1,96 & 0,05 & 2,19 & 0,33 & 0,14 & 1,71 & 2,18 \\
\hline $\begin{array}{l}\text { PEÇAS E OUT. } \\
\text { VEÍCULOS }\end{array}$ & 2,06 & 0,18 & 0,10 & 2,33 & 0,14 & 2,16 & 0,04 & 2,34 & 0,33 & 0,15 & 1,85 & 2,33 \\
\hline $\begin{array}{l}\text { MADEIRA E } \\
\text { MOBILIÁRIO }\end{array}$ & 1,63 & 0,04 & 0,38 & 2,06 & 0,14 & 1,82 & 0,10 & 2,06 & 0,13 & 0,03 & 1,90 & 2,06 \\
\hline $\begin{array}{l}\text { CELULOSE, PAPEL E } \\
\text { GRÁF. }\end{array}$ & 2,03 & 0,03 & 0,18 & 2,24 & 0,40 & 1,73 & 0,08 & 2,21 & 0,53 & 0,02 & 1,64 & 2,20 \\
\hline IND. DA BORRACHA & 1,87 & 0,03 & 0,27 & 2,17 & 0,50 & 1,56 & 0,12 & 2,17 & 0,26 & 0,02 & 1,89 & 2,17 \\
\hline ELEMENTOS QUIMICOS & 1,80 & 0,04 & 0,20 & 2,04 & 0,10 & 1,89 & 0,05 & 2,04 & 0,35 & 0,04 & 1,65 & 2,03 \\
\hline REFINO DO PETRÓLEO & 1,30 & 0,10 & 0,50 & 1,90 & 0,08 & 1,70 & 0,12 & 1,90 & 0,10 & 0,02 & 1,77 & 1,89 \\
\hline QUÍMICOS DIVERSOS & 1,70 & 0,05 & 0,33 & 2,08 & 0,19 & 1,79 & 0,10 & 2,08 & 0,23 & 0,02 & 1,82 & 2,08 \\
\hline $\begin{array}{l}\text { FARMAC. E } \\
\text { VETERINÁRIA }\end{array}$ & 1,57 & 0,02 & 0,25 & 1,85 & 0,15 & 1,64 & 0,05 & 1,84 & 0,18 & 0,01 & 1,64 & 1,84 \\
\hline ARTIGOS PLÁSTICOS & 1,68 & 0,0 & 0,22 & 1,94 & 0,2 & 1,6 & 0,10 & 1,94 & 0,2 & 0,0 & 1,67 & 1,93 \\
\hline IND. TÊXTIL & 1,89 & 0,02 & 0,32 & 2,24 & 0,21 & 1,73 & 0,29 & 2,23 & 0,17 & 0,02 & 2,04 & 2,23 \\
\hline $\begin{array}{l}\text { ARTIGOS DO } \\
\text { VESTUÁRIO }\end{array}$ & 2,03 & 0,02 & 0,18 & 2,22 & 0,42 & 1,64 & 0,16 & 2,22 & 0,22 & 0,01 & 1,99 & 2,22 \\
\hline $\begin{array}{l}\text { FABRICAÇÃOO } \\
\text { CALÇADOS }\end{array}$ & 1,92 & 0,03 & 0,26 & 2,21 & 0,47 & 1,64 & 0,09 & 2,21 & 0,25 & 0,02 & 1,94 & 2,20 \\
\hline
\end{tabular}




\begin{tabular}{|c|c|c|c|c|c|c|c|c|c|c|c|c|}
\hline \multirow{3}{*}{$\begin{array}{l}\text { Setores } \\
\text { INDÚSTRIA DO CAFÉ }\end{array}$} & \multicolumn{4}{|c|}{ Variação demanda de SP } & \multicolumn{4}{|c|}{ Variacao demanda de $M G$} & \multicolumn{4}{|c|}{ Variacao demanda do RB } \\
\hline & \multicolumn{4}{|c|}{$\begin{array}{l}\text { Efeito na economia } \\
\text { de: }\end{array}$} & \multicolumn{4}{|c|}{$\begin{array}{l}\text { Efeito na economia } \\
\text { de: }\end{array}$} & \multicolumn{4}{|c|}{$\begin{array}{l}\text { Efeito na economia } \\
\text { de: }\end{array}$} \\
\hline & 1,63 & 0,33 & 0,52 & 2,49 & 0,08 & 2,37 & 0,03 & 2,49 & 0,08 & 0,46 & 1,96 & 2,50 \\
\hline $\begin{array}{l}\text { BENEF. PROD. } \\
\text { VEGETAIS }\end{array}$ & 1,53 & 0,06 & 0,66 & 2,25 & 0,10 & 2,10 & 0,04 & 2,24 & 0,13 & 0,02 & 2,09 & 2,24 \\
\hline ABATE DE ANIMAIS & 1,74 & 0,06 & 0,57 & 2,37 & 0,10 & 2,24 & 0,04 & 2,37 & 0,11 & 0,02 & 2,24 & 2,37 \\
\hline $\begin{array}{l}\text { INDÚSTRIA DE } \\
\text { LATICÍNIOS }\end{array}$ & 1,96 & 0,35 & 0,14 & 2,45 & 0,10 & 2,30 & 0,04 & 2,44 & 0,41 & 0,15 & 1,87 & 2,44 \\
\hline $\begin{array}{l}\text { FABRICAÇÃO DE } \\
\text { AÇÚCAR }\end{array}$ & 2,31 & 0,04 & 0,19 & 2,54 & 0,15 & 2,33 & 0,06 & 2,53 & 0,64 & 0,05 & 1,84 & 2,53 \\
\hline FAB. ÓLEOS VEGETAIS & 1,58 & 0,06 & 0,96 & 2,60 & 0,10 & 2,45 & 0,06 & 2,61 & 0,11 & 0,03 & 2,46 & 2,60 \\
\hline $\begin{array}{l}\text { OUTROS PROD. } \\
\text { ALIMENT. }\end{array}$ & 1,73 & 0,04 & 0,57 & 2,35 & 0,13 & 2,17 & 0,05 & 2,34 & 0,22 & 0,02 & 2,10 & 2,34 \\
\hline INDÚSTRIAS DIVERSAS & 1,71 & 0,06 & 0,15 & 1,92 & 0,18 & 1,67 & 0,07 & 1,91 & 0,18 & 0,02 & 1,70 & 1,91 \\
\hline S.I.U.P. & 1,53 & 0,01 & 0,04 & 1,57 & 0,05 & 1,50 & 0,02 & 1,57 & 0,10 & 0,05 & 1,41 & 1,57 \\
\hline CONSTRUÇÃO CIVIL & 1,47 & 0,04 & 0,10 & 1,61 & 0,09 & 1,47 & 0,05 & 1,61 & 0,11 & 0,03 & 1,47 & 1,61 \\
\hline COMÉRCIO & 1,42 & 0,01 & 0,21 & 1,64 & 0,09 & 1,48 & 0,08 & 1,64 & 0,09 & 0,01 & 1,54 & 1,64 \\
\hline TRANSPORTES & 1,49 & 0,02 & 0,24 & 1,76 & 0,11 & 1,56 & 0,08 & 1,76 & 0,12 & 0,02 & 1,61 & 1,76 \\
\hline COMUNICAÇÕES & 1,24 & 0,01 & 0,02 & 1,27 & 0,06 & 1,19 & 0,01 & 1,27 & 0,06 & 0,01 & 1,20 & 1,26 \\
\hline $\begin{array}{l}\text { INSTITUIÇÕES } \\
\text { FINANCEIRAS }\end{array}$ & 1,37 & 0,00 & 0,02 & 1,40 & 0,09 & 1,29 & 0,02 & 1,40 & 0,06 & 0,00 & 1,34 & 1,40 \\
\hline $\begin{array}{l}\text { SERV. PREST. À } \\
\text { FAMÍLIA }\end{array}$ & 1,45 & 0,02 & 0,13 & 1,60 & 0,08 & 1,49 & 0,03 & 1,60 & 0,11 & 0,02 & 1,46 & 1,60 \\
\hline $\begin{array}{l}\text { SERV.PREST. À } \\
\text { EMPRESA }\end{array}$ & 1,37 & 0,01 & 0,04 & 1,42 & 0,12 & 1,26 & 0,03 & 1,41 & 0,15 & 0,01 & 1,26 & 1,41 \\
\hline ALUGUEL DE IMÓVEIS & 1,05 & 0,00 & 0,01 & 1,06 & 0,01 & 1,04 & 0,02 & 1,06 & 0,01 & 0,00 & 1,06 & 1,06 \\
\hline $\begin{array}{l}\text { ADMINISTRAÇÃO } \\
\text { PÚBLICA }\end{array}$ & 1,36 & 0,01 & 0,05 & 1,42 & 0,06 & 1,33 & 0,03 & 1,42 & 0,07 & 0,01 & 1,33 & 1,42 \\
\hline $\begin{array}{l}\text { SERV. PRIV. Ñ } \\
\text { MERCANTIS }\end{array}$ & 1,08 & 0,00 & 0,03 & 1,12 & 0,01 & 1,10 & 0,01 & 1,12 & 0,02 & 0,00 & 1,10 & 1,12 \\
\hline
\end{tabular}

Quadro 11. Multiplicadores simples de produção. (cont.)

Fonte: resultados da pesquisa. 
AGROPECUÁRIA

EXTRAT. MINERAL

PETRÓLEOE GÁS

MINERAL Ñ METÁLICO

SIDERURGIA

METALURG. N FERROSOS

OUTROS METALÚRGICOS

MÁQUINAS E EQUIP.

MATERIAL ELÉTRICO

EQUIP. ELETRÓNICOS

AUTOM./CAM/ONIBUS

PEÇAS E OUT. VEICULOS

MADEIRA E MOBILIARIO

CELULOSE, PAPEL E GRAF.

IND. DA BORRACHA

ELEMENTOS QUIMICOS

REFINO DO PETRÓLEO

QUIMICOS DIVERSOS

FARMAC. E VETERINÁRIA

ARTIGOS PLÁSTICOS

IND. TÊXTIL

ARTIGOS DO VESTUÁRIO

FABRICAÇÃO CALÇADOS

INDÚSTRIA DO CAFÉ

BENEF. PROD. VEGETAIS

ABATE DE ANIMAIS

INDÚSTRIA DE LATICINIOS

FABRICAÇĀO DE AÇÚCAR

FAB. OLEOS VEGETAIS

OUTROS PROD. ALIMENT.

INDÚSTRIAS DIVERSAS

S.I.U.P.

CONSTRUÇÃO CIVIL

COMÉRCIO

TRANSPORTES

COMUNICAÇOESS

INSTITUIÇÓES FINANCEIRAS

SERV. PREST. À FAMILIA

SERV. PREST. A EMPRESA

ALUGUEL DE IMÓVEIS

ADMINISTRAÇĀO PÚBLICA

SERV. PRIV. N MERCANTIS

\begin{tabular}{|c|c|c|c|c|c|c|c|c|}
\hline \multicolumn{3}{|c|}{$\begin{array}{l}\text { Variaç. Demanda } \\
\text { SP }\end{array}$} & \multicolumn{3}{|c|}{ Variaç. Demanda MG } & \multicolumn{3}{|c|}{$\frac{\text { Variac. Demanda }}{\mathrm{RB}}$} \\
\hline \multicolumn{3}{|c|}{ Efeito na economia de: } & \multicolumn{3}{|c|}{ Efeito na economia de: } & \multicolumn{3}{|c|}{ Efeito na economia de: } \\
\hline Säo & Minas & Resto & São & Minas & Resto & São & $\overline{\text { Minas }}$ & Resto \\
\hline Paulo & & $\mathrm{Br}$ & Paulc & & $\mathrm{Br}$ & Paulo & & $\mathrm{Br}$ \\
\hline 83,48 & 2,34 & 14,18 & 4,52 & 93,41 & 2,07 & 5,26 & 1,48 & 93,25 \\
\hline 82,09 & 5,32 & 12,59 & 6,50 & 90,32 & 3,18 & 8,55 & 1,73 & 89,72 \\
\hline 93,89 & 2,21 & 3,91 & 5,65 & 92,47 & 1,89 & 7,20 & 1,72 & 91,08 \\
\hline 84,84 & 4,37 & 10,79 & 5,43 & 91,58 & 2,98 & 7,65 & 2,08 & 90,28 \\
\hline 61,49 & 31,71 & 6,79 & 4,10 & 93,90 & 2,01 & 5,99 & 6,12 & 87,90 \\
\hline 89,30 & 4,03 & 6,67 & 5,26 & 92,59 & 2,15 & 8,79 & 1,89 & 89,32 \\
\hline 76,07 & 19,47 & 4,45 & 4,42 & 93,77 & 1,82 & 6,76 & 9,26 & 83,98 \\
\hline 88,48 & 7,72 & 3,80 & 6,3 & 91,90 & 1,76 & 8,93 & 4,67 & 86,40 \\
\hline 89,33 & 5,38 & 5,29 & 12,5 & 85,01 & 2,44 & 16,40 & 3,40 & 80,20 \\
\hline 93,14 & 2,59 & 4,27 & 11,1 & 86,70 & 2,16 & 10,97 & 1,79 & 87,24 \\
\hline 90,22 & 5,59 & 4,19 & 8,22 & 89,66 & 2,12 & 15,28 & 6,38 & 78,33 \\
\hline 88,11 & 7,69 & 4,19 & 5,86 & 92,25 & 1,89 & 14,16 & 6,48 & 79,36 \\
\hline 79,18 & 2,13 & 18,69 & 6,8 & 88,45 & 4,73 & 6,25 & 1,28 & 92,47 \\
\hline 90,95 & 1,15 & 7,91 & 18,16 & 78,33 & 3,51 & 24,27 & 0,97 & 74,77 \\
\hline 86,21 & 1,52 & 12,27 & 22,8 & 71,59 & 5,58 & 11,84 & 0,92 & 87,24 \\
\hline 88,17 & 2,03 & 9,80 & 4,67 & 92,90 & 2,43 & 17,17 & 1,90 & 80,93 \\
\hline 68,43 & 5,40 & 26,18 & 4,02 & 89,55 & 6,43 & 5,54 & 0,84 & 93,62 \\
\hline 81,77 & 2,52 & 15,71 & 9,2 & 85,82 & 4,97 & 11,29 & 0,99 & 87,72 \\
\hline 85,04 & 1,17 & 13,79 & 7,9 & 89,15 & 2,94 & 9,98 & 0,75 & 89,27 \\
\hline 86,82 & 1,81 & 11,37 & 12,08 & 82,86 & 5,06 & 12,45 & 1,05 & 86,50 \\
\hline 84,64 & 1,11 & 14,25 & 9,5 & 77,45 & 13,01 & 7,74 & 0,89 & 91,37 \\
\hline 91,15 & 0,74 & 8,11 & 18,9 & 73,71 & 7,35 & 9,75 & 0,61 & 89,64 \\
\hline 86,89 & 1,14 & 11,98 & 21,50 & 74,29 & 4,21 & 11,38 & 0,76 & 87,86 \\
\hline 65,66 & 13,35 & 20,98 & 3,17 & 95,45 & 1,38 & 3,36 & 18,32 & 78,32 \\
\hline 67,95 & 2,48 & 29,57 & 4,58 & 93,71 & 1,71 & 5,81 & 1,03 & 93,15 \\
\hline 73,31 & 2,57 & 24,12 & 4,02 & 94,37 & 1,59 & 4,59 & 0,91 & 94,49 \\
\hline 79,94 & 14,19 & 5,8 & 4,28 & 94,18 & 1,54 & & 6,24 & 76,74 \\
\hline 91,11 & 1,58 & 7,31 & 5,83 & 91,87 & 2,29 & 25,34 & 1,96 & 72,70 \\
\hline 60,85 & 2,34 & 36,82 & 3,76 & 94,02 & 2,22 & 4,40 & 0,99 & 94,60 \\
\hline 73,83 & 1,79 & 24,39 & 5,44 & 92,60 & 1,96 & 9,23 & 1,05 & 89,72 \\
\hline 89,20 & 3,10 & 7,70 & 9,55 & 87,05 & 3,40 & 9,59 & 1,25 & 89,16 \\
\hline 97,13 & 0,60 & 2,27 & 3,32 & 95,54 & 1,12 & 6,42 & 3,41 & 90,18 \\
\hline 91,44 & 2,65 & 5,91 & 5,5 & 91,21 & 3,26 & 6,63 & 1,78 & 91,59 \\
\hline 86,52 & 0,64 & 12,84 & 5,3 & 89,83 & 4,83 & 5,68 & 0,53 & 93,80 \\
\hline 84,77 & 1,39 & 13,83 & 6,38 & 88,83 & 4,79 & 6,97 & 1,37 & 91,66 \\
\hline 97,72 & 0,63 & 1,65 & $4,8 \varepsilon$ & 93,96 & 1,16 & 4,67 & 0,53 & 94,80 \\
\hline 97,96 & 0,28 & 1,77 & 6,30 & 92,33 & 1,37 & 4,22 & 0,24 & 95,54 \\
\hline 90,80 & 1,18 & 8,03 & 5,18 & 93,02 & 1,80 & 6,99 & 1,30 & 91,71 \\
\hline 96,49 & 0,45 & 3,06 & 8,38 & 89,48 & 2,14 & 10,46 & 0,39 & 89,15 \\
\hline 98,55 & 0,14 & 1,30 & 0,5 & 97,74 & 1,71 & 0,59 & 0,13 & 99,28 \\
\hline 95,65 & 0,53 & 3,82 & 4,37 & 93,75 & 1,88 & 5,19 & 0,63 & 94,18 \\
\hline 96,82 & 0,32 & 2,86 & $1,0 s$ & 98,18 & 0,73 & 1,70 & 0,29 & 98,01 \\
\hline
\end{tabular}

Quadro12. Distribuição do multiplicador simples entre as regiões.

Fonte: resultados da pesquisa. 
Os efeitos da variação da demanda de São Paulo para o Resto do Brasil se mostram concentrados em alguns setores, principalmente em Fabricação de óleos vegetais (29) e Beneficiamento de produtos vegetais (25). Com exceção de Fabricação de açúcar (28), o Resto do Brasil se beneficia fortemente da demanda paulista nos setores ligados aos alimentos e ao processamento vegetal. Já se a demanda desses setores variar em Minas, o Estado retém em sua região uma parcela maior dos efeitos e, consequentemente, o Resto do Brasil se beneficia menos quando comparado ao primeiro caso.

A variação da demanda dos setores de serviços em São Paulo ou Resto do Brasil praticamente não tem nenhum efeito sobre o Estado de Minas. Analisando os valores absolutos do multiplicador, esta questão perde relevância na medida em que os setores de serviços apresentam multiplicadores absolutos relativamente mais baixos que os demais setores.

O setor paulista que mais propaga seus efeitos na região de Minas é a Siderurgia (5). Ao contrário, Fabricação de calçados (23) e Indústria da borracha (15) do Estado de Minas são os setores de maior propagação para São Paulo.

A relação Minas Gerais e Resto do Brasil possui no setor Indústria do Café (24) o maior percentual de propagação do Resto do Brasil para Minas Gerais. No sentido contrário, Indústria Têxtil (21) de Minas tem forte repercussão percentual na região Resto do Brasil.

Essas observações valem também, de modo geral, para o caso do multiplicador total que incorpora os efeitos das famílias. Para o segundo conjunto de resultados, são apresentados nos quadros 13, 14 e 15, os valores do multiplicador total em ordem decrescente, além do multiplicador de renda. Além desses, os quadros 16, 17 e 18 seguem as anteriores e retratam a distribuição regional dos multiplicadores para cada setor. Novamente, os seis quadros estão agrupados pelo fato da interpretação muitas vezes relacionar os dados contidos nesses dois conjuntos de resultados propagação dos multiplicadores em termos absolutos e percentuais. 


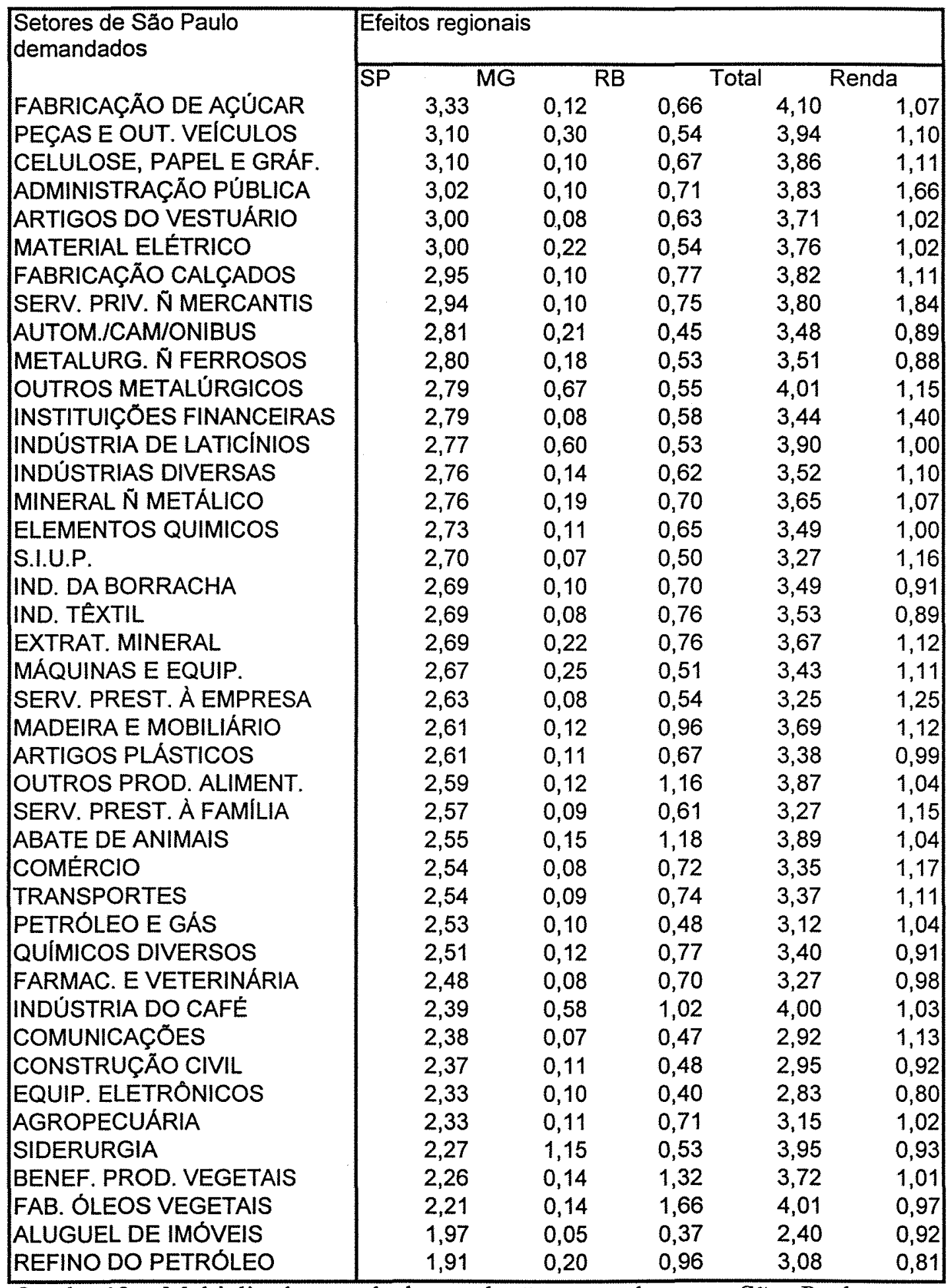

Quadro 13. Multiplicador total de produção e renda para São Paulo em ordem decrescente.

Fonte: resultados da pesquisa. 


\begin{tabular}{|c|c|c|c|c|c|}
\hline \multirow[t]{2}{*}{ Setores de Minas demandados } & \multicolumn{5}{|c|}{ Efeitos regionais } \\
\hline & SP & $\overline{R B}$ & Total & & \\
\hline INDÜSTRIA DO CAFÉ & 0,42 & 3,36 & 0,22 & 3,99 & 1,04 \\
\hline FAB. ÓLEOS VEGETAIS & 0,43 & 3,35 & 0,24 & 4,01 & 0,97 \\
\hline FABRICAÇÃO DE AÇÚCAR & 0,52 & 3,31 & 0,27 & 4,10 & 1,08 \\
\hline SIDERURGIA & 0,43 & 3,29 & 0,23 & 3,96 & 0,93 \\
\hline OUTROS METALÚRGICOS & 0,49 & 3,27 & 0,25 & 4,01 & 1,15 \\
\hline INDÜSTRIA DE LATICININIOS & 0,44 & 3,24 & 0,22 & 3,90 & 1,00 \\
\hline ABATE DE ANIMAIS & 0,44 & 3,22 & 0,23 & 3,89 & 1,04 \\
\hline PEÇAS E OUT. VEICULOS & 0,52 & 3,18 & 0,25 & 3,95 & 1,10 \\
\hline OUTROS PROD. ALIMENT. & 0,49 & 3,14 & 0,24 & 3,87 & 1,05 \\
\hline BENEF. PROD. VEGETAIS & 0,44 & 3,05 & 0,22 & 3,71 & 1,01 \\
\hline ADMINISTRAÇĀO PÚBLICA & 0,58 & 2,95 & 0,30 & 3,83 & 1,66 \\
\hline SERV. PRIV. Ñ MERCANTIS & 0,56 & 2,95 & 0,29 & 3,80 & 1,84 \\
\hline MINERAL Ñ METÁLICO & 0,48 & 2,90 & 0,27 & 3,65 & 1,08 \\
\hline METALURG. Ñ FERROSOS & 0,43 & 2,86 & 0,22 & 3,51 & 0,88 \\
\hline EXTRAT. MINERAL & 0,52 & 2,86 & 0,28 & 3,67 & 1,12 \\
\hline MADEIRA E MOBILIÁRIO & 0,53 & 2,84 & 0,33 & 3,69 & 1,12 \\
\hline ELEMENTOS QUIMICOS & 0,43 & 2,82 & 0,24 & 3,49 & 1,00 \\
\hline MATERIAL ELÉTRICO & 0,69 & 2,80 & 0,27 & 3,76 & 1,02 \\
\hline AUTOM./CAM/ONIBUS & 0,51 & 2,75 & 0,22 & 3,48 & 0,89 \\
\hline MÁQUINAS E EQUIP. & 0,49 & 2,71 & 0,23 & 3,43 & 1,12 \\
\hline INDÚSTRIAS DIVERSAS & 0,58 & 2,65 & 0,29 & 3,53 & 1,11 \\
\hline S.I.U.P. & 0,42 & 2,63 & 0,21 & 3,26 & 1,17 \\
\hline CELULOSE, PAPEL E GRÁF. & 0,89 & 2,63 & 0,34 & 3,86 & 1,13 \\
\hline INSTITUIÇŐES FINANCEIRAS & 0,56 & 2,63 & 0,26 & 3,45 & 1,41 \\
\hline SERV. PREST. Ả FAMILIA & 0,45 & 2,59 & 0,23 & 3,27 & 1,15 \\
\hline TRANSPORTES & 0,49 & 2,58 & 0,30 & 3,37 & 1,11 \\
\hline COMÉRCIO & 0,48 & 2,57 & 0,31 & 3,35 & 1,17 \\
\hline QUIMICOS DIVERSOS & 0,53 & 2,56 & 0,31 & 3,40 & 0,91 \\
\hline FARMAC. E VETERINÁRIA & 0,49 & 2,54 & 0,25 & 3,27 & 0,98 \\
\hline AGROPECUÁRIA & 0,40 & 2,54 & 0,21 & 3,15 & 1,02 \\
\hline FABRICAÇÃO CALÇADOS & 0,97 & 2,49 & 0,36 & 3,82 & 1,11 \\
\hline SERV. PREST. À EMPRESA & 0,54 & 2,46 & 0,25 & 3,25 & 1,26 \\
\hline PETROLLO E GÁS & 0,44 & 2,46 & 0,22 & 3,12 & 1,04 \\
\hline ARTIGOS PLÁSTICOS & 0,61 & 2,45 & 0,32 & 3,38 & 0,99 \\
\hline ARTIGOS DO VESTUÁRIO & 0,85 & 2,43 & 0,42 & 3,71 & 1,02 \\
\hline REFINO DO PETRÓLEO & 0,35 & 2,42 & 0,31 & 3,07 & 0,81 \\
\hline IND. TÉXTIL & 0,55 & 2,42 & 0,56 & 3,53 & 0,89 \\
\hline CONSTRUÇÃO CIVIL & 0,40 & 2,33 & 0,23 & 2,96 & 0,92 \\
\hline COMUNICAÇÕES & 0,42 & 2,29 & 0,20 & 2,92 & 1,14 \\
\hline IND. DA BORRACHA & 0,92 & 2,22 & 0,36 & 3,50 & 0,91 \\
\hline EQUIP. ELETRONICOS & 0,49 & 2,14 & 0,20 & 2,83 & 0,80 \\
\hline ALUGUEL DE IMÓVEIS & 0,28 & 1,95 & 0,17 & 2,40 & 0,92 \\
\hline
\end{tabular}

Quadro 14. Multiplicador total de produção e renda para Minas em ordem decrescente.

Fonte: resultados da pesquisa. 


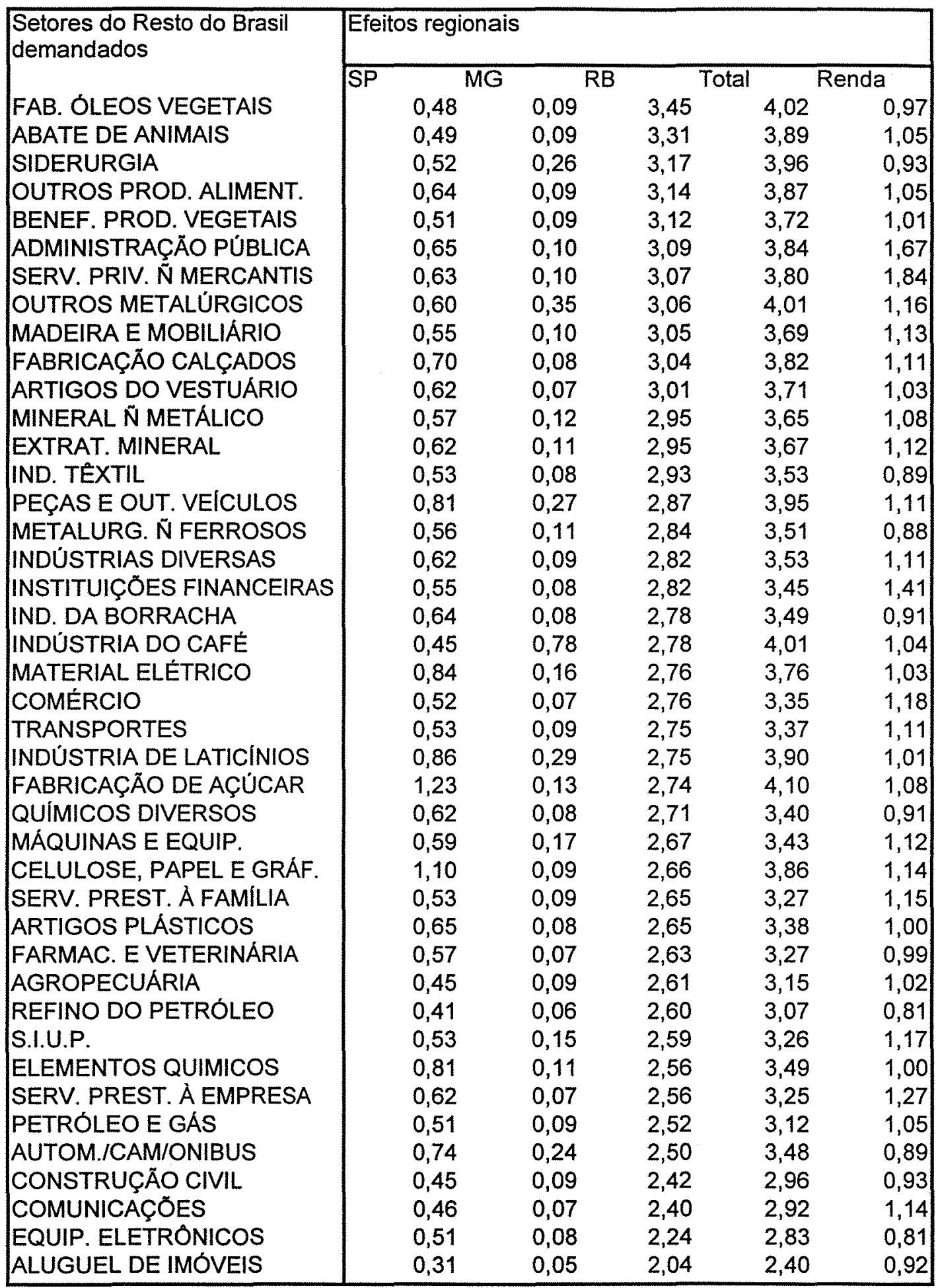

Quadro 15. Multiplicador total de produção e renda para o Resto do Brasil em ordem decrescente.

Fonte: resultados da pesquisa. 


\begin{tabular}{|c|c|c|c|c|}
\hline Setores de Săo Paulo & \multicolumn{4}{|c|}{ Distribuição percentual dos efeitos } \\
\hline em ordem decrescente (SP) & $\mathrm{SP}$ & MG & RB & tal \\
\hline S.I.U.P. & 82,56 & 2,27 & 15,17 & 100,00 \\
\hline ALUGUEL DE IMÓVEIS & 82,35 & 2,10 & 15,55 & 100,00 \\
\hline EQUIP. ELETRONICOS & 82,25 & 3,59 & 14,16 & 100,00 \\
\hline COMUNICAÇŌES & 81,61 & 2,44 & 15,95 & 100,00 \\
\hline PETRÓLEO E GÁS & 81,21 & 3,32 & 15,47 & 100,00 \\
\hline FABRICAÇĀO DE AÇÚCAR & 81,12 & 2,81 & 16,07 & 100,00 \\
\hline INSTITUIÇÕES FINANCEIRAS & 80,98 & 2,31 & 16,70 & 100,00 \\
\hline ARTIGOS DO VESTUÁRIO & 80,98 & 2,10 & 16,92 & 100,00 \\
\hline SERV. PREST. À EMPRESA & 80,95 & 2,32 & 16,73 & 100,00 \\
\hline AUTOM./CAM/ONIBUS & 80,85 & 6,08 & 13,06 & 100,00 \\
\hline CELULOSE, PAPEL E GRÁF. & 80,27 & 2,48 & 17,25 & 100,00 \\
\hline CONSTRUÇÃO CIVIL & 80,10 & 3,64 & 16,26 & 100,00 \\
\hline METALURG. Ñ FERROSOS & 79,88 & 5,01 & 15,11 & 100,00 \\
\hline MATERIAL ELÉTRICO & 79,68 & 5,85 & 14,46 & 100,00 \\
\hline ADMINISTRAÇĀO PÜBLICA & 78,83 & 2,57 & 18,60 & 100,00 \\
\hline PECAS E OUT. VEÍCULOS & 78,67 & 7,59 & 13,74 & 100,00 \\
\hline SERV. PREST. À FAMÍLIA & 78,59 & 2,69 & 18,72 & 100,00 \\
\hline INDÚSTRIAS DIVERSAS & 78,35 & 4,10 & 17,55 & 100,00 \\
\hline ELEMENTOS QUIMICO & 78,26 & 3,24 & 18,50 & 100,00 \\
\hline MÁQUINAS E EQUIP. & 77,95 & 7,16 & 14,89 & 100,00 \\
\hline SERV. PRIV. Ñ MERCANTIS & 77,49 & 2,69 & 19,82 & 100,00 \\
\hline FABRICAÇÃO CALÇADOS & 77,24 & 2,49 & 20,26 & 100,00 \\
\hline IND. DA BORRACHA & 77,11 & 2,77 & 20,12 & 100,00 \\
\hline ARTIGOS PLÁSTICOS & 77,07 & 3,14 & 19,78 & 100,00 \\
\hline IND. TÉXTIL & 76,22 & 2,37 & 21,41 & 100,00 \\
\hline COMÉRCIO & 76,03 & 2,31 & 21,66 & 100,00 \\
\hline FARMAC. E VETERINÁRIA & 75,92 & 2,54 & 21,54 & 100,00 \\
\hline MINERAL Ñ METÁLICO & 75,58 & 5,14 & 19,29 & 100,00 \\
\hline TRANSPORTES & 75,21 & 2,79 & 22,00 & 100,00 \\
\hline AGROPECUÁRIA & 73,81 & 3,62 & 22,57 & 100,00 \\
\hline QUÍMICOS DIVERSOS & 73,74 & 3,58 & 22,68 & 100,00 \\
\hline EXTRAT. MINERAL & 73,28 & 5,96 & 20,76 & 100,00 \\
\hline INDÚSTRIA DE LATICINIOS & 70,99 & 15,44 & 13,57 & 100,00 \\
\hline MADEIRA E MOBILIÁRIO & 70,63 & 3,3 & 26,04 & 100,00 \\
\hline OUTROS METALÚRGICOS & 69,72 & 16,66 & 13,63 & 100,00 \\
\hline OUTROS PROD. ALIMENT. & 67,02 & 3,03 & 29,95 & 100,00 \\
\hline ABATE DE ANIMAIS & 65,71 & 3,84 & 30,46 & 100,00 \\
\hline REFINO DO PETRÓLEO & 62,17 & 6,65 & 31,17 & 100,00 \\
\hline BENEF. PROD. VEGETAIS & 60,84 & 3,72 & 35,44 & 100,00 \\
\hline INDUUSTRIA DO CAFE & 59,81 & 14,55 & 25,64 & 100,00 \\
\hline SIDERURGIA & 57,39 & 29,15 & 13,47 & 100,00 \\
\hline FAB. ÓLEOS VEGETAIS & 55,11 & 3,56 & 41,33 & 100,00 \\
\hline
\end{tabular}

Quadro 16. Distribuição regional dos multiplicadores de produção para os setores de São Paulo .

Fonte: resultados da pesquisa. 


\begin{tabular}{|c|c|c|c|c|}
\hline Setores de Minas demandados & Distribuiçãa & centual & efeitos & \\
\hline em ordem decrescente (MG) & SP & & & tal \\
\hline INDÚSTRIA DO CAFÉ & 10,41 & 84,16 & 5,43 & 100,00 \\
\hline FAB. ÓLEOS VEGETAIS & 10,59 & 83,37 & 6,03 & 100,00 \\
\hline SIDERURGIA & 10,84 & 83,26 & 5,90 & 100,00 \\
\hline INDÜSTRIA DE LATICINIOS & 11,33 & 83,03 & 5,65 & 100,00 \\
\hline ABATE DE ANIMAIS & 11,39 & 82,80 & 5,80 & 100,00 \\
\hline BENEF. PROD. VEGETAIS & 11,91 & 82,12 & 5,98 & 100,00 \\
\hline OUTROS METALÚRGICOS & 12,12 & 81,63 & 6,26 & 100,00 \\
\hline METALURG. N FERROSOS & 12,17 & 81,55 & 6,29 & 100,00 \\
\hline ALUGUEL DE IMÓVEIS & 11,56 & 81,44 & 7,00 & 100,00 \\
\hline OUTROS PROD. ALIMENT. & 12,64 & 81,10 & 6,26 & 100,00 \\
\hline ELEMENTOS QUIMICOS & 12,31 & 80,94 & 6,75 & 100,00 \\
\hline FABRICAÇÃO DE AÇÚCAR & 12,72 & 80,81 & 6,47 & 100,00 \\
\hline S.I.U.P. & 12,82 & 80,72 & 6,46 & 100,00 \\
\hline PEÇAS E OUT. VEICULOS & 13,11 & 80,56 & 6,33 & 100,00 \\
\hline AGROPECUARIA & 12,84 & 80,40 & 6,77 & 100,00 \\
\hline MINERAL Ñ METÁLICO & 13,09 & 79,57 & 7,34 & 100,00 \\
\hline SERV. PREST. À FAMILIA & 13,85 & 79,21 & 6,94 & 100,00 \\
\hline MÁQUINAS E EQUIP. & 14,18 & 79,11 & 6,71 & 100,00 \\
\hline AUTOM./CAM/ONIBUS & 14,64 & 78,92 & 6,44 & 100,00 \\
\hline CONSTRUÇÃO CIVIL & 13,39 & 78,84 & 7,76 & 100,00 \\
\hline PETRÓLEO E GÁS & 14,24 & 78,76 & 7,00 & 100,00 \\
\hline REFINO DO PETRÓLEO & 11,39 & 78,69 & 9,92 & 100,00 \\
\hline COMUNICAÇŌES & 14,48 & 78,55 & 6,97 & 100,00 \\
\hline EXTRAT. MINERAL & 14,29 & 77,99 & 7,72 & 100,00 \\
\hline SERV. PRIV. Ñ MERCANTIS & 14,66 & 77,61 & 7,73 & 100,00 \\
\hline FARMAC. E VETERINÁRIA & 15,05 & 77,45 & 7,50 & 100,00 \\
\hline ADMINISTRAÇÃO PÚBLICA & 15,07 & 77,04 & 7,89 & 100,00 \\
\hline MADEIRA E MOBILIÁRIO & 14,23 & 76,81 & 8,96 & 100,00 \\
\hline COMERCIO & 14,21 & 76,67 & 9,12 & 100,00 \\
\hline TRANSPORTES & 14,43 & 76,57 & 9,00 & 100,00 \\
\hline INSTITUIÇŌES FINANCEIRAS & 16,13 & 76,29 & 7,59 & 100,00 \\
\hline SERV. PREST. À EMPRESA & 16,57 & 75,62 & 7,80 & 100,00 \\
\hline EQUIP. ELETRÔNICOS & 17,42 & 75,59 & 6,99 & 100,00 \\
\hline QUIMICOS DIVERSOS & 15,68 & 75,27 & 9,05 & 100,00 \\
\hline INDÚSTRIAS DIVERSAS & 16,58 & 75,26 & 8,16 & 100,00 \\
\hline MATERIAL ELÉTRICO & 18,44 & 74,36 & 7,19 & 100,00 \\
\hline ARTIGOS PLÁSTICOS & 18,04 & 72,57 & 9,38 & 100,00 \\
\hline IND. TEXXTIL & 15,65 & 68,55 & 15,80 & 100,00 \\
\hline CELULOSE, PAPEL E GRÁF. & 23,06 & 68,24 & 8,70 & 100,00 \\
\hline ARTIGOS DO VESTUÁRIO & 22,98 & 65,59 & 11,43 & 100,00 \\
\hline FABRICAÇÃO CALÇADOS & 25,41 & 65,25 & 9,34 & 100,00 \\
\hline IND. DA BORRACHA & 26,24 & 63,44 & 10,32 & 100,00 \\
\hline
\end{tabular}

Quadro 17. Distribuição regional dos multiplicadores de produção para os setores de Minas Gerais.

Fonte: resultados da pesquisa. 


\begin{tabular}{|c|c|c|c|c|}
\hline Setores do Resto do Brasil & Distribuiçă & o percentua & dos efeitos & \\
\hline em ordem decrescente (RB) & SP & MG & RB & otal \\
\hline FAB. ÓLEOS VEGETAIS & 11,89 & 2,19 & 85,92 & 100,00 \\
\hline ABATE DE ANIMAIS & 12,68 & 2,21 & 85,11 & 100,00 \\
\hline ALUGUEL DE IMÓVEIS & 12,92 & 2,01 & 85,07 & 100,00 \\
\hline REFINO DO PETRÓLEO & 13,42 & 2,10 & 84,48 & 100,00 \\
\hline BENEF. PROD. VEGETAIS & 13,76 & 2,33 & 83,91 & 100,00 \\
\hline IND. TEXTIL & 14,92 & 2,14 & 82,94 & 100,00 \\
\hline AGROPECUÁRIA & 14,41 & 2,86 & 82,73 & 100,00 \\
\hline MADEIRA E MOBILIÁRIO & 14,78 & 2,59 & 82,63 & 100,00 \\
\hline COMERCIO & 15,46 & 2,16 & 82,38 & 100,00 \\
\hline COMUNICAÇŌES & 15,62 & 2,29 & 82,09 & 100,00 \\
\hline CONSTRUÇÃO CIVIL & 15,20 & 2,93 & 81,87 & 100,00 \\
\hline INSTITUIÇŐ́ES FINANCEIRAS & 16,00 & 2,21 & 81,80 & 100,00 \\
\hline TRANSPORTES & 15,81 & 2,69 & 81,51 & 100,00 \\
\hline ARTIGOS DO VESTUÁRIO & 16,77 & 1,95 & 81,28 & 100,00 \\
\hline OUTROS PROD. ALIMENT. & 16,49 & 2,34 & 81,17 & 100,00 \\
\hline SERV. PREST. À FAMÍLIA & 16,19 & 2,72 & 81,09 & 100,00 \\
\hline MINERAL Ñ METÁLICO & 15,76 & 3,24 & 81,01 & 100,00 \\
\hline METALURG. Ñ FERROSOS & 15,95 & 3,07 & 80,98 & 100,00 \\
\hline SERV. PRIV. Ñ MERCANTIS & 16,61 & 2,57 & 80,82 & 100,00 \\
\hline PETRÓLEO E GÁS & 16,29 & 2,96 & 80,75 & 100,00 \\
\hline ADMINISTRAÇĀO PÚBLICA & 16,90 & 2,54 & 80,56 & 100,00 \\
\hline FARMAC. E VETERINÁRIA & 17,55 & 2,15 & 80,30 & 100,00 \\
\hline EXTRAT. MINERAL & 16,78 & 2,95 & 80,28 & 100,00 \\
\hline SIDERURGIA & 13,25 & 6,68 & 80,07 & 100,00 \\
\hline INDÚSTRIAS DIVERSAS & 17,49 & 2,56 & 79,95 & 100,00 \\
\hline QUIMICOS DIVERSOS & 18,15 & 2,23 & 79,62 & 100,00 \\
\hline IND. DA BORRACHA & 18,22 & 2,17 & 79,60 & 100,00 \\
\hline FABRICAÇÃO CALÇADOS & 18,41 & 2,14 & 79,45 & 100,00 \\
\hline S.I.U.P. & 16,13 & 4,54 & 79,32 & 100,00 \\
\hline EQUIP. ELETRÓNICOS & 18,08 & 2,89 & 79,03 & 100,00 \\
\hline SERV. PREST. À EMPRESA & 19,02 & 2,21 & 78,77 & 100,00 \\
\hline ARTIGOS PLÁSTICOS & 19,14 & 2,42 & 78,44 & 100,00 \\
\hline MÁQUINAS E EQUIP. & 17,10 & 5,00 & 77,89 & 100,00 \\
\hline OUTROS METALÚRGICOS & 14,88 & 8,72 & 76,40 & 100,00 \\
\hline ELEMENTOS QUIMICOS & 23,36 & 3,17 & 73,47 & 100,00 \\
\hline MATERIAL ELÉTRICO & 22,36 & 4,21 & 73,43 & 100,00 \\
\hline PEÇAS E OUT. VEICULOS & 20,60 & 6,74 & 72,66 & 100,00 \\
\hline AUTOM./CAM/ONIBUS & 21,32 & 6,88 & 71,80 & 100,00 \\
\hline INDÚSTRIA DE LATICÍNIOS & 22,01 & 7,48 & 70,51 & 100,00 \\
\hline INDÚSTRIA DO CAFE & 11,15 & 19,49 & 69,37 & 100,00 \\
\hline CELULOSE, PAPEL E GRÁF. & 28,56 & 2,34 & 69,10 & 100,00 \\
\hline FABRICAÇÃ̃O DE AÇÜCAR & 30,06 & 3,18 & 66,76 & 100,00 \\
\hline
\end{tabular}

Quadro 18. Distribuição regional dos multiplicadores de produção para os setores do Resto do Brasil.

Fonte: resultados da pesquisa. 
Os quadros 16 e 17 - distribuição regional dos multiplicadores para São Paulo e Minas Gerais - mostram um grau de encadeamento interno dos setores Siderurgia (5), Indústria do café (24) e Fabricação de óleos vegetais oposto para as duas regiões: enquanto em Minas, esses setores lideram o ranking, em São Paulo, eles ocupam as três últimas posições.

A Indústria do café (24) tem, em geral, um expressivo multiplicador. Além disso, como é visto no quadro 17, é o setor de Minas que mais concentra seus efeitos na própria região. Portanto, não há dúvida quanto a importância deste setor para a economia mineira, mesmo sem levar em conta o volume da produção, considerando apenas os encadeamentos de propagação existentes na economia, como é definido o conceito de multiplicador.

Por outro lado, se a demanda deste setor se mudar para outra região, Minas não perde tanto como se poderia supor, justamente porque os efeitos da Indústria de Café (24) nas outras regiões têm um forte reflexo na economia de Minas Gerais.

Um outro setor de especial importância é o de Fabricação de óleos vegetais (28). Sua importância está concentrada nas regiões Resto do Brasil e Minas e sua relevância é clara em todos os aspectos aqui analisados: concentra seus efeitos, tem um grande multiplicador e uma mudança geográfica de demanda impacta fortemente a economia dessas regiões.

No caso dos setores de serviços, se eles apresentam baixos multiplicadores absolutos, são eles também que tem o maior poder de concentração dos seus efeitos na própria região.

Tanto na concentração dos efeitos como também nos valores absolutos do multiplicador, os setores de bens de consumo duráveis como Equipamentos eletrônicos (10), Automóveis, caminhões e ônibus (11) e Peças e outros veículos (12) estão em posições de maior destaque no ranking de São Paulo do que nos das outras duas regiões. 
De um modo geral e ao contrário dos setores de bens duráveis, as indústrias ligadas à agropecuária têm maior destaque em Minas e Resto do Brasil do que em São Paulo.

Finalmente, a Agropecuária (1) concentra mais seus efeitos quando a variação de demanda ocorre no Resto do Brasil e menos se isto ocorre no Estado de São Paulo.

Os quadros 19, 20 e 21 tratam da geração de empregos. Os valores representam o número de empregos gerados através de um aumento de demanda em um milhão de reais. 


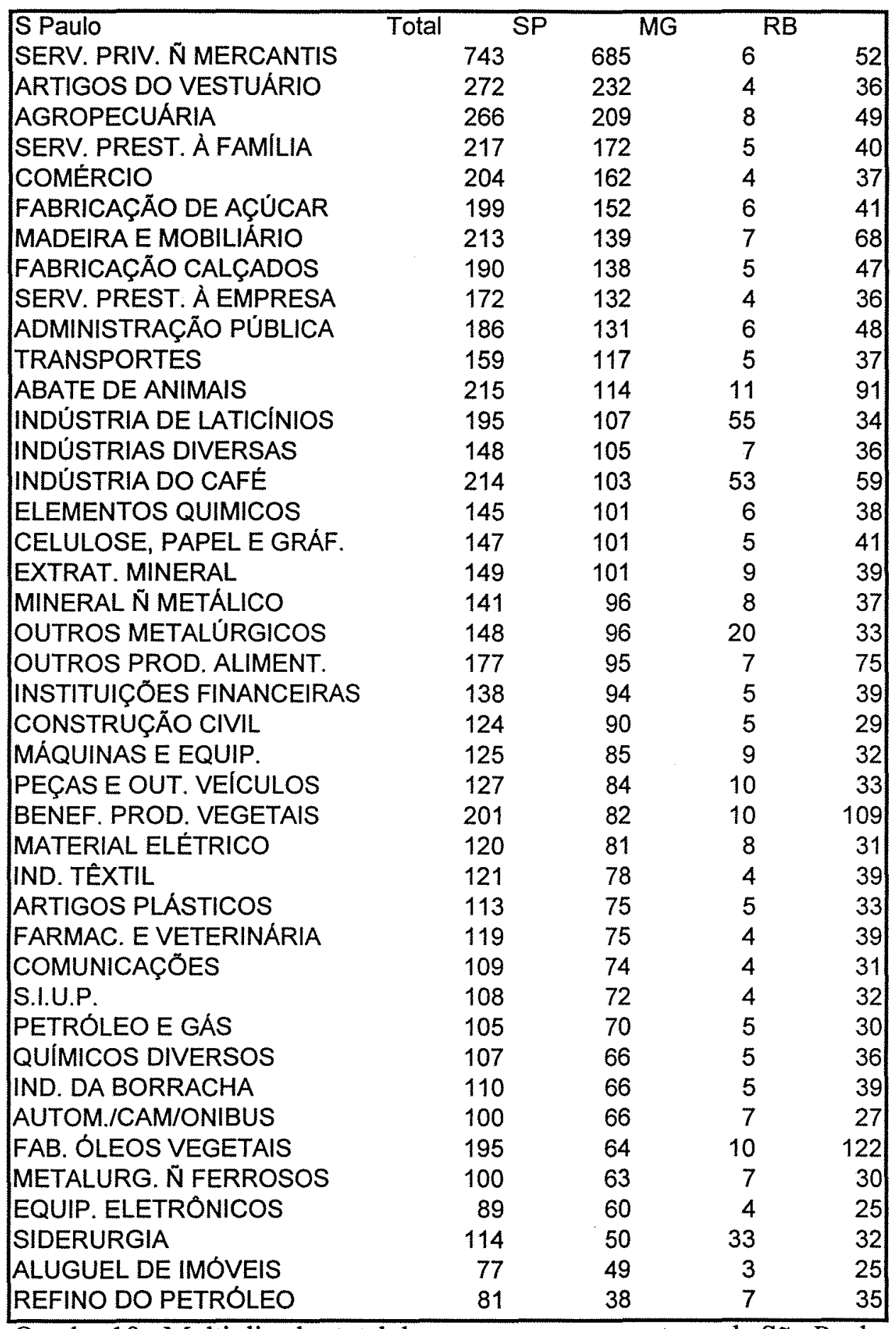

Quadro 19. Multiplicador total de emprego para os setores de São Paulo.

Fonte: resultados da pesquisa. 


\begin{tabular}{|c|c|c|c|c|}
\hline Minas Gerais & Total & MG & RB & \\
\hline SERV. PRIV. Ñ MERCANTIS & 744 & 21 & 705 & 18 \\
\hline AGROPECUÁRIA & 267 & 14 & 241 & 12 \\
\hline ARTIGOS DO VESTUÁRIO & 273 & 28 & 225 & 21 \\
\hline SERV. PREST. À FAMILIA & 218 & 16 & 189 & 13 \\
\hline ABATE DE ANIMAIS & 216 & 16 & 188 & 12 \\
\hline INDÚSTRIA DO CAFÉ & 214 & 15 & 188 & 12 \\
\hline MADEIRA E MOBILIÁRIO & 214 & 18 & 177 & 19 \\
\hline BENEF. PROD. VEGETAIS & 202 & 16 & 174 & 12 \\
\hline COMÉRCIO & 204 & 17 & 171 & 15 \\
\hline INDÜSTRIA DE LATICINNIOS & 196 & 16 & 168 & 12 \\
\hline FABRICAÇÃO DE AÇÚCAR & 200 & 18 & 168 & 14 \\
\hline FAB. OLEOS VEGETAIS & 196 & 15 & 168 & 13 \\
\hline ADMINISTRAÇÃO PÚBLICA & 186 & 21 & 147 & 18 \\
\hline OUTROS PROD. ALIMENT. & 177 & 17 & 147 & 13 \\
\hline SERV. PREST. À EMPRESA & 173 & 19 & 139 & 15 \\
\hline FABRICAÇÃO CALÇADOS & 190 & 36 & 135 & 20 \\
\hline TRANSPORTES & 160 & 17 & 127 & 15 \\
\hline ELEMENTOS QUIMICOS & 145 & 15 & 118 & 13 \\
\hline OUTROS METALÚRGICOS & 148 & 17 & 117 & 14 \\
\hline EXTRAT. MINERAL & 150 & 19 & 116 & 15 \\
\hline INDÚSTRIAS DIVERSAS & 149 & 21 & 112 & 16 \\
\hline MINERAL Ñ METÁLICO & 142 & 17 & 111 & 14 \\
\hline INSTITUIÇŌES FINANCEIRAS & 138 & 20 & 102 & 16 \\
\hline CELULOSE, PAPEL E GRÁF. & 149 & 31 & 99 & 19 \\
\hline CONSTRUÇÃO CIVIL & 124 & 14 & 98 & 13 \\
\hline PECAS E OUT. VEICULOS & 128 & 18 & 96 & 14 \\
\hline MÁQUINAS E EQUIP. & 125 & 17 & 95 & 13 \\
\hline FARMAC. E VETERINÁRIA & 119 & 17 & 89 & 13 \\
\hline SIDERURGIA & 114 & 15 & 87 & 13 \\
\hline MATERIAL ELÉTRICO & 121 & 23 & 83 & 15 \\
\hline COMUNICAÇÕES & 110 & 15 & 82 & 12 \\
\hline S.I.U.P. & 109 & 15 & 81 & 12 \\
\hline IND. TEXXTIL & 122 & 18 & 80 & 23 \\
\hline ARTIGOS PLÁSTICOS & 113 & 19 & 79 & 15 \\
\hline PETRÓLEO E GÁS & 106 & 16 & 77 & 13 \\
\hline QUIMICOS DIVERSOS & 107 & 18 & 75 & 14 \\
\hline METALURG. Ñ FERROSOS & 100 & 15 & 73 & 12 \\
\hline AUTOM./CAM/ONIBUS & 100 & 17 & 71 & 12 \\
\hline IND. DA BORRACHA & 110 & 26 & 66 & 18 \\
\hline EQUIP. ELETRÓNICOS & 90 & 16 & 62 & 11 \\
\hline ALUGUEL DE IMÓVEIS & 77 & 10 & 57 & 10 \\
\hline REFINO DO PETRÓLEO & 81 & 12 & 56 & 13 \\
\hline
\end{tabular}

Quadro 20. Multiplicador total de empregos para os setores de Minas Gerais.

Fonte: resultados da pesquisa. 


\begin{tabular}{|c|c|c|c|c|}
\hline Resto do Brasil & Total & $\overline{M G}$ & $\mathrm{RB}$ & \\
\hline SERV. PRIV. Ñ MERCANTIS & 744 & 22 & 5 & 718 \\
\hline ARTIGOS DO VESTUÁRIO & 273 & 20 & 3 & 250 \\
\hline AGROPECUÁRIA & 267 & 16 & 6 & 246 \\
\hline SERV. PREST. À FAMÍLIA & 219 & 18 & 4 & 196 \\
\hline ABATE DE ANIMAIS & 216 & 17 & 5 & 194 \\
\hline MADEIRA E MOBILIÁRIO & 214 & 18 & 4 & 191 \\
\hline COMÉRCIO & 205 & 18 & 3 & 183 \\
\hline BENEF. PROD. VEGETAIS & 202 & 18 & 5 & 179 \\
\hline FAB. ÓLEOS VEGETAIS & 196 & 17 & 5 & 175 \\
\hline FABRICAÇÃO CALÇADOS & 191 & 23 & 4 & 163 \\
\hline ADMINISTRAÇÄO PÚBLICA & 187 & 22 & 5 & 160 \\
\hline OUTROS PROD. ALIMENT. & 178 & 24 & 5 & 150 \\
\hline SERV. PREST. À EMPRESA & 174 & 21 & 3 & 149 \\
\hline INDÚSTRIA DE LATICINIOS & 196 & 32 & 25 & 140 \\
\hline TRANSPORTES & 160 & 18 & 4 & 138 \\
\hline INDÜSTRIA DO CAFÉ & 214 & 16 & 72 & 127 \\
\hline EXTRAT. MINERAL & 150 & 21 & 4 & 125 \\
\hline INDÜSTRIAS DIVERSAS & 149 & 21 & 4 & 125 \\
\hline FABRICAÇÃO DE AÇÜCAR & 201 & 70 & 8 & 123 \\
\hline OUTROS METALÚRGICOS & 149 & 20 & 11 & 118 \\
\hline MINERAL Ñ METÁLICO & 142 & 19 & 5 & 118 \\
\hline INSTITUIÇÕES FINANCEIRAS & 139 & 19 & 4 & 116 \\
\hline CELULOSE, PAPEL E GRÁF. & 149 & 37 & 4 & 108 \\
\hline CONSTRUÇÃO CIVIL & 125 & 15 & 4 & 106 \\
\hline IND. TEXXTIL & 122 & 17 & 4 & 101 \\
\hline MÁQUINAS E EQUIP. & 126 & 19 & 6 & 101 \\
\hline ELEMENTOS QUIMICOS & 146 & 43 & 6 & 96 \\
\hline FARMAC. E VETERINÁRIA & 119 & 20 & 3 & 96 \\
\hline PEÇAS E OUT. VEICULOS & 128 & 26 & 9 & 94 \\
\hline COMUNICAÇŌES & 110 & 15 & 3 & 92 \\
\hline ARTIGOS PLÁSTICOS & 114 & 20 & 4 & 91 \\
\hline MATERIAL ELÉTRICO & 121 & 26 & 6 & 89 \\
\hline SIDERURGIA & 115 & 18 & 8 & 89 \\
\hline IND. DA BORRACHA & 110 & 19 & 3 & 88 \\
\hline S.I.U.P. & 109 & 17 & 6 & 86 \\
\hline PETRÓLEO E GÁS & 106 & 17 & 4 & 85 \\
\hline QUIMICOS DIVERSOS & 107 & 21 & 3 & 82 \\
\hline METALURG. Ñ FERROSOS & 100 & 19 & 4 & 77 \\
\hline EQUIP. ELETRÓNICOS & 90 & 16 & 3 & 71 \\
\hline AUTOM./CAM/ONIBUS & 101 & 23 & 8 & 70 \\
\hline ALUGUEL DE IMÓVEIS & 78 & 11 & 2 & 65 \\
\hline REFINO DO PETROLLEO & 81 & 14 & 3 & 64 \\
\hline
\end{tabular}

Quadro 21. Multiplicador total de empregos dos setores do Resto do Brasil.

Fonte: resultados da pesquisa. 
Percebe-se facilmente que Serviços não mercantis (42) lidera a geração de empregos nas três regiões de estudo. Esta homogeneidade é mantida até a quarta posição. Em todas as regiões, o conjunto dos quatro setores mais geradores de empregos coincide. São eles: Serviços privados não mercantis (42), Agropecuária (1), Artigos de vestuário (22) e Serviços prestados a família (38).

Como o fato gerador de emprego é um aumento de demanda, entre os setores de menores multiplicadores de emprego, há uma predominância daqueles caracterizados por serem de capital intensivo, como Refino de petróleo (17), Metalurgia não ferrosos (6) e Equipamento eletrônico (10).

Setores como Siderurgia (5) e Outros metalúrgicos (7) também ocupam posições modestas na lista dos setores com maior potencial de geração de empregos, apesar dos expressivos multiplicadores de produção. Um setor com alto multiplicador de produção nem sempre tem um alto multiplicador de emprego. Acontece o contrário com setores de serviço. Pode-se empregar um raciocínio simplificado para entender esta tendência: grandes demandantes de trabalho geram empregos, mas possuem pequenos coeficientes técnicos inter-setorial. Em outras palavras, se demandam muito trabalho, têm a tendência de demandar diretamente pouca produção. Um exemplo deste caso é o setor de serviços da economia.

De certa forma, refletindo a importância já verificada do setor da Indústria de café (24) em Minas, uma variação de demanda deste setor em São Paulo ou Resto do Brasil tem impactos expressivos em Minas Gerais.

O quadro 22 traz o multiplicador de renda para a variação de um real, não mais na demanda final, mas na renda das famílias. A pergunta neste caso é para cada um real de aumento na renda de determinado setor quanto aumenta a renda de toda a economia. 


\begin{tabular}{|c|c|c|c|}
\hline Setores & \multicolumn{3}{|l|}{ Regiōes } \\
\hline AGROPECUARIA & 3,06 & 3,06 & 3,07 \\
\hline EXTRAT. MINERAL & 4,54 & 4,55 & 4,57 \\
\hline PETRÓLEO E GÁS & 3,19 & 3,21 & 3,22 \\
\hline MINERAL Ñ METÁLICO & 4,34 & 4,36 & 4,37 \\
\hline SIDERURGIA & 8,41 & 8,41 & 8,44 \\
\hline METALURG. Ñ FERROSOS & 6,35 & 6,36 & 6,37 \\
\hline OUTROS METALÚRGICOS & 4,09 & 4,09 & 4,11 \\
\hline MÅQUINAS E EQUIP. & 3,08 & 3,09 & 3,10 \\
\hline MATERIAL ELÉTRICO & 5,34 & 5,36 & 5,38 \\
\hline EQUIP. ELETRÓNICOS & 3,66 & 3,67 & 3,68 \\
\hline AUTOM./CAM/ONIBUS & 6,00 & 6,02 & 6,04 \\
\hline PEÇAS E OUT. VEICULOS & 4,93 & 4,93 & 4,96 \\
\hline MADEIRA E MOBILIÁRIO & 4,23 & 4,24 & 4,25 \\
\hline CELULOSE, PAPEL E GRÁF. & 5,20 & 5,28 & 5,33 \\
\hline IND. DA BORRACHA & 4,98 & 4,98 & 5,00 \\
\hline ELEMENTOS QUIMICOS & 4,85 & 4,86 & 4,86 \\
\hline REFINO DO PETRÓLEO & 4,84 & 4,83 & 4,84 \\
\hline QUÍMICOS DIVERSOS & 4,78 & 4,79 & 4,80 \\
\hline FARMAC. E VETERINÁRIA & 3,64 & 3,66 & 3,67 \\
\hline ARTIGOS PLÁSTICOS & 3,65 & 3,65 & 3,66 \\
\hline IND. TEXXTIL & 5,65 & 5,66 & 5,68 \\
\hline ARTIGOS DO VESTUÁRIO & 4,18 & 4,19 & 4,20 \\
\hline FABRICAÇÃO CALÇADOS & 4,40 & 4,41 & 4,43 \\
\hline INDÚSTRIA DO CAFÉ & 8,61 & 8,63 & 8,65 \\
\hline BENEF. PROD. VEGETAIS & 7,64 & 7,64 & 7,67 \\
\hline ABATE DE ANIMAIS & 8,71 & 8,72 & 8,75 \\
\hline INDÚSTRIA DE LATICÍNIOS & 8,63 & 8,65 & 8,67 \\
\hline FABRICAÇÃO DE AÇÚCAR & 9,08 & 9,11 & 9,12 \\
\hline FAB. OLEOS VEGETAIS & 14,94 & 14,94 & 15,00 \\
\hline OUTROS PROD. ALIMENT. & 5,85 & 5,87 & 5,89 \\
\hline INDÚSTRIAS DIVERSAS & 3,88 & 3,90 & 3,92 \\
\hline S.I.U.P. & 2,99 & 3,00 & 3,01 \\
\hline CONSTRUÇÃO CIVIL & 3,05 & 3,06 & 3,07 \\
\hline COMÉRCIO & 3,00 & 3,01 & 3,02 \\
\hline TRANSPORTES & 3,22 & 3,23 & 3,24 \\
\hline COMUNICAÇǑES & 2,32 & 2,33 & 2,33 \\
\hline INSTITUIÇÕES FINANCEIRAS & 2,57 & 2,58 & 2,59 \\
\hline SERV. PREST. A FAMÍLIA & 2,74 & 2,74 & 2,75 \\
\hline SERV. PREST. À EMPRESA & 2,50 & 2,51 & 2,52 \\
\hline ALUGUEL DE IMÓVEIS & 2,03 & 2,03 & 2,04 \\
\hline ADMINISTRAÇĀO PÚBLICA & 2,37 & 2,38 & 2,38 \\
\hline SERV. PRIV. Ñ MERCANTIS & 2,02 & 2,02 & 2,03 \\
\hline
\end{tabular}

Quadro 22. Multiplicador de renda para uma variação inicial de um real na renda dos setores.

Fonte: resultados da pesquisa. 
Os cinco primeiros setores com maior potencial de multiplicação de renda são da indústria de alimentos: Fabricação de óleos vegetais (29), Fabricação de açúcar (28), Abate de animais (26), Indústria de laticínios (27) e Indústria do café (24).

Os dez setores que apresentam os menores índices são ligados aos serviços. Este resultado se justifica pelo fato desses setores serem intensivos em mão-de-obra e, por isso, o aumento de uma unidade monetária na renda do setor corresponde a um aumento menor de produção se comparado a setores intensivos em capital. Neste último caso, a necessidade de insumo dos setores industrias impactam mais fortemente na economia.

Finalmente, os valores para os mesmos setores das três regiões têm índices muito próximos em função da hipótese assumida de mesma tecnologia. Sendo assim, a análise aqui deve estar concentrada na comparação entre os setores e não entre as regiões. 


\section{APLICAÇÃO PARA A GUERRA FISCAL}

"Neste mundo não há nada certo, exceto a morte e os impostos"

Benjamin Franklin

\subsection{Considerações Iniciais e Aspectos Legais}

Nos primeiros anos da década de 90, uma nova modalidade competitiva ganhou importância no debate econômico nacional: a guerra fiscal entre os estados da federação. Nesta guerra, as armas de combate são, basicamente, as isenções fiscais e o objetivo é a atração de novos investimentos ao estado.

Embora o acirramento da disputa tenha ocorrido a partir de 1993, alterações no sistema tributário brasileiro implantadas nos dez anos precedentes viriam a se constituir em condições essenciais para as unidades federativas se lançarem na guerra fiscal.

Durante a década de 80 , os estados passaram a ter uma maior participação na arrecadação tributária da União, através do aumento do Fundo de Participação dos Estados (FPE) Esta alteração diminuiu, relativamente, a importância da arrecadação do ICMS (Imposto sobre Circulação de Mercadorias e Serviços), mesmo tendo permanecido como a principal fonte de receita dos governos estaduais. Além disso, a Constituição de 88 delegou maior autonomia aos estados na gestão de seus recursos (Piancastelli e Perobelli, 1996). Estas alterações incentivaram a disseminação da prática e colocaram os estados em disputa pelos investimentos. 
Nem mesmo uma lei complementar de 1975 consegue deter este processo. Como lembra Varsano (1997), "a guerra fiscal se trava à revelia da Lei Complementar $\mathrm{n}^{\circ}$ 24/75, que veda as concessões de isenções e outros incentivos relacionados ao ICMS, salvo quando previstas em convênios celebrados em reuniões do Conselho de Política Fazendária (Confaz) que congrega todos os estados e o Distrito Federal. A lei determina que a aprovação da concessão de um benefício dependa de decisão unânime dos estados representados".

O Confaz, criado em 1975 pela lei citada, funcionou eficientemente nesta questão até o final do regime militar, quando se iniciou uma proliferação da prática de isenções e incentivos por parte dos estados (Cavalcanti e Prado, 1998). Mas os autores ressalvam que, mesmo durante o período ativo do conselho, os governos estaduais lançavam programas à margem da lei.

Em 1996, a Lei Complementar n87/96 tinha, originalmente, dispositivos legais que procuravam reforçar a proibição à guerra fiscal, mas um acordo entre o executivo e o legislativo, este último defendendo os interesses dos governos dos seus respectivos estados, resultou no veto dos dispositivos que tratavam do assunto por parte do Presidente da República (Varsano, 1996).

Os governadores não se mostraram dispostos a obedecer a uma lei federal e qualquer esforço em restringir as isenções não encontraram, na década de 90, apoio na maior parte dos representantes do legislativo federal. Com isso, o Brasil tem assistido há alguns anos um jogo que poucos podem antecipar o desfecho e nem mesmo avaliar com precisão benefícios e malefícios a curto e longo prazo.

Em 2000, o governo federal propõe a Lei de Responsabilidade Fiscal (LRF) no intuito, dentre outros, de inibir a prática da guerra fiscal e obrigar os gestores públicos a uma disciplina de gastos mais rigorosa. A LRF, aprovada pelo legislativo no mesmo ano, estabelece, em seu artigo 14, algumas condições de implicação direta à prática de utilização da isenção físcal e/ou incentivos à atração de novas empresas. 
"Art.14 A concessão ou ampliação de incentivo ou beneficio de natureza tributária da qual decorra renúncia de receita deverá estar acompanhada da estimativa do impacto orçamentário-financeiro no exercício em que deva se iniciar sua vigência e nos dois seguintes, atender ao dispositivo na lei de diretrizes orçamentárias e a pelo menos uma das seguintes condições:

$I$ - Demonstração pelo proponente que a renúncia foi considerada na estimativa de receita da lei orçamentária, na forma do artigo 12, e de que não afetará as metas de resultados fiscais previstas no anexo próprio da lei de diretrizes orçamentárias

II - estar acompanhada de medidas de compensação, no período mencionado no caput, por meio do aumento de receita, proveniente da elevação de alíquotas, ampliação da base de cálculo, majoração ou criação de tributo ou contribuição".

(Ministério de Planejamento, Orçamento e Gestão, 2001)

Esta nova tentativa do governo central tem enfrentado resistência por partes de alguns governadores e muitos prefeitos recém empossados. De qualquer forma, a LRF representa uma tentativa de impedir políticas agressivas de renúncia fiscal em favor da atração de novos investimentos privados e, caso seja respeitada, pode iniciar um novo capitulo na história da guerra fiscal brasileira. 


\subsection{Histórico}

Durante as últimas décadas, a carga tributária global brasileira em relação ao PIB saltou de 13,84 em 1947 para aproximadamente $30 \%$ no final dos anos $90^{5}$ (Varsano et al, 1998). Não é por outra razão que os impostos têm disputado com as altas taxas de juros o papel de principal vilão da economia brasileira na visão dos empresários.

Não existe um critério simples que possa ser usado para determinar se a carga tributária brasileira é alta. Encontram-se no mundo exemplos de países desenvolvidos e com qualidade de vida superior à brasileira que apresentam tributação maior e menor que a do Brasil. Noruega, Dinamarca, Suécia, Áustria, Holanda são países com o total de tributos próximo a 50\% do PIB (Varsano et al, 1998). Por outro lado, no Japão e nos EUA os tributos variam entre 27 e 29\%. (Coordenação Geral de Estudos Econômicos e Tributários da Receita Federal citado por Cavalcanti, 2000).

Alto ou baixo, a questão é que os impostos têm ganhado importância na contabilidade das empresas e na luta por menores custos. Essa luta nem sempre é decidida no campo legal: em estudo divulgado em 1998, a Secretaria da Receita Federal estimava em $41,8 \%$ a parcela da renda tributável que não pagava imposto de renda ( Lima, 1999).

Se as últimas décadas apresentaram um aumento da participação da carga tributária no total do PIB, a história da industrialização brasileira é marcada por isenções e renúncias fiscais como política de desenvolvimento, principalmente para incentivar o

\footnotetext{
${ }^{5}$ Conforme estudo da Coordenação Geral de Estudos Econômicos e Tributários da Receita Federal publicado em O Estado de São Paulo em 3 de junho de 2000, a carga tributária do Brasil em 1999 chegou a $30,32 \%$ do PIB. Vale ressaltar que o PIB utilizado corresponde a uma estimativa, tendo em vista que o IBGE ainda não havia divulgado os valores oficiais até a data da publicação.
} 
desenvolvimento regional. Em 1997, cálculos da Receita Federal davam conta de algo acima de 9 bilhões de reais não arrecadados em função de renúncias fiscais (IRPJ, IPI e II) do governo federal ${ }^{6}$ (Zackseski e Rodrigues, 1999).

Portanto, de um lado, tem-se o aumento dos impostos ao longo do tempo e, de outro, uma política federal de incentivos executada através de isenções e renúncias fiscais em montantes expressivos.

A partir dos anos 80, algumas condições começaram a favorecer a entrada de um novo ator neste cenário: os governos estaduais. Isenções e reduções tarifárias estaduais não são práticas novas no Brasil. Desde a década de 60, as disputas entre estados estão presentes na economia nacional (Cavalcanti e Prado, 1998). Mas o acirramento desta batalha se inicia nos primeiros anos da última década, viabilizado pelos acontecimentos dos anos precedentes.

As transferências da União para estados e municípios, que vinha desde 1976 oscilando em torno dos $9 \%$ do total arrecadado pelo governo federal, iniciou um processo de crescimento a partir de 1984, chegando aos 16\% em 1988 (Cavalcanti e Prado, 1998).

Neste ano, com a nova Constituição brasileira, passou-se a ter uma maior autonomia dos estados na fixação das alíquotas do ICMS (Imposto sobre Circulação de Mercadorias e Serviços), principal fonte de receita estadual, e uma ampliação da base de incidência desse imposto (até então ICM - Imposto sobre Circulação de Mercadorias). A competência estadual sobre o ICMS é uma peculiaridade brasileira. A experiência internacional mostra que os países que utilizam IVA (imposto sobre valor adicionado), como é o caso do ICMS, mantêm o controle da fixação de alíquotas com o governo central. (Giambiagi e Além, 1999).

\footnotetext{
${ }^{6}$ Estudo do Ministério da Previdência Social, publicado em O Estado de São Paulo no dia 04 de junho de 2000, estimava, a partir de dados do INSS e Pnad/IBGE, em 5,4 bilhões de reais de subsídios e isenções exclusivos da Previdência Social. Para o ano de 2001, o estudo projetava algo em torno de 6,6 bilhões de reais.
} 
Somado às mudanças citadas, em 1993, ocorreu um novo aumento dos repasses da União aos estados e municípios. Este processo se manteve: a participação das transferências no PIB brasileiro cresceu de 2,4\% para 3,0\% entre 1994 e 1998 (Boletim do Banco Central do Brasil, 94,95 e 99), um aumento de mais de $20 \%$. O fim da inflação e o crescimento da economia brasileira durante os primeiros anos do Plano Real também podem ser apontados como elementos que melhoraram as condições de arrecadação dos governos estaduais. Esta conjuntura favoreceu a entrada de investimentos estrangeiros e o aumento do investimento privado nacional no biênio 93/94, o que é considerado por Cavalcanti e Prado (1998) como um elemento a mais que contribuiu para o início das disputas.

Apesar de já haver algumas condições favoráveis à guerra fiscal, os primeiros anos de 90 foram marcados por uma retração econômica devido ao Plano Collor, o que limitou a atuação dos governos estaduais que tiveram, neste período, uma postura defensiva com algumas reduções de alíquotas, apenas com o intuito de evitar um desmantelamento maior da economia do estado. Além disso, as finanças estaduais vinham demonstrando deterioração desde o início dos anos $80^{7}$, mesmo com o processo de renegociação das dívidas estaduais iniciado em 1987 que atenuava o comprometimento das receitas (Cavalcanti e Prado, 1998).

Dessa forma, montava-se, até os primeiros anos da década de 90, uma estrutura institucional que favorecia o agravamento das disputas estaduais. Problemas fiscais dos Estados e recessão econômica serviram apenas para retardar um processo, cujas condições já vinham sendo viabilizadas pelo conjunto de alterações fiscais ocorridas até então.

\footnotetext{
${ }^{7}$ Piancastelli e Perobelli (1996) apontam, como causas da deteriorização das finanças estaduais, elevação das despesas de pessoal decorrente das transferências de encargos para estados e municípios estabelecidos pela Constituição de 1988, aumento da contratação de pessoal e crescimento negativo da receita nos primeiros anos da década de 90.
} 
Passado o período de retração, em 1993 e 1994, as unidades federativas contavam com maior autonomia sobre seus recursos e tiveram suas respectivas arrecadações e transferências ampliadas em um cenário de crescente investimento privado.

Neste ambiente e com a abertura da economia brasileira, algumas multinacionais chegaram ao Brasil com a intenção de instalar suas primeiras ou novas fábricas no país.

Enquanto os governos estaduais se confrontavam através da imprensa, executivos de montadoras estrangeiras punham em "leilão" sua nova planta: quem oferecer mais isenção fiscal e vantagens para a instalação ganha o investimento para seu estado ${ }^{8}$.

Essas disputas pontuais ganham destaque no noticiário, mas a guerra fiscal extrapola os casos individuais e relevantes do setor automotivo e entra no terreno da política tributária de cada estado participante. O principal instrumento de atração de empresas é a diminuição das alíquotas do ICMS.

A arrecadação deste imposto pertence "ao estado de origem da operação tributada pelo imposto. Nas transações interestaduais, a operação é partilhada entre o estado de origem e o estado de destino" (Giambiagi e Além, 1999, p. 262). Esta sistemática reforça o papel do imposto como um instrumento poderoso na guerra fiscal.

O ICMS foi criado em 1988 em substituição ao antigo ICM. Conceitualmente, este imposto tem origem em 1922, com a criação do Imposto sobre Vendas Mercantis (IVM). Nas primeiras décadas do século, o IVM não era expressivo para as contas do governo (Varsano, 1996). Hoje, o quadro é outro.

\footnotetext{
${ }^{8}$ Dados da Secretaria de Ciência, Tecnologia e Desenvolvimento Econômico do Estado de São Paulo dão mostra da expressiva participação do setor automotivo no total de investimentos realizados no estado de São Paulo. Para os anos de 1997 e 1998, dos 15,4 bilhões correspondentes ao total de investimentos confirmados, 5,6 bilhões eram relativos aos setores automotivo e autopeças.
} 
Em 1997, o ICMS correspondeu a aproximadamente $25 \%$ do total arrecadado nas três instâncias de governo e seus valores giraram em torno de 7\% do PIB brasileiro a preços de fatores durante a década de 90 (Banco Central do Brasil; 1994, 1995 e 1999).

O ICMS é a principal fonte de receita dos governos estaduais e responde, "em média, por $90 \%$ dos recursos orçamentários dos estados mais desenvolvidos" (Giambiagi e Além, 1999, p. 260). A importância deste imposto para o total das receitas estaduais varia conforme o estado analisado. As transferências da União tendem a não obedecer a uma proporcionalidade em relação ao tamanho das economias estaduais. Disto decorre o fato da arrecadação própria de estados como São Paulo, Rio de Janeiro e Paraná responderem por mais de $80 \%$ da receita total enquanto a médias da região Norte e Nordeste são, respectivamente, 45 e $58 \%$ (Afonso $^{9}$ citado por Cavalcanti e Prado, 1998).

Autonomia na fixação da alíquota, incidência sobre a produção e volume expressivo de arrecadação fazem do ICMS o instrumento que viabiliza e sustenta o conflito fiscal entre os estados brasileiros (Cavalcanti e Prado, 1998)

Portanto, constitui-se numa arma poderosa de barganha por novos investimentos, mas, justamente pela sua importância, alterações em suas alíquotas podem representar impactos relevantes às condições fiscais dos estados.

Existem diversos exemplos de programas desenvolvidos que procuram institucionalizar de maneira legal a entrada dos respectivos estados na disputa por novos investimentos.

Minas Gerais lançou em 1993 o Programa de Indução à Modernização Industrial (PROIM) que se constitui em um fundo rotativo "com o objetivo de garantir recursos para o financiamento do capital fixo das empresas, priorizando, ainda que de

\footnotetext{
${ }^{9}$ AFONSO, J. R. Descentralização: um estudo de caso sobre o Brasil. Jan. 1994 (Texto para Discussão CEPP, n.20).
} 
forma difusa, setores e regiões do estado" (Cavalcanti e Prado, 1998). O PROIM financia, depois de análise do pedido, até $80 \%$ do investimento total previsto no projeto. "O pagamento é feito com carência de 36 meses e prazo de amortização de até 60 meses(...) A taxa de juros é de 6\% ao ano"(O Estado de São Paulo, 02/08/1999).

O governo ainda implantou dois instrumentos de estímulo aos investimentos: FIND e FUNDIEST, tendo, este último, sido criado exclusivamente como instrumento de barganha na disputa pela fábrica da Mercedes Benz, sendo, mais tarde, estendido a outros setores.

Paraná e Rio de Janeiro também lançaram programas no início da década. $\mathrm{O}$ Programa Bom Emprego Fiscal, criado em 1992 pelo governo paranaense, visava a atração de setores tecnológicos e a Lei n. 2.273/94 e o FUNDES tinham a intenção de inserir o estado do Rio de Janeiro no cenário dos novos investimentos.

Um dos protagonistas nessa disputa é o estado de São Paulo. Estado de maior importância econômica, São Paulo pode desempenhar papel decisivo na guerra fiscal. Do total de ICMS arrecado em 1998, 38,3\% foram arrecadados pelo governo paulista (Banco Central do Brasil, 1994, 1995 e 1999).

A partir dos estudos do IPEA a respeito de estimativas dos PIBs estaduais e dos dados divulgados pelo IBGE, Ferreira (1998) calcula para todos os estados a relação renda per capita estadual / renda per capita brasileira. No caso de São Paulo, o valor encontrado $(1,65)$ indica uma renda per capita paulista $65 \%$ superior à média nacional.

Portanto, uma análise da economia de São Paulo tem um alcance que vai além das fronteiras do estado, dada a relevância da economia paulista e sua interação e influência na economia das demais regiões. 


\subsection{São Paulo na Guerra Fiscal}

\subsubsection{O Conceito de Estado Hegemônico}

A análise de Cavalcanti e Prado (1998) parte da constatação que São Paulo, por deter em seu território aproximadamente $40 \%$ do setor industrial brasileiro, desempenha o papel de estado hegemônico. Esta posição traz implicações específicas às políticas de São Paulo no tocante à guerra fiscal.

Como os setores do estados são, em geral, diversificados e compostos por um conjunto de empresas competindo entre si, um incentivo concedido a uma empresa será motivo de fortes pressões para que as vantagens sejam estendidas às demais do mesmo setor. Portanto, a perda de receita em função de isenções concedidas pode ter um efeito multiplicador no caso do estado de São Paulo no aspecto tributário.

Sob este ponto de vista, os estados vizinhos entram na disputa sem nada, ou muito pouco, a perder, principalmente quando se trata do setor automotivo que até poucos anos atrás era fortemente concentrado em São Paulo.

Considerando a incidência do ICMS, os autores introduzem uma outra questão denominada por eles de "dilema do estado hegemônico". O estado hegemônico tende a ser superavitário nas relações comerciais com os demais e, como o ICMS incide sobre a produção, São Paulo é mais "beneficiado quanto maior for aproximação do princípio do IVA ao princípio de origem" (Cavalcanti e Prado, 1998, p.16). Por outro lado, o princípio da origem se constitui no principal instrumento dos estados concorrentes na atração de novos investimentos. Portanto, uma mudança de regime tributário inibiria a guerra fiscal, mas se constituiria numa perda automática para São Paulo.

Os efeitos para o estado hegemônico no curto e longo prazo são diversos. Inicialmente, como há, em São Paulo, uma concentração dos setores que fornecem e demandam da empresa que se instala em outro estado, São Paulo recebe efeitos positivos 
em decorrência da instalação de uma fábrica em outra unidade da federação. A longo prazo, dependendo de vários fatores como já foi exposto, ocorre uma atração maior ou menor pelo setores ligados à empresa em questão. Portanto, a descentralização iniciada por algumas empresas de grande porte pode desencadear um aprofundamento deste processo no longo prazo. Mas "quanto menos diversificada e moderna for a estrutura industrial no estado (que recebe a empresa), maior é a probabilidade que ocorram vazamentos dos impactos dinâmicos associados ao investimento" (Cavalcanti e Prado, 1998, p.103). De qualquer forma, os efeitos de curto e longo prazos parecem distintos e o segundo caso é de difícil mensuração.

\subsubsection{Políticas de São Paulo}

A perda de participação do estado de São Paulo no total arrecadado de ICMS ocorrida nos anos de 1990 e 1991 de, aproximadamente, 4 pontos percentuais muitas vezes é atribuída aos efeitos nefastos da guerra fiscal sobre o estado e serve como munição aos oponentes na crítica à postura conservadora do executivo paulista nesta disputa.

Mas, segundo Cavalcanti e Prado (1998), analisando a evolução do ICMS dentro do contexto econômico nacional, percebe-se que períodos recessivos são acompanhados de queda na participação relativa do estado de São Paulo no total arrecadado deste imposto. Esta relação já havia sido registrada nos primeiros anos da década de 80 .

Em 1989, o governo paulista lança o Programa de Desenvolvimento Econômico do estado de São Paulo e em 91 cria instrumentos de utilização do programa, através de uma triangulação entre a empresa, o Banespa e o montante devido de ICMS. Os empréstimos em condições favoráveis eram limitados pela arrecadação do ICMS adicional recolhido em função das expansões e dos novos investimentos. Este programa foi timidamente utilizado pelo setor de bebidas, sem apresentar grandes repercussões para o estado. 
Até 1995, São Paulo manteve uma postura legalista e assistia algumas perdas de receita em razão de políticas mais agressivas de outros estados. $O$ primeiro embate se deu em torno da questão portuária. O Espírito Santo, por intermédio de uma lei estadual, ampliou o prazo de pagamento do ICMS das importações. Várias empresas, como IBM e General Motors, alteraram seu canal de importação e montaram seus escritórios comerciais no estado.

Outros casos pontuais se sucediam como a transferência da fábrica da Arisco para Goiás, mas a postura do governo de São Paulo não se modificava.

Em 1995, inicia-se um processo de reação de São Paulo quanto às questões dos benefícios concedidos pelos outros estados brasileiros. A mudança de postura do governo paulista está intimamente relacionada à entrada das fábricas de automóveis na disputa e se pauta como uma sucessão de respostas do governo às políticas dos concorrentes.

Em outubro de 1995, três meses após a instalação da fábrica da Volkswagen em Resende-RJ, o governo de São Paulo lança o Programa de Desenvolvimento e Competitividade (PDC) e as Câmaras Setoriais Paulistas com a missão de equipar e aperfeiçoar a infra-estrutura do estado. Esta fase, ainda segundo Cavalcanti e Prado (1998), é marcada por uma concentração das ações do governo em duas frentes: melhoria da infra-estrutura e intensificação dos informativos, na tentativa de convencer o setor privado sobre as vantagens de se investir em São Paulo.

A disputa pela fábrica da Mercedes Benz entre os estados de São Paulo e Minas Gerais gerou mais um conjunto de medidas por parte do primeiro. Durante as negociações, São Paulo cogitou a possibilidade de lançar mão dos mesmos expedientes utilizados pelo governo mineiro.

Em julho de 96, São Paulo anuncia o Programa Estadual de Incentivo ao Desenvolvimento Econômico e Social, forma o Conselho Estadual de Desenvolvimento Econômico e Social e constitui o Fundo Estadual de Incentivo ao Desenvolvimento 
Social (FIDES) e o Fundo Estadual de Incentivo ao Desenvolvimento Econômico (FIDEC).

Os fundos definiam de maneira genérica as empresas que poderiam contar com o benefício. Especificamente em relação ao FIDEC, o modelo segue o instituído por outros estados: uma triangulação que possibilita isenções disfarçadas do ICMS. Mas, o projeto em sua última etapa não é integralmente sancionado pelo governador que retira artigos mais agressivos e estipula, como dotação orçamentária, o montante de 50 milhões de reais. Dessa forma, a timidez do executivo paulista se mantém e se a disposição inicial do governo consegue retardar a definição da Mercedes, não impede a instalação da fábrica em Juiz de Fora-MG.

O caso mais recente de disputais estaduais por fábricas de automóvel se refere à instalação da unidade da Ford no estado da Bahia. Em 1999, a direção da empresa decidiu pela transferência de suas atividades do Rio Grande do Sul e recebeu incentivos não só do governo baiano como também do Banco Nacional de Desenvolvimento Econômico e Social (BNDES). O empréstimo do BNDES foi visto pelos demais estados como uma interferência do governo central nas disputas estaduais, o que gerou grande repercussão na imprensa nacional (Caso, 1999).

Nos últimos anos, o governo de São Paulo tem atuado em três frentes distintas: reduz a alíquota de ICMS para alguns produtos, entra com Ações Diretas de Inconstitucionalidade (Adin) e ainda procura anular benefícios dados por outros estados às empresas que comercializam em São Paulo. Como políticas de redução de ICMS, pode-se citar a queda da alíquota para carros novos de 12 para $9 \%$ (Reinert, 1999) e para produtos supérfluos de 25 para 18\% (Covas reduz, 2000). As ações de inconstitucionalidade foram movidas em fevereiro de 2000 e tiveram como alvo os governos da Bahia e do Paraná (Covas, 2000).

Finalmente, o governo de São Paulo tem procurado eliminar o direito, para alguns setores, de descontar do ICMS a ser pago no estado os valores já recolhidos ao 
Tesouro dos outros estados na compra das mercadorias (Osman e Terraz, 2000 e Osman, 2000).

\subsection{Limitações da aplicação}

Além das limitações intrínsecas ao modelo insumo-produto que trabalha com equações lineares e com função de produção de Leontief (coeficientes fixos), os resultados do presente trabalho relativos à guerra fiscal não têm a ambição de responder questões relativas a estratégias ótimas de enfrentamento da guerra fiscal.

As conseqüências da guerra fiscal são de difícil mensuração e os critérios de análise são, em muitos casos, arbitrários para qualquer metodologia que se empregue. $\mathrm{O}$ desafio, portanto, é estreitar o foco de análise, pela impossibilidade de se contemplar todos os aspectos da questão, na justa medida, para que sejam alcançadas concomitantemente a consistência dos dados e a relevância dos resultados.

Seguindo a análise feita por Cavalcanti e Prado (1998), pode-se levantar algumas questões sobre trabalhos que tenham como tema a guerra fiscal.

Como contabilizar os gastos públicos na duplicação de uma estrada que servirá de canal de escoamento da produção da fábrica que se instala? Certamente, a estrada servirá os cidadãos do estado, mas é difícil saber qual a necessidade e prioridade da obra, caso a fábrica não se instalasse à sua margem. Todos os gastos voltados à melhoria da infra-estrutura apresentam o mesmo problema de mensuração.

Outra questão de difícil resposta está relacionada aos efeitos de longo prazo. Uma grande fábrica, demandante de expressiva quantidade de insumo, atrai fornecedores para sua região? Se esta fábrica estiver localizada em Minas Gerais ou no Piauí atrairá da mesma forma? A distância do centro consumidor, o porte da fábrica e o setor em que atua modificam os efeitos de longo prazo? O estudo de um caso não alcança estes aspectos e a variedade de setores que barganham por isenções e incentivos tornam a análise ainda mais complexa. 
Uma indagação para a qual não se tem resposta diz respeito a decisão prévia da empresa que busca os incentivos. O leilão entre os estados da federação decide a localização da nova fábrica ou os executivos dessas fábricas já conhecem previamente o vencedor? Quanto um estado teria que oferecer para tomar o investimento de outro?

Este leilão guarda, portanto, um aspecto interessante. As capacidades de induzir novos investimentos e de determinar sua localização espacial são duas qualidades muitas vezes atribuídas à guerra fiscal. Cavalcanti e Prado (1998) argumentam que, além da decisão do investimento já ter sido tomada em muitos casos, sua localização só será determinada pelas propostas estaduais se o investimento for realizado em local diferente do previamente definido. Os autores utilizam-se do conceito de curvas de equivalência (ou indiferença) dos tomadores de decisão privados formadas a partir de fatores globais, para argumentar que os incentivos e isenções somente terão efeitos se cobrirem as vantagens globais do concorrente. Como essas curvas não são conhecidas pelos Estados, muitas vezes o efeito do leilão é apenas tornar ainda mais favoráveis para as empresas as condições do estado previamente vencedor. Os autores lembram ainda que, do ponto de vista nacional, as vantagens de uma eventual mudança da localidade do investimento só trará benefícios ao país, caso haja concorrentes estrangeiros, o que não tem sido a regra.

Para confirmar sua argumentação, Cavalcanti e Prado (1998) lançam mão de pesquisa realizada pela CNI/CEPAL (1997) junto às empresas que mostra a proximidade do mercado e o custo da mão-de-obra como fatores tão importantes quanto os benefícios fiscais na decisão de uma empresa instalar suas plantas em outra unidade da federação.

Guerra fiscal é um tema de múltiplos aspectos e pode ser analisada de diversos ângulos distintos.

Os resultados ambicionam contribuir para o debate do tema, na medida em que procuram estimar impactos inter-regionais presentes na estrutura econômica brasileira. 


\subsection{Resultados da Aplicação e Análise}

Imaginando que uma fábrica de automóveis deixa de produzir seus carros em Minas e passa a produzi-los em São Paulo, qual a perda para o Estado de Minas? Esta é a pergunta que o quadro 23 a seguir procura responder, estimando estes efeitos para todos os setores e para as seis possíveis combinações de pares regionais. Tomando, como exemplo, do primeiro elemento da primeira coluna, o valor 1,92 corresponde ao efeito do multiplicador de produção para a economia de São Paulo decorrente de um aumento de demanda final do setor paulista Agropecuária menos o efeito do multiplicador de produção também para São Paulo ocorrido em função de uma mudança da demanda final do setor Agropecuária mineiro. 


\begin{tabular}{|c|c|c|c|c|c|c|}
\hline Perda de & $\mathrm{SP}$ & SP & MG & MG & RB & $\mathrm{RB}$ \\
\hline Transferência para & MG & RB & SP & RB & SP & MG \\
\hline AGROPECUÁRIA & 1,92 & 1,87 & 2,42 & 2,45 & 1,90 & 2,40 \\
\hline EXTRAT. MINERAL & 2,16 & 2,07 & 2,64 & 2,75 & 2,19 & 2,66 \\
\hline PETRÓLEO E GÁS & 2,09 & 2,02 & 2,35 & 2,36 & 2,04 & 2,30 \\
\hline MINERAL Ñ METÁLICO & 2,28 & 2,18 & 2,72 & 2,78 & 2,25 & 2,69 \\
\hline SIDERURGIA & 1,84 & 1,75 & 2,14 & 3,03 & 2,63 & 2,93 \\
\hline METALURG. Ñ FERROSOS & 2,38 & 2,24 & 2,69 & 2,76 & 2,31 & 2,62 \\
\hline OUTROS METALÚRGICOS & 2,31 & 2,20 & 2,60 & 2,92 & 2,52 & 2,81 \\
\hline MÁQUINAS E EQUIP. & 2,19 & 2,08 & 2,47 & 2,54 & 2,16 & 2,44 \\
\hline MATERIAL ELÉTRICO & 2,30 & 2,16 & 2,58 & 2,64 & 2,22 & 2,49 \\
\hline EQUIP. ELETRÓNICOS & 1,84 & 1,82 & 2,04 & 2,06 & 1,84 & 2,04 \\
\hline AUTOM./CAM/ONIBUS & 2,30 & 2,07 & 2,54 & 2,51 & 2,04 & 2,27 \\
\hline PEÇAS E OUT. VEICULOS & 2,58 & 2,29 & 2,88 & 2,91 & 2,33 & 2,62 \\
\hline MADEIRA E MOBILIÁRIO & 2,08 & 2,06 & 2,71 & 2,74 & 2,09 & 2,72 \\
\hline CELULOSE, PAPEL E GRÁF. & 2,21 & 1,99 & 2,54 & 2,54 & 2,00 & 2,33 \\
\hline IND. DA BORRACHA & 1,78 & 2,06 & 2,12 & 2,14 & 2,08 & 2,42 \\
\hline ELEMENTOS QUIMICOS & 2,30 & 1,92 & 2,71 & 2,71 & 1,92 & 2,33 \\
\hline REFINO DO PETRÓLEO & 1,56 & 1,50 & 2,21 & 2,36 & 1,64 & 2,29 \\
\hline QUIMICOS DIVERSOS & 1,98 & 1,89 & 2,44 & 2,49 & 1,93 & 2,40 \\
\hline FARMAC. E VETERINÁRIA & 1,99 & 1,91 & 2,45 & 2,47 & 1,93 & 2,38 \\
\hline ARTIGOS PLÁSTICOS & 2,00 & 1,96 & 2,35 & 2,37 & 1,98 & 2,33 \\
\hline IND. TEXTIL & 2,14 & 2,16 & 2,34 & 2,34 & 2,17 & 2,37 \\
\hline ARTIGOS DO VESTUÁRIO & 2,15 & 2,38 & 2,35 & 2,36 & 2,39 & 2,59 \\
\hline FABRICAÇÃO CALÇADOS & 1,98 & 2,25 & 2,40 & 2,41 & 2,26 & 2,68 \\
\hline INDÜSTRIA DO CAFÉ & 1,97 & 1,94 & 2,78 & 2,58 & 1,75 & 2,56 \\
\hline BENEF. PROD. VEGETAIS & 1,82 & 1,75 & 2,91 & 2,96 & 1,80 & 2,90 \\
\hline ABATE DE ANIMAIS & 2,11 & 2,06 & 3,07 & 3,13 & 2,13 & 3,08 \\
\hline INDÚSTRIA DE LATICÍNIOS & 2,33 & 1,91 & 2,64 & 2,95 & 2,22 & 2,53 \\
\hline FABRICAÇÃO DE AÇÚCAR & 2,81 & 2,10 & 3,20 & 3,18 & 2,08 & 2,47 \\
\hline FAB. ÓLEOS VEGETAIS & 1,79 & 1,73 & 3,20 & 3,26 & 1,79 & 3,21 \\
\hline OUTROS PROD. ALIMENT. & 2,10 & 1,95 & 3,02 & 3,05 & 1,98 & 2,90 \\
\hline INDÜSTRIAS DIVERSAS & 2,17 & 2,14 & 2,51 & 2,56 & 2,20 & 2,53 \\
\hline S.I.U.P. & 2,28 & 2,17 & 2,56 & 2,49 & 2,09 & 2,38 \\
\hline CONSTRUÇĀO CIVIL & 1,97 & 1,92 & 2,22 & 2,24 & 1,94 & 2,19 \\
\hline COMÉRCIO & 2,07 & 2,03 & 2,49 & 2,49 & 2,04 & 2,45 \\
\hline TRANSPORTES & 2,05 & 2,00 & 2,49 & 2,49 & 2,01 & 2,45 \\
\hline COMUNICAÇŌES & 1,96 & 1,92 & 2,22 & 2,23 & 1,93 & 2,19 \\
\hline INSTITUIÇŐES FINANCEIRAS & 2,23 & 2,24 & 2,55 & 2,55 & 2,25 & 2,56 \\
\hline SERV. PREST. À FAMILIA & 2,12 & 2,04 & 2,50 & 2,50 & 2,04 & 2,43 \\
\hline SERV. PREST. À EMPRESA & 2,09 & 2,01 & 2,38 & 2,39 & 2,02 & 2,31 \\
\hline ALUGUEL DE IMÓVEIS & 1,70 & 1,66 & 1,90 & 1,90 & 1,67 & 1,87 \\
\hline ADMINISTRAÇÃO PÚBLICA & 2,44 & 2,37 & 2,85 & 2,86 & 2,38 & 2,79 \\
\hline SERV. PRIV. N N MERCANTIS & 2,39 & 2,31 & 2,84 & 2,85 & 2,32 & 2,78 \\
\hline Média & 2,11 & 2,03 & 2,55 & 2,60 & 2,08 & 2,52 \\
\hline
\end{tabular}

Quadro 23. Perdas em reais por transferência de um real da demanda.

Fonte: resultados da pesquisa. 
Antes de analisar os resultados do quadro e relacioná-los com a guerra fiscal, deve-se ter em mente que os valores foram obtidos a partir do modelo construído neste trabalho. Isto quer dizer que não foram levadas em conta as eventuais mudanças estruturais decorrentes das transferências de unidades produtivas. Os setores permaneceram com a mesma estrutura e o cálculo do QL não foi alterado. Portanto, os resultados estimam perdas regionais para os casos em que as transferências de unidade produtiva se constituem em mudanças marginais da produção total do setor e a tecnologia de produção permanece a mesma.

Uma conclusão geral é que o Resto do Brasil, para todos os setores, perde mais se a mudança de demanda for em favor de Minas ao invés de São Paulo. Ou seja, para o Resto do Brasil, a transferência de uma unidade produtiva até então localizada em seu território para Minas significa uma perda de produção maior - em montantes que variam de setor para setor - do que se esta planta se transferir para São Paulo.

No caso de São Paulo, com exceção de cinco setores - Indústria da borracha (15), Indústria têxtil (21), Artigos de vestuário (22), Fabricação de calçados (23) e Instituições financeiras (37) - acontece o mesmo: a transferência de uma unidade paulista para Minas é mais prejudicial quando comparado com uma mudança para o Resto do Brasil.

Neste aspecto, o Estado de Minas Gerais é praticamente indiferente ao destino de sua antiga unidade produtiva. As perdas não apresentam valores significativamente diferentes para os dois casos possíveis: mudança da demanda de Minas para São Paulo ou para o Resto do Brasil.

A região de Minas é que, de uma maneira geral, mais perde com a transferência de uma unidade produtiva dentro de suas fronteiras para outra área. Não se pode dizer, por esta razão, que Minas Gerais é a região economicamente mais fechada porque este resultado reflete indiretamente o tamanho das economias. 
Neste modelo, uma nova planta em Minas ou em São Paulo compra de outras regiões o volume determinado pelo Quociente Locacional. Não há motivo, a princípio, para acreditar que o tamanho da economia dos dois estados possa interferir na proporção comercializada com outras regiões.

Por outro lado, quando esta planta sai de Minas, por exemplo, e vai para outra região (SP ou RB), suas compras inter-regionais advêm de Minas Gerais ou da terceira região (RB ou SP). Deste modo, o tamanho das economias competidoras interfere nos volumes transacionados. Portanto, é de se esperar que, para a menor economia do modelo, a perda decorrente da transferência da planta seja maior a partir da metodologia empregada aqui.

De certa forma, a mesma questão deve ser levantada para se analisar o fato do Resto do Brasil e de São Paulo terem piores resultados para as suas economias na hipótese de uma transferência de sua fábrica para o Estado de Minas. Neste caso, o Resto do Brasil (ou São Paulo) passa a competir pelas vendas inter-regionais com São Paulo (ou o Resto do Brasil). Sendo assim, a análise da tabela acima deve dar maior ênfase a comparações setoriais dentro de cada região.

Setorialmente, uma alteração na demanda do setor Fabricação de óleos e vegetais (29) no sentido de Minas Gerais para o Resto do Brasil ou vice-versa é a que tem maior impacto para as duas regiões.

No caso da transferência de Minas para São Paulo, o setor que gera a maior perda para Minas é o Artigo de vestuário (22), seguido de Administração pública (40) e Serviços privados não mercantis (42). Os baixos índices de ligação dos setores de serviços contribuem para explicar estes resultados.

Analisando o efeito contrário - transferência de São Paulo para Minas Gerais - Serviços privados não mercantis (42) lidera a lista, seguido de perto de Metalurgia não ferrosos (6) e Outros metalúrgicos (7). 
Na relação São Paulo e Resto do Brasil, Artigo de vestuário (22) é o setor de mais perda para São Paulo no caso de uma transferência para o Resto do Brasil. Este resultado se dá porque São Paulo e Resto do Brasil competem nos setores que são fornecedores de Artigos de vestuário (22).

No sentido oposto, Siderurgia (5) representa a maior perda para o Resto do Brasil, justamente porque, com essa alteração geográfica, o Resto do Brasil passa a competir com Minas Gerais pelo fornecimento de insumos da Siderurgia (5). Como este setor tem alta demanda por ele próprio e Minas se destaca em Siderurgia (5), a competição gera uma perda significativa para o Resto do Brasil.

Por último, vale ressaltar que a Agropecuária (1) não se mostra, aparentemente, muito relevante nos valores da tabela. Mas como os setores da agroindústria têm destaque, principalmente em Minas Gerais e Resto do Brasil, a relevância da Agropecuária (1) se dá justamente no encadeamento destes setores. Portanto, uma mudança na distribuição de produção agropecuária vai refletir no poder de concentrar os efeitos da agroindústria nas respectivas regiões. 


\section{CONCLUSÃo}

Inicialmente, vale o destaque para a similaridade estrutural existente entre as economias do Resto do Brasil e do Estado de Minas Gerais. Os índices de HirschamanRasmussen apresentam os mesmos setores líderes e os de menores valores para as duas regiões. Esta semelhança de estrutura econômica também é comprovada através dos resultados dos coeficientes de correlação calculados para as posições dos setores nos rankings de ligação para frente e para trás.

O campo de influência ressalta a importância dos setores Agropecuária (1) e Siderurgia (5) para as duas regiões. Os multiplicadores, mais uma vez, mostram resultados próximos para Minas e Resto do Brasil. Os setores de alimentos e extração vegetal, somados à indústria pesada (Siderurgia e Metalurgia) são os que possuem maiores multiplicadores para os dois casos.

Portanto, estruturalmente, fica clara a relação estreita entre as economias de Minas Gerais e do Resto do Brasil. A economia de São Paulo, segundo os resultados da presente pesquisa, caracteriza-se por outra estrutura.

Celulose, papel e gráfica (14) tem importância especial para São Paulo em função de seu multiplicador de produção, índice de ligação de Hirschaman-Rasmussen e campo de influência. Além do setor 14, Peças e outros veículos (12), ao contrário do que ocorre para as outras regiões tem destaque nos multiplicadores de produção e a Indústria têxtil (21) aparece fortemente no campo de influência. Quando a análise é feita através do índice puro, que leva em consideração o volume de produção, os setores de serviço ganham destaque. 
No tocante ainda ao índice puro de ligação, um resultado expressivo diz respeito às importâncias regionais dentro da economia brasileira. Apesar de, em termos absolutos, São Paulo não ter a mesma participação que o Resto do Brasil, quando se leva em conta as interações econômicas no índice puro, o cálculo relativo à importância regional mostra que o Estado de São Paulo é a região do modelo que mais influencia a economia nacional.

Os multiplicadores permitem também algumas conclusões relativas à guerra fiscal. O que mais chama a atenção é que as maiores perdas para cada região estão centradas, de modo geral, em setores diferentes. Não só isso, como também o destino da unidade produtiva interfere nos resultados setoriais. Os valores apresentados na aplicação podem auxiliar na definição de prioridades na inserção regional na guerra fiscal.

Durante o transcorrer deste trabalho, foram apontadas algumas limitações metodológicas e operacionais do modelo aqui construído.

Como sugestão de continuidade, pode-se salientar a utilização dos valores para as transações inter-regionais obtidos através do Quociente Locacional. A confrontação com dados reais poderia aperfeiçoar a estimativa.

$\mathrm{Na}$ estimativa da demanda final, alguns setores apresentaram Variação de Estoque negativa em um montante expressivo, relativamente à produção total. Este fato indica possíveis problemas nos valores estimados. Uma revisão nesta parte poderia enriquecer o modelo como um todo.

Além desses pontos, o número de empregos por setor foi distribuído, seguindo a proporção de produção das regiões. Este aspecto pode ser melhorado com dados relativos a esta questão, o que implicará mais precisão nos resultados obtidos para o multiplicador de empregos. 
Finalmente, a hipótese assumida de mesma tecnologia entre as regiões é extremamente forte e pode afastar os resultados apresentados da realidade. Trabalhos voltados à determinação das tecnologias regionais poderiam contribuir para o aperfeiçoamento dos resultados da pesquisa. 


\section{REFERÊNCIAS BIBLIOGRÁFICAS}

BANCO CENTRAL DO BRASIL. Boletim do Banco Central do Brasil. Brasília: Banco Central, v.30, n.9, set. 1994.

BANCO CENTRAL DO BRASIL. Boletim do Banco Central do Brasil. Brasília: Banco Central, v.31, n.8, ago. 1995.

BANCO CENTRAL DO BRASIL. Boletim do Banco Central do Brasil. Brasília: Banco Central, v.35, n.10, out. 1999.

CASO Ford mostra falta de rumo. O Estado de São Paulo. http://www.estado.com.br (02/08/1999).

CAVALCANTI, C.E.G.; PRADO, S. Aspectos da guerra fiscal no Brasil. Brasília; São Paulo: IPEA/FUNDAP, 1998. 165p.

CAVALCANTI, S. Carga tributária foi de $30,32 \%$ do PIB em 99 . O Estado de São Paulo, São Paulo, 03 jun. 2000. p. B-3.

CELLA, C. The input-output measuremente of interindustry linkages. Oxford Bulletin of Economics and Statistics, v.46, p.73-84, 1984.

CONSIDERA, C. M. ; MEDINA, M.H. PIB por unidade da federação: valores correntes e constantes - 1985/96. Rio de Janeiro: IPEA, 1998. 32 p. (Texto para Discussão, n. 610). 
COVAS apresenta ações contra Bahia e Paraná no STF. Revista Época, n.109. http://www.epoca.com.br (24/02/2000).

COVAS REDUZ ICMS de supérfluos. 0 Estado de São Paulo. http://www.estado.com.br (21/05/2000).

CROCOMO, F.C. Análise das relações inter-regionais e intersetoriais na economia brasileira em 1985: uma aplicação de insumo-produto. Piracicaba, 1998. 179p. Tese (Doutorado) - Ecola Superior de Agricultura "Luiz de Queiroz", Universidade de São Paulo.

DOMINGUES, E. P.; HADDAD, E. A. EFES - um modelo aplicado de equilíbrio geral para economia brasileira: projeções setoriais para 1999 a 2004. São Paulo: IPE/USP, 2000. (Texto para discussão, n. 25)

FERREIRA, A H.B. Evolução recente das rendas per capita estaduais no Brasil. Revista de Economia Política, v.18, n.1. p. 90-97, 1998.

FERREIRA FILHO, J.B.S. Megabrás: um modelo de equilíbrio geral computável aplicado à análise da agricultura brasileira. São Paulo, 1995. 159p. Tese (Doutorado) - Faculdade de Economia e Administração, Universidade de São Paulo.

FIPE (Fundação Instituto de Pesquisas Econômicas). Efeitos multiplicadores dos investimentos públicos no Estado de São Paulo. São Paulo: FIPE, 1993. 53p.

FUNDAÇÃO INSTITUTO BRASILEIRO DE GEOGRAFIA E ESTATÍSTICA. Matriz de insumo-produto: Brasil, 1995. Rio de Janeiro: IBGE, 1997. 217p. 
FUNDAÇÃO ANSTITUTO BRASILEIRO DE GEOGRAFIA E ESTATÍSTICA. Sistema de contas nacionais: Brasil, 1990 a 1996 (compact disc). Rio de Janeiro: IBGE, 1997.

FUNDAÇÃO INSTITUTO BRASILEIRO DE GEOGRAFIA E ESTATÍSTICA. Contas regionais do Brasil: 1985 a 1997 (compact disc). Rio de Janeiro: IBGE, 1999.

FUNDAÇÃo SISTEMA ESTADUAL DE ANÁlise DOS DADOS. Pesquisa de atividade econômica paulista: PAEP (compact disc) São Paulo: SEAD, 1999.

GIAMBIAGI, F.; ALÉM, A.C. Finanças públicas: teoria e prática. Rio de Janeiro: Campus, 1999.

GOVERNO do Estado de Minas Gerais. Setores. http://www.indi.mg.gov.br/minas/setores/in-setores.htm (02/04/2001).

GOVERNO do Estado de São Paulo. Invista em São Paulo. http://www.saopaulo.sp.gov.br/home/index.htm (02/04/2001).

GUILHOTO, J.J.M. Um modelo computável de equilíbrio geral para planejamento e análise de políticas agrícolas (PAPA) na economia brasileira. Piracicaba, 1995. 258p. Tese (Livre Docência) - Escola Superior de Agricultura "Luiz de Queiroz", Universidade de São Paulo.

GUILHOTO, J.; SONIS, M.; HEWINGS, G. Linkages and multipliers in a multiregional framework: integration of alternative approaches. Urbana: University of Illinois/Regional Economics Applications Laboratory. 1996 (Discussion paper). 
GUILHOTO, J.; SONIS, M.; HEWINGS, G.; MARTINS, E. B. Índices de ligações e setores-chave na economia brasileira: 1959/80. Pesquisa e Planejamento Econômico, v.24, n.2, p.287-314, 1994.

GUILHOTO, J.; SONIS, M.; HEWINGS, G.; MARTINS, E.B. Linkages, key sectors and structural change: some new perspectives. The Developing Economies, v. 33, n.3, Set. 1995.

GUILHOTO, J.; SONIS, M.; HEWINGS, G. Interdependence, linkages and multipliers in Asia: an international input-output analysis./Apresentado ao 5. Summer Institute of the PRSCO of the RSAI, Nagoya, Japão, 1997/

HEWINGS, G.J.D. Aggregation for regional impact analysis. Growth and Change, v.3 n.1, 1972.

HULU, E.; HEWINGS, G.J.D. The development and use of interregional input-output models for Indonesia under conditions of limited information. Review of Urban and Regional Development Studies, v.5, n.2, p.135-152, July 1993.

LEONTIEF, W. A economia do insumo-produto. São Paulo: Nova Cultural., 1986. 226p.

LIMA, C.P.L. Reforma tributária no Brasil: entre o ideal e o possível. Rio de Janeiro: IPEA, 1999. 27p. (Texto para discussão, n. 666)

MILLER, R. E.; BLAIR, P. D. Input-output analysis: fundations and extensions. Englewood Cliffs, New Jersey: Prentice-Hall, 1985. 464p.

MINISTÉRIO DO PLANEJAMENTO, ORÇAMENTO E GESTÃO. Leis de responsabilidade fiscal http://www.planejamento.gov.br/legislacao/imp/leiresponsabilidade-fiscal/index.htm $(08 / 04 / 2001)$. 
MINISTÉRIO DO DESENVOLVIMENTO, INDÚSTRIA E COMÉRCIO EXTERIOR. http://www.mdic.gov.br $(06 / 04 / 2001)$.

MONTOYA, M.A. A matriz insumo-produto internacional do Mercosul em 1990: a desigualdade regional e o impacto intersetorial do comércio inter-regional. Piracicaba, 1998. 217p. Tese (Doutorado) - Escola Superior de Agricultura "Luiz de Queiroz", Universidade de São Paulo.

MORETTO. A. C. Relações intersetoriais e inter-regionais na economia paranaense em 1995. Piracicaba, 2000. 161p. Tese (Doutorado) - Escola Superior de Agricultura "Luiz de Queiroz", Universidade de São Paulo.

OSMAN, R. SP notificará 30 empresas que compram da Bahia. O Estado de São Paulo. http://www.estado.com.br $(22 / 01 / 2000)$.

OSMAN, R.; TERRAZ, R. Setor de embalagem plástica do PR é o primeiro alvo de Covas. O Estado de São Paulo. http://www.estado.com.br (18/01/2000).

PIANCASTELLI, M.; PEROBELLI, F. ICMS: evolução recente e guerra fiscal. Rio de Janeiro: IPEA, 1996. 53p. (Texto para discussão, n.402)

REINERT, H. Modelo em ruínas. Revista Época. n.46. http://www.epoca.com.br $(05 / 03 / 1999)$.

RODRIGUES, R.L. Cooperativas agropecuárias e relações intersetoriais na economia paranaense: uma análise de insumo-produto. Piracicaba, 2000. 171p. Tese (Doutorado) - Escola Superior de Agricultura "Luiz de Queiroz", Universidade de São Paulo.

RUND, J. I. Nonsurvey techniques: a critical review of the theory and the evidence. International Regional Science Review, v. 8, n. 3, p. 189-212, 1983. 
SHIKIDA, P.F.A., GUILHOTO, J.J.M., Um panorama das indústrias do setor de açúcar e do álcool em 1980: Minas Gerais e Brasil comparados. Revista de Economia e Sociologia Rural, v.34 n.1 / 2, p.253 - 284, 1996.

SILVEIRA, S. F. R. Inter-relação econômica dos estados na bacia do rio São Francisco: uma análise de insumo-produto. Piracicaba, 2000. 245p. Tese (Doutorado) - Escola Superior de Agricultura "Luiz de Queiroz", Universidade de São Paulo.

SIMÕES, R.C.F. Uma análise de insumo-produto da economia brasileira no período de transição (1990-1994) para a formação do Mercosul. Piracicaba, 1998. 198p. Tese (Doutorado) - Escola Superior de Agricultura "Luiz de Queiroz", Universidade de São Paulo.

SONIS, M.; HEWINGS, G.J.D. Fields of influence in input-output systems. Urbana: University of Illinois/Regional Economics Applications Laboratory, 1995.

VARSANO, R. A evolução do sistema tributário brasileiro ao longo do século: anotações e reflexões para futura reformas. Rio de Janeiro: IPEA, 1996. 34p (Texto para discussão, n.405).

VARSANO, R. A guerra fiscal do ICMS: quem ganha e quem perde. Rio de Janeiro: IPEA, 1997. 13p. (Texto para discussão, n.500).

VARSANO, R. et al. Uma análise da carga tributária no Brasil. Rio de Janeiro: IPEA, 1998. 55p. (Texto para discussão, n.583).

ZACKSESKI, N.F.; RODRIGUES, M.L.O.F. Uma aproximação à atual política regional no Brasil. Rio de Janeiro: IPEA, 1999. 32p. (Texto para discussão, n.694). 